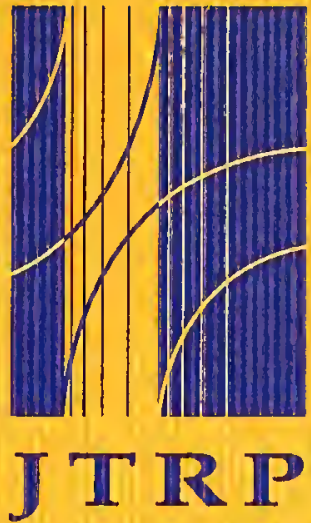

Joint

Transportation

Research

Program

FHWA/IN/JTRP-97/2

Final Report

STRATEGIC PLANNING FOR THE

ACTIVATION OF THE NORTH CENTRAL

SUPERPAVE CENTER (NCSC)

Jan Olek

Rebecca McDaniel

December 1997

Indiana

Department

of Transportation

Purdue

University 

FINAL REPORT

\title{
STRATEGIC PLANNING FOR THE ACTIVATION AND OPERATION OF THE NORTH CENTRAL SUPERPAVE CENTER (NCSC)
}

FHWAIN/JTRP-97/2

\author{
by \\ Jan Olek \\ Director \\ and \\ Rebecca S. McDaniel \\ Technical Director \\ North Central Superpave Center \\ P.O. Box 2382 \\ West Lafayette, Indiana 47906
Joint Transportation Research Program
Project No. C-36-56B
File No. 2-13-2
SPR-2129
Prepared in Cooperation with the
Indiana Department of Transportation
Federal Highway Administration \\ and the U.S. Department of Transportation
}

The contents of this report reflect the views of the authors who are responsible for the facts and the accuracy of the data presented herein. The contents do not necessarily reflect the official views or policies of the Federal Highway Administration. This report does not constitute a standard, specification, or regulation.

\author{
School of Civil Engineering \\ Purdue University \\ West Lafayette, Indiana 47907
}




\begin{tabular}{|l|l|}
\hline I. Report No. & 2. Government Accession No. \\
FHWA/TN/JTRP-97/2 & \\
\hline
\end{tabular}

4. Title and Subtitle

Strategic Planning for the Activation and Operation of the North Central Superpave Center (NCSC)

7. Author(s)
Jan Olek and Rebecca S. McDaniel

Jan Olek and Rebecca S. McDaniel

9. Performing Organization Name and Address Joint Transportation Research Program 1284 Civil Engineering Building

Purdue University

West Lafavette. Indiana 47907-1284

12. Sponsoring Agency Name and Address

Indiana Department of Transportation

State Office Building

100 North Senate Avenue

Indianapolis, IN 46204

15. Supplementary Notes

Prepared in cooperation with the Indiana Department of Transportation and Federal Highway Administration.

\section{Abstract}

The North Central Superpave Center (NCSC) was established to serve the needs of the states and industry in ten states and two Canadian provinces as they implement the Superpave system. Accomplishing this goal requires the cooperation and active support of a number of people and organizations. Organizational and operational issues related to infrastructure, personnel, equipment and finances also needed to be resolved. This project was designed to address those issues, develop a comprehensive strategic plan and initiate a number of activities of the North Central Superpave Center (NCSC).

This report summarizes the efforts in the following areas:

1. Personnel Recruitment - hiring a Technical Director, Technician, Secretary and later a Communications Specialist.

2. a. Organizational Structure - setting up a Steering Committee to establish the mission of the NCSC and direct its operational policies. b. Funding Structure - initiating regional pooled fund studies to obtain state support for the base level operation of the center and regional research, and seeking outside funding sources.

3. NCSC Newsletter - designing and publishing a quarterly newsletter and later expanding this function to include an Internet web page.

4. Collaboration with Other Centers - initiating routine contact and technical and administrative exchange between the five centers and FHWA.

5. Internal Training - ensuring NCSC staff is adequately trained in Superpave binder, mixture and mix analysis issues through specialized training courses and on-the-job training.

6. Regional Workshop - this was changed to organizing and conducting a national workshop on Superpave technology and its impacts on industry.

7. Development of Training Courses - assessing training needs in the North Central region and developing training courses to meet those needs.

8. Laboratory Development - remodeling a former classroom space into a state-of-the-art Superpave testing lab.

Significant progress was made in all of these areas, as highlighted in this report. The North Central Superpave Center is now fully operational and fulfilling needed functions in technology transfer, training and research for the region and beyond.

\section{Key Words}

Superpave, organization, planning, communication, finances
18. Distribution Statement

No restrictions. This document is available to the public through the National Technical Information Service, Springfield, VA 22161
19. Security Classif. (of this report)

Unclassified
20. Security Classif. (of this page)

Unclassified

\begin{tabular}{|c|c|}
\hline 21. No. of Pages & 22. Price \\
99 &
\end{tabular}




\section{Introduction}

In August 1995, the Indiana Department of Transportation, Purdue University and Federal Highway Administration jointly agreed to establish the North Central Superpave Center (NCSC) in Indiana. The NCSC is one of five centers established by the FHWA around the country to facilitate the implementation of Superpave. The NCSC was charged with assisting the states and provinces of the North Central Region with Superpave implementation. Ten states and one Canadian province have since joined together in support of the center (see Table 1).

\begin{tabular}{cc}
\multicolumn{2}{l}{ Table 1} \\
\hline Participating States/Provinces \\
\hline Illinois \\
Indiana \\
lowa \\
Kansas \\
Manitoba \\
Michigan \\
Minnesota \\
Missouri \\
Nebraska \\
Ohio* \\
Wisconsin
\end{tabular}

* The Ohio DOT has chosen not to participate in funding the NCSC using the pooled fund approach adopted by the other states, but will pay for services as they are used. Ohio industry has been very supportive of the NCSC.

The NCSC is to serve governmental agencies within the region as well as private industry, including contractors, material suppliers, consultants, equipment manufacturers and others.

The Indiana Department of Transportation, as host state, and Purdue University, as host partner, proposed this study for the initiation and activation of the NCSC.

\section{Problem Statement}

The goals of this project were directed at laying the groundwork for the successful operation of the NCSC into the future. It was recognized by INDOT and Purdue that the activation and subsequent operation of the NCSC require the cooperation and active support of many people representing the highway agencies, industry and academia. Numerous organizational and operational issues related to infrastructure, personnel, equipment and finances had to be resolved. This project was to develop a comprehensive strategic plan and initiate a number of activities of the center, as outlined below. 


\section{Objectives}

Specific objectives of this project included the development of long-range financial and research/implementation plans. The activities proposed in this project include:

1. Key Customer Analysis - identifying and establishing contact with the various state and private organizations in the region to ensure their active involvement in the center.

2. Environmental Analysis - reviewing internal strengths and weaknesses of existing efforts surrounding the center including issues related to staffing, coordination of infrastructure remodeling, equipment installation, collaboration with other centers, etc.

3. Critical Areas Analysis - giving special attention to internal training, developing external training, publicity and supplementary equipment.

\section{Work Plan and Progress/Actions Taken}

Each activity outlined in the original proposal is individually detailed below. 
Objective:

To identify and hire suitable candidates for the positions of Technical Director, Technician and Secretary for the Center.

Description:

A suitable candidate with a strong technical background in the SHRP program and Superpave technology will have to be identified and hired as Technical Director to lead day-to-day operation of the center. In addition, two well-skilled technicians will also have to be recruited to assist with the testing, evaluation and training programs proposed for the center. Also, a part-time secretary needs to be hired to assist with correspondence, telephone and newsletter development.

Tasks:

1. Develop job descriptions and advertise the positions.

2. Screen the pool of candidates and organize the interviews of the finalists to identify the most suitable candidates.

Status:

1. The Technical Director position was filled October 9, 1995, with the hiring of Rebecca McDaniel. This followed establishing a search committee, writing job descriptions, posting the position, reviewing applications and interviews with three qualified candidates.

2. The secretarial position was filled November 4, 1995, by Julie Smith. Three candidates were interviewed for the position. Ms. Smith's excellent graphics abilities have been a great asset when preparing the newsletter (see Activity 3 below).

3. The Technician position at the Mixture Branch was filled February 5, 1996, by the hiring of Travis Lovvorn. Mr. Lovvorn resigned in August 1996 for personal reasons. The position was filled again February 3, 1997, by Stephen P. Bowman. Mr. Bowman has an extensive electronics background, which is proving beneficial when working with the complicated test equipment.

Binder Branch is staffed by INDOT personnel from the Division of Materials and Tests. Laboratory technicians there are cross trained to be able to move from lab to lab as the work load requires. Therefore, there is not one individual who can be identified as the Binder Branch technician. There is, however, enough flexibility to use several technicians part-time to equal one full-time technician.

4. As the work of the Center evolved, it became apparent that more emphasis needed to be placed on communication through a variety of means including the Internet, newsletter, brochures, etc. Consequently, the position of Communications Specialist was created. Following posting of the position and reviewing applications, the position was offered to Ms. Julie Smith, who will move from the secretarial position into the Communication Specialist position effective October 1,1997 . When additional funding is identified, the part-time secretarial position will once again be advertised and filled.

Future Actions:

A part-time secretary will be hired when funding is identified. 
Digitized by the Internet Archive in 2011 with funding from

LYRASIS members and Sloan Foundation; Indiana Department of Transportation 
ACTIVITY 2A - DEVELOPMENT OF CENTER'S ORGANIZATIONAL STRUCTURE Objective:

To finalize the organizational structure of the NCSC.

Description:

A concentrated effort is needed to solicit support and funding from potential supporters (states and industry) in the North Central region. A Steering Committee needs to be activated to help with this effort and provide guidance on the center's direction.

Tasks:

1. Solicit input on needs for the services of the center by meeting with key state and industry representatives from the North Central region.

2. Convene with the Steering Committee as soon as possible to gather input and reach agreement on the structure and direction of the center.

\section{Status:}

A Steering Committee was formed and held its first meeting in Indianapolis November 14 and 15, 1995. The committee now meets approximately every six months in conjunction with the North Central Asphalt User Producer Group meeting. The committee is currently composed of one representative of each state/province in the region appointed by the Chief Administrative Officer of each state, and a representative of industry from the states in the region named by those states' respective asphalt pavement associations. A representative of the Asphalt Institute was added following the April 3, 1997, Steering Committee meeting.

At the first meeting, the Steering Committee established the vision and mission statements for the NCSC. The group also identified functions they thought the center could serve to benefit the region. These are detailed in Appendix A.

Future Actions:

The Steering Committee has proven to be an efficient means of soliciting input and guidance from the states/provinces and industry in the region, and, therefore, will continue to function. 
ACTIVITY 2B - DEVELOPMENT OF THE CENTER'S FUNDING STRUCTURE Objective:

To finalize the funding structure of the NCSC.

Description:

A concentrated effort is needed to solicit support and funding from potential supporters (states and industry) in the North Central region. A Steering Committee needs to be activated to help with this effort and provide guidance on the center's direction.

Tasks:

1. Solicit input on needs for the services of the center by meeting with key state and industry representatives from the North Central region.

2. Convene with the Steering Committee as soon as possible to gather input and reach agreement on the structure and direction of the center.

\section{Status:}

A draft financial plan was developed and presented to the Steering Committee at its April 18, 1996, meeting. The proposed funding plan includes two possible forms of financial support from the states; base funding at a level of $\$ 20,000$ per year from each participating state and special research and projects funding to cover additional activities. The base funding is the minimum needed to keep the regional resource center operational and available. It covers such items as material and maintenance costs, partial salaries for the staff working at the center, communications (newsletter, WWW site, etc.), travel to appropriate meetings for NCSC staff and Steering Committee members, some level of training support, some limited research/testing work (like round robins), among other things. The special and research funding is anticipated to be generated from projects of interest to a few selected states in the region which may require additional temporary staff and resources to accomplish the work. They may include research projects or other special activities, such as customized training at a remote location. The Steering Committee identified two research topics of high priority including a RAP study and a study on Fine Aggregate Angularity, which we plan to initiate by the end of the year. Participation in these special projects is purely voluntary. Additional income is needed to cover the expenses of the center and will be generated through fees for training programs and outside support (for research projects through NCHRP, for example). Training generated over $\$ 60,000$ in $1996 / 97$ and the NCSC received a $\$ 400,000$ research contract from NCHRP to study The Incorporation of Reclaimed Asphalt Pavement (RAP) in the Superpave System.

A regional pooled fund project has been initiated to effect the transfer of base funds from the participating states/provinces to the NCSC. Indiana serves as the lead state in organizing this pooled fund. Steering Committee members from most of the states/provinces have supported funding at the $\$ 20,000$ as indicated in Table 1. A mechanism to effect the transfer of funds from the Canadian provinces has been worked out. The transfer of funds from Year 1 is now in progress. Similarly, a pooled fund project has been initiated to fund a regional research project on Use of Reclaimed Asphalt Pavement Under Superpave Specifications.

At its first and second meetings the NCSC Steering Committee expressed that they did not want to require any form of financial support from industry. This came as a surprise to many people, including industry. Some industry supporters of the center, however, 
expressed a willingness to contribute financially to the center as parners, though not necessarily equal partners. Industry contributions may be used to offset some communication-related expenses, such as printing and distribution of the newsletter. Future Actions:

Now that the Base Funding pooled fund mechanism has been established, continuation from year to year is anticipated to proceed smoothly. We are hopeful that industry support, at some level, will be obtained. 


\section{ACTIVITY 3 - NEWSLETTER DEVELOPMENT}

\section{Objective:}

To publish a quarterly newsletter about the activities of the center and the services available through the center.

The newsletter will serve as a major promotional medium for the center.

Description:

The newsletter will keep the region and selected groups outside of the region (NAPA, NCAT, other centers, TRB, etc.) informed of the center's activities, schedule of courses, and recent developments related to Superpave implementation.

Tasks:

1. Develop a mailing list.

2. Gather information and write feature articles.

3. Publish a newsletter.

\section{Status:}

A mailing list of over 1,200 names has been developed. The core of the list is the mailing list from the North Central Asphalt User-Producer Group. That list was supplemented with additions from the Association of Asphalt Paving Technologists, attendees at training courses, interested parties from various meetings, and others. The mailing list is maintained and added to every month.

A logo and style for the newsletter were developed. The front and back pages include color, so they were printed up as "blanks" to be used for later issues. Text and photos are added in black. This way, the quarterly printings are only in black, saving printing time and money.

Volume 2, Number 3 will be published and distributed in early October 1997. (See Appendix C.) The newsletter, the first produced by one of the Superpave Centers, has been very well received and highly complimented. An attempt is made to provide helpful, informative, practical information in every issue.

Three of the other four centers have developed newsletters of their own, however one is dropping the activity due to costs. At a center coordination meeting (see Activity 4), it was suggested that the centers work with FHWA to develop an insert that could be used by all of the centers to provide national updates.

Industry is considering offering to reimburse the center for the cost of producing and distributing the newsletter to allow us to use those funds for other needed activities.

Because communication is such an important function, the NCSC has also developed a site on the world wide web to electronically share information. The site is at http://ce.ecn.purdue.edu/ spave/.

Future Actions:

We will continue to publish the newsletter quarterly on an on-going basis. Further consideration will be given to coordinating newsletter publication with the other centers. Efforts to continually update and upgrade our WWW site will continue. More types of information will be added to the site as requested by our Steering Committee. 


\section{ACTIVITY 4 - ESTABLISHMENT OF COLLABORATION WITH OTHER CENTERS}

Objective:

To establish strong working relationships with other Superpave Centers and organizations that own the new binder and mixture testing equipment in order to start the exchange of information, experiences and ideas. The overall objective of this collaboration will be to make the process of Superpave technology implementation as effective and economical as possible.

Description:

The Superpave technology is based on limited data and considerable validation and verification of the test methods and specifications will be required before full implementation of this system will be possible. The purpose of this activity is to develop a framework for an effective exchange of information between the centers in the areas of equipment functionality and data analysis and interpretation.

Tasks:

1. Contact other centers and develop a scheme for effective communication and data transfer activities.

2. If appropriate, coordinate the distribution of data and samples to participating agencies for cooperative analysis and testing.

3. Interact with other organizations that own and operate the Superpave testing equipment as appropriate.

Status:

The five Superpave Centers have begun meeting every six months to coordinate activities and share experiences. The first meeting was held at the Asphalt Institute in Lexington. A large group including representatives of the host states and FHWA division offices also attended the first meeting. The second meeting was held at the NCSC in West Lafayette and focused more on technical matters. These biannual meetings are proving to be very helpful for establishing a dialogue between the centers.

All five centers are also represented on the Mixture ETG, which provides another opportunity to get the centers together to coordinate. As a result of one ETG meeting, three centers worked together on a newsletter article regarding the Superpave Gyratory Compactor so that we all presented the same message.

Other companies and groups that have the SST and IDT are also represented on one or both of the above groups, giving them an opportunity to interact with the centers. This includes Koch Materials, Heritage Research Group, University of California-Berkeley, the Washington DOT, etc. The contacts and relationships established through these meetings are helpful for sharing information and experiences, which occurs on almost a weekly basis through phone calls, faxes, e-mail, etc.

At the second Superpave Center Coordination meeting, Jon Epps of the Western Superpave Center at the University of Nevada-Reno stressed the importance of the centers working together on training and certification issues. The NCSC Technical Director has attended two meetings of training personnel from Regions 5 and 7 (and across the country). These meetings were organized to work towards uniformity of training requirements and reciprocity of certification across state lines. The Superpave 
Centers will work together to establish uniform training standards that can be used by the states to ensure that a uniform message is being presented, to the extent possible. The centers will also work with the Asphalt Institute and National Highway Institute on Superpave training for managers, local agencies and field personnel.

Future Actions:

The centers will continue working together on certification, training standards and training for managers and engineers. Technical and administrative dialogue between the centers will continue through the coordination meetings, ETG meetings, periodic phone calls and sharing newsletter articles and other information. 
Objective:

To become thoroughly familiar with the theory and operation of the binder and mixture testing equipment and the Superpave software.

Description:

Time and effort will be required to familiarize the center's personnel with the operation of the newly released equipment before hands-on training sessions can be organized.

Tasks:

1. Obtain, review and synthesize all technical literature related to the theory and operation of the Superpave testing equipment and software, particularly as it relates to development of the specifications.

2. Attend hands-on training sessions at the Asphalt Institute (Al), National Center for Asphalt Technology (NCAT) or any other organization that offers such training.

3. Conduct internal training sessions to train prospective instructors who will participate in conducting future training courses for outside agencies.

4. Keep track of activities associated with the proposed FHWA technical assistance program designated to support and update Superpave software, and integrate changes and new developments into the training courses.

Status:

The Director of the NCSC attended a one-week training course at the University of Wisconsin and a one-week training course on Mix Analysis at the Asphalt institute. He also attended a two-week NCAT Course for University Professors on Asphalt

Technology.

The Technical Director attended the following courses at the Asphalt Institute:

- One-week Superpave Binder training

- One-week Mixture Analysis training

- Two-week, hands-on Mix Analysis training

In addition, the Technical Director received some training at the NCSC Binder Branch and hands-on training from the manufacturers of the SST and IDT at the time of installation.

The Mixture Branch technician received extensive binder training at the Binder Branch preparatory to pursuing AASHTO accreditation for the Mixture Branch (the Binder Branch is already accredited). The technician also attended the one-week Mixture Analysis training course. That technician, however, left the NCSC. The new technician has received hands-on training on the mixture equipment from the Technical Director and Dan Quire of the South Central Superpave Center. Arrangements are now being made to have the SST and IDT vendors return to do more hands-on training. The technician has also attended the pilot $\mathrm{NHI}$ course on Superpave for the Generalist Engineer and Project Staff and will sit in on Binder and Mix Design courses at the NCSC this winter.

Several members of the Binder Branch staff have attended one-week training courses at the Asphalt Institute in Binder and Mixture Design. The FHWA Division representative working with the center has also attended the one-week Mix Analysis course. 
Future Actions:

This task is essentially complete except for some follow-up training for the technician, which has already been arranged. 


\section{ACTIVITY 6 - REGIONAL WORKSHOP}

Objective:

To develop, organize and conduct a workshop regarding the impact of Superpave technology on the industry.

The workshop will be used as a forum to familiarize industry with the Superpave technology. Emphasis will also be placed on the specification changes and QC/QA programs.

Description:

The workshop will be developed in cooperation with INDOT, the Asphalt Institute, National Center for Asphalt Technology, Heritage Research Group, Koch Material Co., and other DOT's and producers/suppliers from the region.

The primary participants in the workshop will be state materials engineers and key industry representatives. The workshop will provide for interaction and feedback to address the concerns the participants have regarding implementation of Superpave technology and the QC/QA initiatives.

Tasks:

Develop content of workshop, develop agenda and conduct workshop.

- clearly identify the key elements and goais for the workshop

- coordinate state participation in the workshop to present the implementation schedules and QC/QA initiatives

- prepare workshop materials

- coordinate, schedule and conduct workshop

Status:

Instead of a regional workshop, a national open house was held in Indiana August 2122, 1996. The open house was hosted by INDOT, FHWA, Asphalt Pavement Association of Indiana, Indiana Mineral Aggregates Association and NCSC. The meeting was attended by over 250 people from around the country. Speakers at the open house represented FHWA, INDOT, National Asphalt Pavement Association, the National Stone Association, aggregate suppliers, asphalt paving contractors, Heritage Research Group, University of Maryland, University of Nevada-Reno/WesTrack, University of Texas, and the DOT's of Maryland, Florida and Arizona, among others.

The NCSC staff is working with the Asphalt Institute, FHWA, NAPA and others to organize a second national conference entitled Superpave: Today and Tomorrow to be held in St. Louis in April 1998.

In addition, NCSC staff has made presentations at numerous state and regional meetings including: Indiana, lowa, Minnesota, Missouri and Ohio Asphalt Paving Conferences; Indiana Road School; Indiana Association of Cities and Counties; Region 5 and 7 Training Conferences; North Central Asphalt User-Producer Group meetings; National, Indiana and Kentucky User-Producer Groups; Asphalt Technical Working Group and Mixture Expert Task Group; and Local Technical Assistance Program Conference. Travel funding is usually provided by the sponsoring organization.

Future Actions:

NCSC staff will continue to make presentations at appropriate meetings upon request, 
as funding and schedules allow. 
Objective:

1. More clearly identify training needs in the North Central region and develop the framework for a set of courses that will meet these needs.

2. Develop training courses.

Description:

A set of courses to be offered by the NCSC will be developed. This will be accomplished by first identifying specific audiences and their training needs, followed by development of course modules that are appropriate for these audiences.

Tasks:

1. Obtain and become thoroughly familiar with course material being offered by the Asphalt Institute and other organizations.

2. Identify specific audiences and their training needs.

3. Develop modules that address the needs identified.

4. Prepare course materials and organize courses.

Status:

Two training courses have been developed based largely on materials used by the National Asphalt Training Center at the Asphalt Institute. (See detailed course outlines in Appendix D.) The Superpave Volumetric Mixture Design course has been offered nine times and 124 people have been trained, including one course for the lllinois DOT at Lake Land College in Mattoon. The Superpave Binder Course has been taught three times to 29 people. Other, customized courses, such as a half-day course on the Superpave Gyratory Compactor, have also been taught. The 1997/98 training schedule includes nine mix design courses (two in lowa and one in Minnesota) and three binder courses. The NCSC will also teach a special five day Superpave Binder and Mix Design course to engineering faculty and staff from other Indiana universities; this is part of an FHWA initiative to begin moving Superpave into the undergraduate curricula.

An additional training course for managers and field engineers who need to understand the Superpave concepts without having to know all of the details of the test methods, etc., is being offered through the National Highway Institute. This course will be available for organizations to sponsor at their location. FHWA is planning to offer this course through the National Highway Institute $(\mathrm{NHI})$ and has contracted with the five centers to provide the courses.

As training demands increase in the future, additional courses in Mixture Analysis and Software/Performance Modeling will be needed. In addition, more offerings of the mix design and binder courses will be needed. There will be a great need for training as Superpave implementation progresses - literally thousands of people will eventually need training.

Regions 5 and 7 are working towards establishing reciprocity of training and certification across state lines. The NCSC is working with them and coordinating with the other Superpave centers to establish minimum Superpave training standards for use by the states. Superpave offers a real opportunity to achieve uniformity since nearly everyone is starting at the same level. 
The NCSC, INDOT and FHWA worked out details of providing training for a fee with Purdue University Continuing Education. There is no mechanism through Purdue for the NCSC to take in income from training directly. That income must come through Continuing Education to ensure all funds are accounted for and all university, state and federal regulations are followed.

Future Actions:

Continue working with other centers, FHWA and Asphalt Institute to develop course for managers and field engineers, and eventually mix analysis and software.

Continue working with the states in Regions 5 and 7 and coordinating with the other Superpave Centers on regional certification and training issues.

Continue promoting training opportunities available through the NCSC. 


\section{ACTIVITY 8 - TRAINING LABORATORY DEVELOPMENT}

Objective:

To organize the testing facilities to conduct training exercises.

Description:

A suitable laboratory training facility will have to be developed. Existing laboratory space both at the Research Division and at the Division of Materials and Tests will have to be reexamined and perhaps rearranged to accommodate future training needs.

Tasks:

1. Identify space requirements.

2. Develop a suitable layout for the laboratory.

3. If needed, reorganize the laboratory space.

4. Install and check new equipment once received.

5. Supplement existing laboratory equipment as needed for effective training courses.

Status:

This task applies to the Mixture Branch, since the Binder Branch already existed. Space requirements were established, a layout was designed, cabinetry was ordered and the lab renovations were completed. Purdue University designed an air handling system to heat/cool and properly ventilate the lab space. The design underwent review by an independent designer and, based on that approval, a contract was let to construct the system. The system is essentially complete and functioning. Only a final walk-through and training are needed; these are scheduled for October 1997.

The SST and IDT have been received and installed. Training was provided by the equipment manufacturers after installation. Both items are now fully operational. The SST may need an additional air dryer and/or air purge and changes may need to be made to the method of supplying cooling water if the SST is to be used extensively. At this point, the actual workload for the SST is not certain and some changes in the SST may be coming as a result of work by the Models Group. These changes may obviate the need for revisions to the current SST set-up.

Significant difficulties have been experienced during routine testing with the Indirect Tensile Tester and vendor response has been slow. We are working with the other centers and FHWA to resolve these problems. The individual problems are erratic and varied, but taken together have made testing difficult.

Future Actions:

Future changes in the Superpave system may require modifications at a later date, but none are known at the present time. A new mixer will be procured. The IDT problems will be resolved eventually. 


\section{Conclusions}

Significant progress has been made on all of the tasks outlined in the original proposal. For the most part, the tasks as originally outlined were completed. However, developments have continued as this work was in progress suggesting some additions to the work originally outlined; FHWA's approach to training through the $\mathrm{NHI}$ is an example of this type of development. There have also been some set backs, such as the loss of our trained technician. Some of the tasks also took longer than anyone would have expected, such as setting up a funding mechanism for the NCSC or designing/building the air handling system. The work remaining to be done on each item is detailed in the previous summaries. In summary, the remaining activities include the following:

- continue publishing newsletter

- further develop and enhance world wide web site

- collaborate with other centers on publications as needed

- obtain industry support for funding publication and distribution of newsletter

- establish regional training standards for certification reciprocity

- continue technical and administrative dialogue with other centers

- continue making presentations at state and local level within region

- continue promoting training opportunities through NCSC

- resolve difficulties with the Indirect Tensile Tester.

\section{Recommendations}

The NCSC is fulfilling needed functions in technology transfer, training and research for the North Central Region and beyond. The operation should continue for at least two more years, at which time its contributions and value can be reexamined. This study should be terminated since the initiation and activation functions are complete.

\section{Implementation Suggestions}

The Indiana Department of Transportation is very progressive regarding Superpave implementation and has been charged by AASHTO with serving as a lead state to promote implementation by the other states. The North Central Superpave Center can assist in furthering those efforts by continuing the activities initiated under this study. That is, by providing training and continuing to work on development and refinement of existing training programs, working with the states on reciprocity, and continuing to spread the word regarding Superpave through the newsletter, WWW site, personal contacts and presentations.

\section{Appendices}

A Vision and Mission Statements, Action Plan

B Financial Plan

C Newsletters

D Training Brochure and Detailed Training Plans 
APPENDIX A 


\title{
NORTH CENTRAL SUPERPAVE CENTER
}

\author{
Vision Statement \\ An industry-recognized source of Superpave expertise.
}

\section{Mission Statement}

To lead further development and implementation of the Superpave technology by providing services to its customers.

1. Communication

\section{Action Plan}

- Center representation at ETG and TWG meetings

- Distribution of ETG and TWG meeting minutes

2. Ruggedness, Bias and Precision Testing

3. Research and Development

- Recycling

- Validation of Superpave criteria

- Low temperature algorithms

- Cost effectiveness

- Modifiers

4. Training 


\section{APPENDIX B}




\section{Proposed \\ North Central Superpave Center \\ Financial Plan}

\section{Background}

The budget for the North Central Superpave Center for the first two years is based upon funding provided by the Federal Highway Administration, Indiana Department of Transportation, Purdue University and outside funding from other states, industry and contract research. The start-up and first two years' operation are heavily subsidized by INDOT and FHWA. Beyond Year 2, the Center is to be self-sufficient and must be funded by contributions from the member states, industry and contract research. The estimated costs to be covered by outside funding are shown in Tables 1 through 3 .

A financial strategy focused on securing outside funding is proposed to assure the successful operation of the Center. The funding sources must be stable and dependable, since the continuity of the Center's operations hinges on this funding. Salaries must be paid continuously to keep qualified people on staff. Essential costs for communications and travel must be covered if the Center is to achieve its mission. Certain equipment maintenance and testing material costs will also have to be covered.

During the first meeting of the North Central Superpave Center Steering Committee two major funding schemes for the Center were proposed. In principle, representatives from all agencies present were in agreement that some base level funding should be provided by each of the participating states and provinces. The proposed levels of contributions varied from $\$ 5,000$ to $\$ 20,000$ per year.

Predominant among the proposed functions of the Center discussed at the first Steering Committee meeting was the need for the Center to serve as an information clearinghouse. Communication and dissemination of Superpave technology related information were seen as key to serving the needs of the region and important components of the services the Center can deliver to the member states.

Furthermore, it was proposed that any additional funds needed for the Center's operations be generated by other means, including focused research projects (proposed by individual states or groups of states), FHWA contributions, industry contributions, etc. For example, it was suggested that some states would be doing more Superpave work than other states, especially at the intermediate and complete mix analysis levels, and would, therefore require an increased level of support from the Center for training and mix design work; the states requiring this extra support, should fund the additional work.

The originally proposed budgets were critically examined by the Center's staff in light of the Steering Committee's comments. For the most part, the budgets appear adequate, though tight. Depending on the scale of implementation and training efforts, the budgets for communications and travel may also need to be supplemented with outside funding. No funding was included in the original proposal for office supplies; equipment purchase, replacement or upgrades; or equipment maintenance. Should these items become 
significant in the future, additional funding would be needed. Estimates of these costs are included in the budget for Year 3 and beyond (Table 3).

The views expressed by the Steering Committee and the Center's needs were taken into consideration in preparing the following proposed funding strategy.

\section{Proposed Funding Structure}

\section{Base Funding}

It is proposed that a stable funding source be established by contributions from the member states in the form of base funding. To meet the financial requirements in Years 1 and 2 , a contribution of $\$ 20,000$ per state is suggested. These funds would be used to provide basic services related to the Center, including establishing an information clearinghouse; publishing a regular newsletter; providing technical updates; limited research and testing of regional interest, such as round robin binder testing; development of certification programs; and travel for Center staff and Steering Committee state representatives. This funding will cover the cost of training with the exception of costs of duplication, travel and lodging for participants, or travel for instructors if training is provided outside Indiana.

After a careful examination of the budget, it was determined that the proposed base fee is needed to keep the Center operational long term. The original proposal for the NCSC anticipated funding support from the other states in the region and from industry amounting to $\$ 95,494$. Because the process of approving this financial plan and establishing a regional pooled fund process to obligate funds too so long, it was not possible to secure any outside support during Year 1. Some planned expenditures for Year 1 were deferred to a later date or eliminated, such as moving expenses for NCSC staff. Some of the expenses to be supported by this funding, however, had to be incurred. The shortfall from Year 1, which must be recouped in Year 2, is shown in Table 2 and includes the partial salary and benefits for the Technical Director.

Projecting beyond Year 2, the funding needed is approximately $\$ 400,000$. Additional sources of funding will be pursued to help offset some of the expenses, i.e. the NCSC does not plan to rely solely on state contributions to fund its operations. This additional funding, however, is not assured. The issue of future funding can be revisited and adjusted as needed.

Part of the FHWA's vision for the Centers is to provide regional training, therefore the North Central Superpave Center staff will be available to provide training to a small number of key personnel from each state as part of the basic services described above. Additional training for larger numbers of state personnel to be held at the NCSC or in another state, could be accommodated as a special service since extensive training may require increased staff and resources. Similarly, if a contractor or industry group wanted to arrange training, at their facility or at the NCSC, they would be expected to fund the training through the payment of tuition and/or associated expenses. Based on the actual costs for providing training, the tuition figure was determined to be about $\$ 200$ per person per day in Indiana and about $\$ 260$ per person per day elsewhere in the region. These 
fees would be used to cover the cost of providing the training (salaries, training materials, travel to the training site, etc.).

The issue of base funding for the Centers was discussed during the first coordination meeting between all of the Centers held in Lexington, KY, in January 1996. Based on these discussions, it appears that the base fee proposed for the NCSC is very much in line with those proposed by the other Centers. The Center at Auburn is also asking for contributions of $\$ 20,000$ from each of its participating states. Reno is asking for higher contributions on the order of $\$ 40,000$. The Center in Texas is being fully supported by its host state. The North Eastern Superpave Center is being fully supported by the joint efforts of PennDOT and the Pennsylvania Asphalt Pavement Association at about $\$ 250,000 /$ year for five years; this level of funding is comparable to what would be generated by the proposed base fee for the NCSC.

The base fee in Years 3 and beyond will have to be re-examined in the future, taking into account the status of implementation efforts by individual states, funding from other sources and the need for the Center's services. Other funding would be solicited, from NCHRP, FHWA and other contract research agencies, for example. The actual dollar amount would be determined in Year 2, when we will have a clearer picture of actual operating costs and work load.

The budgets for Year 1 and 2 are shown in Tables 1 and 2 respectively. Each table includes a column labeled Funds from Outside Agencies. These dollar amounts need to be obtained from outside agencies through the base funding and special projects and research funding. Since no funding was provided from outside agencies for Year 1 , this represents a shortfall that must be recovered in Year 2. In Year 2, the critical items that must be covered by the stable base funding amount to about $\$ 240,000$ and the recommended items that can be funded through special projects and research funding amount to about $\$ 80,000$. Details related to the special projects and research funding portion of the budget are discussed subsequently.

\section{Special Projects and Research Funding}

Some agencies may have a need for the Center's assistance with specific projects and for such services an extra payment over and above the base fee would be required. Special services could include specialized training courses, mix designs, regional or local research projects, support of LTPP and SPS-9 projects, and the like. These services are anticipated to be things that would benefit one particular state or group of states, rather than the region as a whole. In addition, since these activities may be viewed as supplementary to the primary mission of the Center, additional staff and resources may be needed to accomplish these activities. It is not anticipated that special funding will represent a significant portion of the budget for Year 1 .

Based on the discussion held during the Steering Committee meeting and contacts of the Center's staff with other Superpave Centers and research institutions in the North Central region, several research projects that could be addressed under this funding category were identified. Possible research topics previously identified include: Use of Reclaimed Asphalt Pavement Under Superpave Specifications, Influence of Local Aggregate Angularity on Design and Performance of Superpave Level 1 Mixes, Compatibility of 
Different Modifiers for PG Graded Binders, Added Service Life Attributable to the Use of Superpave (Life Cycle Costs), Appropriate Reliability Factors to Use in Different Applications of Superpave, QC/QA Under Superpave, The Use of Locally Available Materials within the Superpave Framework, and Low Temperature Algorithms.

The NCSC staff has obtained partial funding of the first two research topics above through INDOT. That research funding can be used as seed money to fund larger projects of regional interest. Details related to some of these research topics have been sent to the members of the Steering Committee previously. Two research projects will be developed as regional pooled fund projects. One on Use of Reclaimed Asphalt Pavement (RAP) Under Superpave Specifications is in the progress of being funded now; another on Influence of Local Aggregate Angularity on Design and Performance of Superpave Mixtures is in the proposal development stage.

Industry contributions could be accommodated under this NCSC funding plan and would be welcomed to reduce the funding requested from the states. Industry involvement could include: contributions to cover special expenditures for such things as promotional materials, upgraded computer equipment, partial sponsorship of steering committee meetings, and other items not included in the routine budget; tuition for participating in training courses, which would be used to cover the costs of providing the training (travel, salaries, course materials, etc.); and more. After the initial shakedown of the equipment and basic ruggedness and bias testing is underway, industry will be welcome to participate in special research projects if they have particular needs and if time and resources permit.

\section{Indirect Costs}

Normally Purdue University, like other universities and private industry, charges overhead rates of up to $52 \%$ in order to recover indirect costs. This overhead supports necessary functions of the organization which cannot be directly charged to particular projects; this includes functions such as accounting and payroll, purchasing, utilities, etc. Purdue's standard off-campus overhead rates are $25 \%$ for research and $23 \%$ for other activities.

Because the North Central Superpave Center is operating through the Joint Highway Research Project, a long-standing agreement between INDOT and Purdue, no indirect costs will be recovered on the regional pooled funds that the states and provinces provide for base funding or research. Industry contributions that reimburse specific expenses are also not subject to indirect cost recovery. Overhead will have to be charged, however, in cases where a separate contract is required, such as for NCHRP research.

\section{Summary}

This proposed funding strategy is recommended for several reasons. First, it provides stable, dependable funding to keep the Center in operation while meeting the primary goals of the region. Alternate funding schemes, such as pay-as-you-go funding, are more cumbersome, are less stable, and may lead to legal problems with providing a service for a fee. Base funding would ensure that state representatives' travel expenses to Steering Committee meetings would be covered by the Center. Second, extraordinary needs for Center support, like mix designs and extensive training, are funded by the states needing that extra effort. The funding generated by these activities would be used to offset the 
additional costs associated with providing them, with any balance returning to the Center to offset operational costs.

The training needs of the region can therefore be addressed by a dual approach: basic training is provided for a limited number of people and additional training can be obtained as a special service, if needed. Industry is invited to participate on a voluntary basis by funding special items, participating in training opportunities and sharing in the exchange of information. 
Table 1

Year 1 Budget

\begin{tabular}{|c|c|c|c|c|c|}
\hline Item & FHWA & INDOT & $\begin{array}{l}\text { Purduel } \\
\text { JHRP }\end{array}$ & $\begin{array}{l}\text { States, Provinces, } \\
\text { Industry, Focused } \\
\text { Research Project }^{1}\end{array}$ & Total \\
\hline Professional Staff $^{2}$ & $\$ 2,835$ & $\$ 7,000$ & $\$ 61,185$ & $\$ 46,000$ & $\$ 117,020$ \\
\hline Technical/Clerical $^{3}$ & $\$ 59,000$ & $\$ 14,000$ & $\$ 4,600$ & $\$ 46,640$ & $\$ 124,240$ \\
\hline Fringe Benefits(est.) & $\$ 19,911$ & $\$ 8,985$ & $\$ 22,267$ & $\$ 16,439$ & $\$ 67,602$ \\
\hline Grad Fee Remission & & & & $\$ 4,588$ & $\$ 4,588$ \\
\hline Total Sal \& Fringes & $\$ 81,746$ & $\$ 29,985$ & $\$ 88,052$ & $\$ 113,667$ & $\$ 313,450$ \\
\hline Renovations & & $\$ 319,000$ & $\$ 16,000$ & & $\$ 335,000$ \\
\hline Consultants & $\$ 2,000$ & & & & $\$ 2,000$ \\
\hline Communications & $\$ 1,000$ & & & $\$ 5,000$ & $\$ 6,000$ \\
\hline Travel $^{4}$ & $\$ 12,000$ & & & $\$ 2,500$ & $\$ 14,500$ \\
\hline Pub. \& Dupl. & $\$ 3,000$ & & & $\$ 1,500$ & $\$ 4,500$ \\
\hline Equip, Supplies & $\$ 12,000$ & $\$ 34,000$ & & & $\$ 46,000$ \\
\hline Total S\&E & $\$ 30,000$ & $\$ 353,000$ & $\$ 16,000$ & $\$ 9,000$ & $\$ 408,000$ \\
\hline Indirect Costs & & $\$ 20,673$ & $\$ 105,180^{5}$ & $\$ 0$ & $\$ 125,853$ \\
\hline Grand Totals & $\$ 111,746$ & $\$ 403,658$ & $\$ 209,232$ & $\$ 122,667$ & $\$ 847,303$ \\
\hline
\end{tabular}

Notes:

1. The funds shown in this column were not received in Year 1. Those expenditures that could be deferred or eliminated were, but salary and fringe benefit expenses for the Technical Director had to be incurred and must be recouped in Year 2. (See Table 2.)

2. Professional Staff includes Director, Technical Director, Faculty Researcher, Engineer/Manager at Binder Branch.

3. Technical/Clerical Staff includes 2 Technicians, Binder Branch Lab Manager, Co-Op Student, 2 Graduate Assistants, Secretary and Computer Technician.

4. Travel includes travel for NCSC staff and Steering Committee participants.

5. Indirect costs are not charged to Joint Highway Research Project (JHRP) studies, therefore this is income Purdue University is giving up and is shown as a Purdue contribution. 
Table 2

Year 2 Budget

\begin{tabular}{|c|c|c|c|c|c|}
\hline Item & FHWA & INDOT & $\begin{array}{l}\text { Purduel } \\
\text { JHRP }\end{array}$ & $\begin{array}{l}\text { States, Provinces, } \\
\text { Industry, Focused } \\
\text { Research Project }\end{array}$ & Total \\
\hline Professional Staff $^{1}$ & $\$ 2,977$ & $\$ 7,210$ & $\$ 32,745$ & $\$ 79,480$ & $\$ 122,412$ \\
\hline Technical/Clerical $^{2}$ & $\$ 60,770$ & $\$ 14,420$ & $\$ 4,120$ & $\$ 46,640$ & $\$ 125,950$ \\
\hline Fringe Benefits (est) & $\$ 20,500$ & $\$ 9,255$ & $\$ 12,261$ & $\$ 27,650$ & $\$ 69,666$ \\
\hline Grad Fee Remission & & & & $\$ 10,032$ & $\$ 10,032$ \\
\hline Total Sal \& Fringes & $\$ 84,247$ & $\$ 30,885$ & $\$ 49,126$ & $\$ 163,802$ & $\$ 328,060$ \\
\hline Consultants & $\$ 2,100$ & & & & $\$ 2,100$ \\
\hline Communications & $\$ 1,050$ & & & & $\$ 1,050$ \\
\hline Travel $^{3}$ & $\$ 12,600$ & & & $\$ 8,500$ & $\$ 21,100$ \\
\hline Pub. \& Dupl. & $\$ 3,150$ & & & $\$ 1,500$ & $\$ 4,650$ \\
\hline Lab Supplies & $\$ 12,600$ & $\$ 14,000$ & & & $\$ 26,600$ \\
\hline Total S\&E & $\$ 31,500$ & $\$ 14,000$ & $\$ 0$ & $\$ 10,000$ & $\$ 55,000$ \\
\hline Deficit from Year $1^{4}$ & & & & $\$ 39,966$ & $\$ 39,966$ \\
\hline Indirect Costs & & $\$ 13,465$ & $\$ 114,630^{5}$ & $\$ 0$ & $\$ 128,095$ \\
\hline Grand Totals & $\$ 115,747$ & $\$ 58,350$ & $\$ 163,756$ & $\$ 213,768$ & $\$ 551,621$ \\
\hline
\end{tabular}

Notes:

1. Professional Staff includes Director, Technical Director, Faculty Researcher, Engineer/Manager at Binder Branch.

2. Technical/Clerical Staff includes 2 Technicians, Binder Branch Lab Manager, Co-Op Student, 2 Graduate Assistants, Secretary and Computer Technician.

3. Travel includes travel for NCSC staff and Steering Committee participants.

4. Deficit from Year 1 due to regional pooled funds not being available.

5. Indirect costs are not charged to Joint Highway Research Project (JHRP) studies, therefore this is income Purdue University is giving up and is shown as a Purdue contribution. 
Table 3

Budgetary Needs - Year 3 and Beyond

\begin{tabular}{|c|c|}
\hline Item & Cost \\
\hline Professional Staff $^{1}$ & $\$ 99,750$ \\
\hline Technical/Clerical $^{2}$ & $\$ 124,820$ \\
\hline Fringe Benefits (est.) & $\$ 69,199$ \\
\hline Grad Fee Remission & $\$ 11,000$ \\
\hline Total Sal \& Fringes & $\$ 304,769$ \\
\hline Consultants & $\$ 2,500$ \\
\hline Communications & $\$ 5,000$ \\
\hline Travel $^{3}$ & $\$ 30,000$ \\
\hline Publications and Duplicating & $\$ 5,000$ \\
\hline Equipment and Supplies & $\$ 53,500$ \\
\hline Subtotal S\&E & $\$ 96,000$ \\
\hline Grand Total $^{4}$ & $\$ 400,769$ \\
\hline
\end{tabular}

Notes:

1. Professional Staff includes Director, Technical Director and Faculty Researcher.

2. Technical/Clerical Staff includes 2 Technicians, Co-Op Student, 2 Graduate Assistants, Secretary and Computer Technician.

3. Travel includes travel for NCSC staff and Steering Committee participants.

4. No indirect costs are applied to funds coming in to the NCSC via pooled fund projects through the JHRP. Indirect costs must be charged on activities for which a separate contract, verbal or written, is required. In those cases, indirect costs are calculated at $25 \%$ of the total of Salaries and Fringes plus Supplies and Expenses less Graduate Fee Remissions. 


\section{Sources of Income}

\begin{tabular}{|l|l|}
\hline Source & Estimated Funding Level \\
\hline State/Province Base Funding & $\$ 200,000-240,000$ \\
\hline Training & $\$ 20,000-40,000$ \\
\hline Regional Pooled Fund Research & \\
\hline Supply Reimbursement (Industry) & $\$ 2,000-5,000$ \\
\hline & \\
\hline & \\
\hline
\end{tabular}




\section{APPENDIX C}



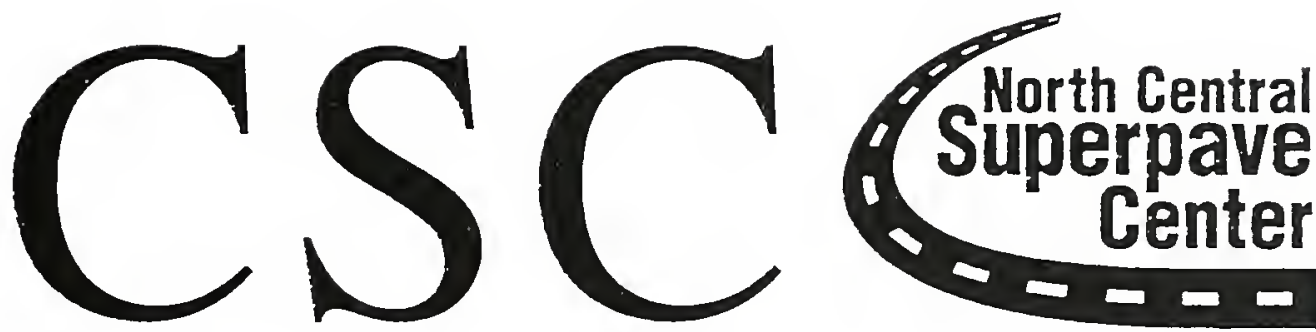

Volume 1, Number 1

Spring 1996

\section{North Central Superpave Center Begins Operations}

$\mathrm{W}$ ith the signing of the contract on April 28, 1995 between FHWA and lNDOT/Purdue University, the North Central Superpave Center (NCSC) became the first of five regional centers established in the country. The $\therefore$ CSC will serve 13 states and two Canadian provinces by being a Superpave information clearinghouse; performing Superpave validation, ruggedness, precision and bias testing; conducting research of regional interest: planning and presenting training and certification programs; and more.

Two branches of the NCSC have been established to serve the needs of the region. The Binder Branch is located at the Indiana Deparment of Transportation (INDOT) Materials and Tests Division in Indianapolis. The Binder Branch has actually been in operation as a testing laboratory and training facility for more than three years, and has processed more than 500 samples. Two sets of binder equipment, including different brands of dynamic shear rheometers and pressure aging vessels, make this an ideal training facility; mary students can be trained on the brand of equipment they will use routinely. The Binder Branch is staffed by experienced personnel who have been involved in implementation of the Superpave binder and volumetric mix design specifications and procedures at the state level: these people are available as valuable resources to the region.

The Mixture Branch of the NCSC is located at INDOT's Research Division in West Lafayette, in close proximity to Purdue University. The Mixture Branch will serve as the main office of the NCSC and will house the full-time technical director and technician. and the part-time secretary. Correspondence, questions and comments should be addressed to the NCSC at the Mixture Branch unless they are specifically for the Binder Branch. To assist with this research and development work, the Mixture Branch is being equipped with advanced mixture analysis tools including the Superpave Shear Tester (SST) and the Indirect Tensile Tester (DT). Superpave mix design anajysis techniques (formerly called Levels 2 and 3) are still seen as experimental at this time and need more research and development work before they are implementable.

\section{Steering Committee Guides Center Operations}

\footnotetext{
$A$ Steering Comminee consisting of representatives of each state in the region has been formed to guide the overall operation of the North Central Superpave Center. The Steering Committee held its first meeting in November 1995. The second meeting of the group is scheduled for April 18, 1996 in Kansas City, in conjunction with the North Central Asphalt User-Producer Group meeting.

Steering Committee representatives include the state highway agencies and asphait pavement industry groups in the region. The Federal Highway Administration also has representatives on the Commintee. A complete list of the members is shown to the right.

(conrinued on page 6)
}

\section{NCSC Steering Committee Members}

David Andrewski. Indiana DOT Mark Blow, South Dakota DOT Bernard Brown, Iowa DOT Douglas Coleman, Michigan DOT James Gehle:. Mlinois DOT

An Hill. Minnesola DOT

Ron Homer. North Dakora DOT

Leonnie Kavanagh. Maritoba

Department of Highways Richard McReynolds, Kansas DOT David Powers, Ohio DOT

Bill Trimm. Missouri Highway

Transporzuon Deparment John Volker. Wisconsin DOT Dwight Walker. Kenncky

Transporation Cabinet Laird Weishahn, Nebraska

Department of Roads Allan Widger. Saskatchewan Highways \& Transportation

\section{FHWA Contacts}

Ken Archuleta Kansas Ciry, MO Dudley Brown. Frankfor KY Tom Bryan, Olympia Fields, II Dennis Dvorak Topeka. KS Lee Gallivar. Indianapolis, $\mathrm{N}$; Andy Games, Columbus. $\mathrm{OH}$ Stan Graczyk. Saint Paul, MN Brett Hestdalen, Pienre. SD Roger Hoovestol, Bismarck, ND Frank Howell, Ames. IA. Bemie Kutz, Adanta. GA Kevin McLaury. Lincoln. NE Scon McGuire, Colurobus, $\mathrm{OH}$ Frank Rich. Lakewood, CO Ryan Rizzo, Lansing, MI Virgil Stiffler. Jefferson City, MO Hal Wakefield. Springtield, II 


\section{North Central Superpave Center Introduces Staff}

$\mathrm{T}$ The Norh Central Superpave Center has assembled its permanent staff. We would like to introduce the personnel to you and explain their roles in the NCSC's operation. These personnel will staff the Mixture and Binder Branches and are available to help you get information and answers to your questions.

Dr. Jan Olek is the Director of the North Central Superpave Center. Olek has 18 years of experience as a university professor and researcher. As Director. Olek is responsible for overall management of the operation of the NCSC. He will also oversee such activities as long range planning, securing future funding. coordinating validation efforts for SPS-9 studies. identifying critical research needs and

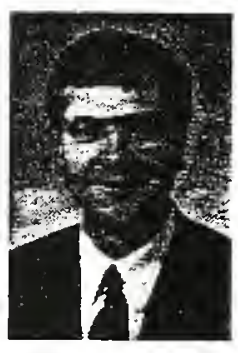
implementing work in those areas, balancing the budget. planning and conducting training exercises, coordinating with other Centers and agencies. chairing the Technical Advisory Committee and sering on the Steering Commuttee. Olek will devote 50 percent of his time to the NCSC.

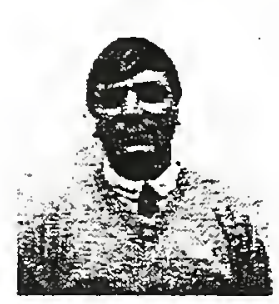

David Andrewski is the Associate Director of the NCSC and is primarily responsible for overseeing its overall activities in cooperation with Olek. He will be placing a strong emphasis on the field implementation of Superpave technology. Andrewski has 20 years of experence with the Indiana Deparment of

Transportation in the Design Division and the Matenals and Tests Division. Andrewski is the INDOT Materials Manager, a position he has held for four years. As Associate Director. Andrew ski chairs the Steering Committee. acts as a liajson with the North Central Asphalt User-Producer Group, coordjnates activities between the Binder and Mixrure Branches, paricipates in training activities, is a member of the Technical

Committee. reviews capital expenditures and manages field implementation of the Superpave technology and QC/QA procedures.

Rebecca McDaniel is the full-time

Technical Director. She is primarily responsible for the day-to-day operations of the NCSC. including planning and overseeing daily activities: coordinating with the Binder Branch: supervising the staff: managing and performing shakedown, ruggedness. precision and bias. SPS-9 and research testing; editing the neu sletter. establishing the information clear-

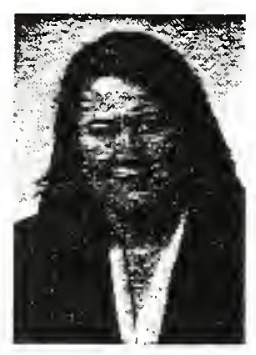
inghouse. and communicating progress to the region; preparing technical repors: planning, organizing and conducting training activities: making presentations to local and national groups: assisting in the development of cerification and quality control programs: and more. McDaniel brings ten years of experience in highway pavement and materials to the position.

Travis Lovvorn was recently hired as the NCSC's full-time technician. He was previously employed as the laboratory technician at the INDOT Division of Research, where he worked extensively in asphalt research testing. Prior to that, Lovvorn worked as an asphalt paving inspector on the Indiana SPS-9 site. among others. and as a Dynaflect operator. Lovvorn has broad technical shills that will be very helpful in the researcin and development work envisioned for the Mixture Branch.

Julie Smith is the half-time secretary for the NCSC. She will work from 10:00 a.m. to 2:00 p.m. daily. Currently, Smith is working out of an office at Purdue Liniversity. but she will relocate to the Mixture Branch when her office remodeling is completed. Smith will provide general secretarial suppor for the NCSC. Smith is a graduate student at Purdue

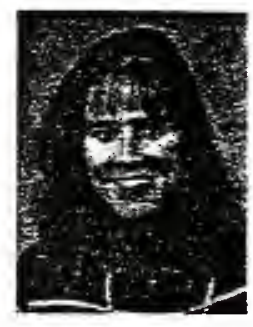
University studying Political Science. She has eight years of experience in various office environments and has exiensive graphic capabilities that will be reflected in this new'sletter and other NCSC publications.

As Acting Bituminous Engineer for INDOT. Mike Prather has been involved in setting up and overseeing all of INDOT's trial Superpave binder and mix design projects. Prather is also a graduate of the Asphalt Institute's mix design class. Prather will spend 20 percent of his time working with the Superpave Center providing practi-

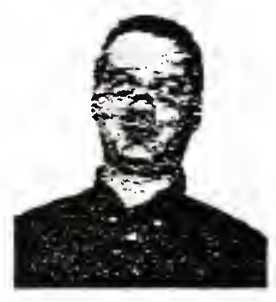
cal and technical suppor for training. research, implementation and development work.

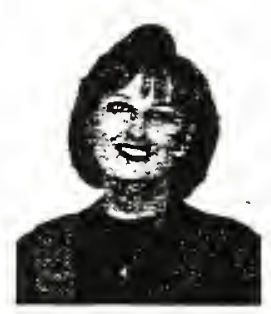

At the Binder Branch. Rhonda Richardson is the Superpave Laboratory Manager. She will devote 50 percent of her time to NCSC activities. For 18 years, Richardson has worked in various capacities at INDOT Materials and Tests. and has managed the Superpave Binder Laboratory since its inception. As a graduate of both the binder and mixture classes at the Asphalt Institute and a regular user of the Superpave technology, Richardson brings a wealth of experience to the Binder Branch.

Bob Rahn is the Laboratory Tesing Manager at INDOT Materiais and Tests. He will be involved in coordinating work at the Binder Branch and assisting with training. Rahn has 35 vears of experience with INDOT and also is a part-time faculty member at Indiana University-Purdue University at Indianapolis (ILPUI) teaching soils. Rahn has extensive experience with calibrating and adjusting the binder and mix design equipment. Rahn will be assisted by Matt Doherty. the Assistant Laborator Manager and Quality System Manager.

Technicians at the INDOT Materials and Tests Division are cross-trained to enable them to move between laboratories to where they are most needed. Several of these technicians will be available to assist in the Binder Branch as needed. Key among them is Cartia Martin, who works essentially full-time with the binder equipment. Others who will assist as needed include John Ryan, John Korbley, Harley Phillips and Brian Cooper. 


\section{Binder Lab Costs Add Up}

T The pooled fund equipment buy has provided complete sets of binder equipment to each state in the North Central region. Many, but not all, states have set up and are operating their binder laboratories. If you have not set up your lab yet, you may find there are many smaller, but essential, items you will need. Rhonda Richardson has prepared a list of items and associated cosis based on their experience at the Binder Branch. This list is available from the NCSC upon request.

Depending on your particular situation, you may not need all of the items, but you may want to use this list as a reference to look over your inventory of equipment, tools and supplies. If you are staning from scratch and do need everything on the list, you will add almost $\$ 15,000$ to the cost of setting up your binder lab.

To clean rolling thin film oven (RTFO) bottles, you either will need a parts cleaner tank (S600) and solvent, or you can bum off the asphalt in an oven. There is a special oven on the market for cleaning glassware that runs $\$ 8,000$ to 10,000 (from Tempyrox of Dallas, Texas). Fawaz Hamoui of Gilson reports that they are working on an accessory for the asphalt ignition oven that will allow you to load your RTFO bottles into the ignition oven to clean. The rack may be available soon. If you consider the amount of time your technician may have to spend cleaning RTFO bottles and the cost of solvent, it may justify spending a few thousand dollars on an oven.

\section{Work Progresses on Mixture Branch}

4 stablishment of the Mixture Branch in West Lafayette has involved extensive remodeling work to the space in the INDOT Division of Research. The NCSC is being located in a large classroom adjacent to the existing Research Laboratory. Work is progressing with full occupation expected in Spring 1996. The technical director and technician are currently occupying temporary offices at the Division of Research and the secretary is working in an office at Purdue University.

A contract for the electrical upgrades for the NCSC is being let and work should be completed within two months. Plans for an air handling system to vent fumes and provide needed fresh air exchanges have been developed and are being reviewed.

The Indirect Tensile Tester (IDT) and the Superpave Shear Tester (SST) have been delivered and are awaiting installation.

The remodeling is being designed by the expers in the Facilities Planning Office at Purdue. The work is being financed by the Indiana Deparment of Transportation.

\section{Ohio Works Toward Superpave Validation}

$A$ t February's 20th Annual Ohio Asphalt Paving Conference, speakers described an Ohio Department of Transportation (ODOT) pro-

ject that will help to validate the Superpave technology and further study environmental and structural factors related to Superpave. Roger Green of ODOT described the project. located on U. S. 23 in Delaware County, north of Columbus. The site includes test sections that are part of four Long Term Pavement Performance (LTPP) experiments:

- SPS-1 Structural Factors for Flexible Pavements

- SPS-2 Structural Factors for Rigid Pavements

- SPS-8 Environmental Faciors in the Absence of Heavy Traffic

- SPS-9 Verification of Performance-Based Specifications and Mix Design Analysis System

Lisa Zigmund, the ODOT project engineer, further described some of the test sections and the complexities of coordinating a project of this scope. All of the LTPP test sections have been completed: the remaining four ODOT test sections will be completed this summer.

Gary Ferguson, of S. E. Johnson Company, Inc., spoke about designing and placing the Superpave mixtures used on the project. Six trial blends were required to design the $19 \mathrm{~mm}$ mixture and 13 tral blends were needed to design the $12.5 \mathrm{~mm}$ mixture; surprisingly, both of the successful mix designs passed over the top of the restricted zone. Ferguson raised questions regarding the measurement and calculation of VMA, the fourhour aging period and other issues that need to be further investigated.

Shad Sargand, a professor at Ohio University, described the extensive pavement instrumentation installed in the experimental sections. This site is the only instrumented SPS-1 site in the United States. Sensors are in place to measure soil moisture and suction, frost depth, deflection and more. A weather station located at the site will also allow measurement of temperature, solar radiation, rain or snowfall and wind speed.

This site will be providing very valuable information to the Long Term Pavement Performance program and the region.

\section{Binder Round Robin Being Initiated}

A t the request of the North Central Asphalt User-Producer Group (NCAUPG), the NCSC has initiated a binder round robin testing program. Samples of two modified and one unmodified asphalt cements were collected and shipped out to participating laboratories for testing.

Preliminary test results will be summarized and presented at the April 17 meeting of the NCAUPG in Kansas City. Final results will be collected, analyzed and presented in a formal report with copies to all participating labs and other interested organizations. Participating labs will be identified in the reports so that groups can immediately see how their results compare to other labs.

Current participants include ail of the states in the North Central region and industry labs that signed up at the last NCALPG meeting. If your lab is interested in paricipating, please contact the North Central Superpave Center. 


\section{Superpave Centers Meet, Coordinate}

T The first meeting of the five regional Superpave Centers was held at the Asphalt Institute in Lexington. Kentucky, on January 16 and 17, 1996. The FHWA sponsored the meeting to encourage cooperation and collaboration between the Centers. The meeting was attended by representatives of the Centers in Alabama, Indiana, Nevada. Pennsylvaria and Texas. and by Chref Engineers (or their delegates) and FHWA Division Administrators from each host state.

Ed Miller, President of the Asphal: Institute. welcomed the attendees and expressed the suppon of the Asphalt Inscitute and its willingness to cooperate with the Centers.

John $D^{*}$ Angelo and John Bukowski, both with the FHWA in Wastington, D.C., outlined the rationale for establishing the Centers and their current status from the FHWA's point of view. Byron Lord, FHWA Chief of the Highway Technology Applications Division, stressed the need for uniformity of training and application of the Superpave specifications.

Each Superpave Center then gave an update on its status. activities, funding strategy and other issues. Rebecca McDaniel, of the North Cenural Superpave Center, outlined its plans and status. as detailed elsewhere in this newsletter.

Ray Brown. of the Superpave Center at Aubum, stated that they are doing some rehabilitation and will be ready to install the Superpave Shear Tester (SST and Indirect Tensile Tester (DT) in February. They have provided some training courses and are planning more ir. 1996. They are asking for contributions of $\$ 20,000$ from each paricipating state in their region.

Jon Epps, of the Superpave Center ir. Reno, Nevada, presented a uniquc concept of establishing a "mini-NCHRP" on a regional scale to fund research relatec to Superpave. This approach would involve establishing research prionties. writing requests for proposals. reviewing proposals and awarding the research to the group with the best proposal. This approach would allow the Superpave Center and other universities to solve regional issues and would ensure that not all of the research funding for Superpave goes to the Center. The goal of working cooperatively with other research groups in their respective regions was a concern oi all the Centers. The Reno Center is targeting $\$ 500.000$ per year in contributions from its member states, FHW A and the Nevada DOT.

According to David Anderson o: the North Eastem Superpave Center. located at

Pennsylvaria State University. that Center will receive $\mathrm{S} 1$ milion from the Pennsylvaria DOT
Austin. outlined their plans. The Texas DOT is fully funding this Center with no conuributions from other states in the region. The Center will be relocated with new Texas DOT laboratories in a new building which is currently under construction. It is anticipated that constuction will be completed by May. Until ther. the Center is operating out of space at the University of Texas at Austin.

During the general discussions, it was determined that Don Lucas. Chief Engneer of the Indiana DOT. should address the spring AASHIO meeting to encourage suppor of the regional centers and implementation of Superpave. Rod
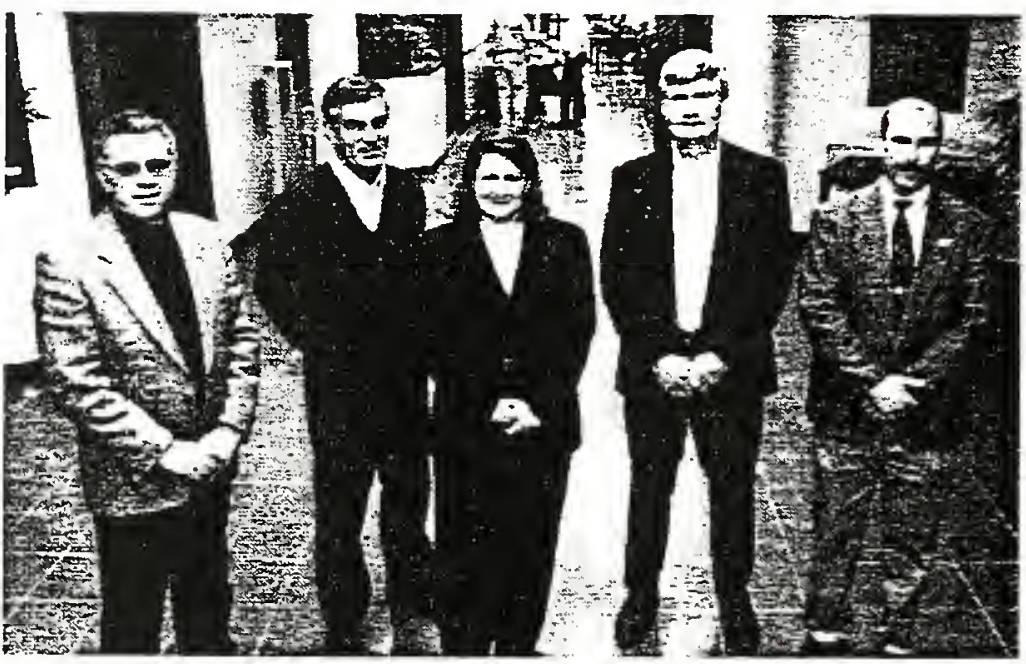

Johnson, of the Nevada DOT. agreed that the CEO's need to buy in and "drive that train."

This full meeting was followed by a half-day meeting of the technical people from each Superpave Center. This smaller group thoroughly discussed working together cooperatively, establishing lines of communication, and sharing information and experise. It was decided to continue to hold periodic meetings of this group in the future, to exchange newsletters and other information. 10 pursue the idea of networking the Centers via the Internet and videoconferencing, and more. Plans for the upcoming pilor course in mix anaysis and performance testing to be offered at the Asphalt Institute in February and the SST and DT ruggedness tesung program were discussed.

A summer meeting of the smaller group representing only the Superpave Centers (not including the Chief Engineers and FHWA Division Administrators) was scheduled for July: 11 and 12. The goal of the meeting will be to continue discussions on susiainability of funding, status, cooperation.

national research needs. communications mecharisms, and ongoing FHW A work. The meeting will be hosted by the NCSC in West Lafayctte, Indiana. 


\section{NCSC Staff Attends Advanced Mix Analysis Training}

$\mathrm{M}$ embers of the NCSC staff attended the pilot course on Advanced Superpave Asphalt Mixture Analysis the week of February 19th. The FHWA sponsored the course through the Nacional Asphalt Training Center II (NATC) at the Asphalt Institute. This pilot course was designed to introduce users of the Superpave Shear Tester (SST) and Indirect Tensile Tester (DT) to the test methods, specimen preparation. data checking and analysis, and modeling software. The course combined classroom instruction and laboratory demonstration to reinforce the concepts presented.

The course was attended by beginners and experienced users from the Superpave Centers, academia and private industry. In addition to leaming about the Superpave mix analysis procedures, the attendees provided important feedback to the NATC to help them fine tune the course before it is presented again. The NCSC was represented by Dr. Jan Olek. Rebecca McDaniel and Travis Lovvom. Lee Gallivan, of the FHWA Indiana Division. also attended on behalf of the NCSC.

This training course marks the beginning of the intensive training the NCSC staff will undergo over the next few months as they prepare to begin using the SST and IDT for ruggedness and other testing. Additional training will be provided by the equipment manufacturers when they complete installation of the equipment at the NCSC. Other training opportunities will likely be arranged by the FHWA as needed.

\section{Superpave Blossoms in Spring 1996}

1 The Indiana Department of Transportation (INDOT) plans to construct 16 Superpave projects during the 1996 construc-

tion season. Two of these 16 projects will be mix verification projects (previously referred to as Level 2 design). Another mix verification project is planned to be let by an Indiana county using 100 percent local funds. Confidence is high that these Superpave projects placed on high volume roads will provide Superior Performing Pavements.

INDOT contractors have embraced the Superpave system to the extent that INDOT's first asphalt pavement warranty project was let giving the successful bidder the option to use any mix design he desired. The contractor who was awarded this project intends to design his mixes using the Superpave mix design with mix verification.

Confidence in the Superpave system comes from successful Superpave projects completed to date. This successful transition to Superpave is due in large part to the cooperation and partnership between industry and INDOT.

\section{SHRP Binder ETG Meets in February}

1

he SHRP Asphait Binder ETG met in Phoenix, Arizona on

February 14 and 15, 1996. Agenda items included updates on

the binder equipment (DSR, PAV, BBR and Direct Tension Tester), low temperature data, RTFOT, binder QC. WRI contract findings, linearity, RA.P, fatigue criteria, PP- 5 and the high temperature specification.

Highlights of the binder equipment discussion included which gap size to use on the DSR to accommodate filled systems--indications are that results using a 2.5 to 5 millimeter gap with $\# 40$ or $\# 80$ mesh material may be valid. ATS PAV's meeting PP-1 have been delivered to 51 states. The Prentex PAV may have problems meeting the ten minute temperature requirement. This spring, the FHWA will be studying this with experiments using three asphalts. The new Direct Tension Device looks promising. The new test machine looks similar to a BBR and will fit in the back of a station wagon.

The AASHTO specification states that the RTFOT botles "may be scraped." The ETG is recommending to AASHTO that the specification be changed to "shall be scraped to get out at least 90 percent of the material." For very stiff marerials (PG 82 or 88 ), the group is looking into raising the test temperature.

Low temperature data presented indicated that the Superpave algorithm is conservative. The group questioned the type of sensor used in the pavement. Further study on this matter is under way.

The Asphalt Institute's reply to AASHTO's proposed binder certification plan was reviewed. Numerous items were discussed. Members concerned with the specification or the Asphalt Institure's reply are to comment to the Asphalt Institute and AASHTO in writing. Remaining issues appear to be minor and with minor modifications may be an acceptable specification for all.

Gelled asphalts do not fit into the current linearity requirements: however, some of the limits were selected arbitrarily. Tony Kriech will respond to the ETG members before the next meetings.

Tier 1, 2 and 3 RAP mixrures using blending charts were discussed. Both the Asphalt Insuitute and NCAT plans were reviewed. No final decision was reached. The Asphalt Institute will conunue research through the summer. Caution should be exercised when blending RAP containing a modified liquid with a virgin modified liquid.

There was some concern that the Superpave fatigue parameter. $G^{*} \sin \delta$, does not predict field performance. SHRP researchers. because of time limitations, used binder accelerated aging procedures over long term aging of the mix. Ron Reese presented the Califormia research conducted to compare binder properties with the fatigue life of mix. The full report will be included in the ETG minutes.

The ETG minutes will be distributed as soon as they become available. If you have more immediate concerns. please contact Dave Andrewski at (317) 232-5280. 


\section{NCSC Plans and Offers Training Courses}

I n February, the North Central Superpave Center conducted its first pilot training course for the North Central Region. The pilot course was designed for experienced Marshall mix designers and provided them with training in the Superpave volumetric mix design procedures and hands-on experience using the Superpave Gyratory Compactor. The course also provided an overview of the Superpave binder specifications and the performance testing that will become a part of mix design and analysis in the future.

At the request of the Rieth-Riley Construction Company. the pilot course was put on for foureen members of its technical and professional staff. Rieth-Riley works in Indiana. Michigan and other states. Similar courses will be offered for the open enrollment of other contractors and state personnel in April. as shown on the schedule below. Industry representatives will be asked to pay a tuition fee to help offset the costs of providing the training.

\section{April 1-3 Superpave Binder Training}

Indianapolis, Indiana (Binder Branch) TENTATVE

April 8-11 Superpave Mix Training for Experienced Marshall Mix Designers

Indianapolis, Indiana (Binder Branch) TENTATVE

The NCSC is also planning to offer other training courses for specific audiences. Current plans call for these courses to be ready for the Fall of 1996 (towards the end of or after the construction season); if enough interest is expressed, however, the courses could be presented earlier in the year. A more detailed mix design course for new mix designers will be available. This course will provide more hands-on experience in determining specific gravities. mixing samples and performing the required volumetric calculauons. A hands-on binder training course will be offered in April. Train-thetrainer courses uill be offered so that a state or contractor can send a small number of people to training out of state. who can then bring back what they leam and disseminate it throughout the organization. Eventually: mix analysis courses also will be offered to provide traming in the use of the SST and DT, but these courses are not planned for the near future since few states or contractors will have access to this type of equipment.

The NCSC will be working to promote development and adoption of Qualiry ControVQuality Assurance procedures for Superpave. We will coordinate with other regional and rational groups workng on these issues for both binders and mixtures. As these procedures are developed. we will work on planning training courses to explain these procedures to industry and state personnel at various levels from upper management to field personnel.

Genenc training courses are being developed based mostly on the models prepared by the National Asphalt Training Center (NATC). These courses can be customized or specialized for particular audiences or states as needed. Other special courses also can be developed. Under our draft financial plan. we are proposing to offer basic courses to a limited number of state personnel as par of the base services of the NCSC. Training courses for industry representatives or specialized training courses over and above the basic courses would require additional funding. This draft financial plan will be distributed to members of the Steering Committee for review prior to its April meeting, when the funding strategies for the NCSC finally will be resolved.

\section{NCSC Speakers Available}

$\mathrm{T}$ The NCSC Steering Committee identified communication as one of the key services they expect the region's Superpave Center to provide. This newsletter is one attempt to begin serving that function. In addition, we are investigating the use of the Intemei in cooperation with the four other Superpave Centers, establishing a regional information clearinghouse. looking into the possibility of a regiona! Superpave experience database, and more. Face-to-face personal communication is not being neglected. In recent months. representatives of the North Central Superpave Center have addressed the following groups: the Indiana Association of Cities and Counties: the Kentucky Asphalt User-Produce- Group: the Asphalt Pavement Association of Indiana: the Superpave Center Coordination Group; the Indiana Asphalt UserProducer Group: the Ohio Asphalt Paving Conference; and the Binder Exper. Task Group. Future presentatons are planned for the ConExpo/ConAgg convention in Las Vegas and the Annual Purcue Road School in West Lafayette.

If your state or group would like to arrange for a member of the NCSC staff to make a presentation, please contact the NCSC to discuss the possibility. Presentations have already been developed for local agencies. management and industry groups.

If time allows, the NCSC staff is also interested in atrending meetings of state user-producer groups or similar bodies to get a first-hand impression of the status of Superpave implementation around the region. Time and finances will not permit us to attend all of these meetings, but we will make an attempt to usit each state eventually. In addition. if you notify us of your meetings early enough. we cas promote them through this newsletter and inform others in the region about what is going on in your state.

\section{(con:mued from front page)}

Individuals who are interested in suggesting research. training or other activities in which the Superpave Center should be involved are encouraged to contact a Steerng Committee representative from their state.

At its first meeting, the Committee developed the vision and mission statements for the . NCSC, outlined the functions the NCSC should serie. discussed possible funding options, and examined the overall role of the NCSC in the region. At its second meeing. the Committee is expected to further discuss regional research needs and finalize a funding strategy for the future operations of the NCSC, among other things. 


\section{North Central Superpave Center Administrative Organization}

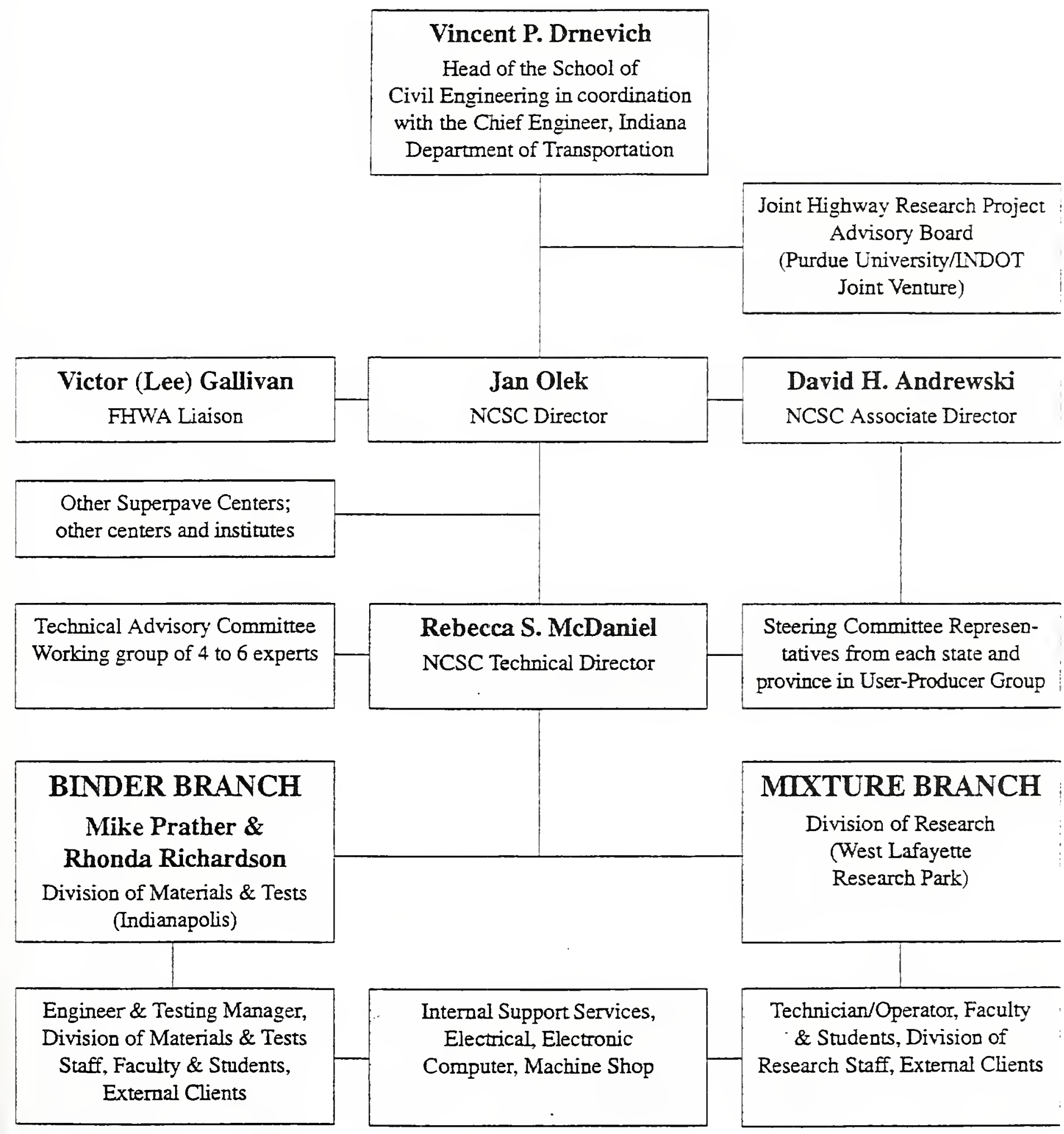




\section{Tips and Techniques: Help Wanted}

$\mathrm{E}$ xperienced lab personnel often develop clever or effective techniques for completing their testing efficiently, cleanly or reliably. We would like to help share those ups and techniques so that others may benefit. This column is intended to be a regular feature of the NCSC Newsletter where we can suggest laboratory techniques relating to Superpave binder or mixrure testing.

If you have a technique that has worked to simplify your laboratory testing in some way, and you are willing to share the idea, please let us know. The types of things we have in mind include special tools you have developed or adopted for handling specimens. pouring, scraping, etc; timing of the steps that make the testing process flow better; tips for batching or mixing specimens; cooling or heating samples; or any other tips you suggest. All tips should be compatible with the specifications and test methods. Credit for the sources of the tips will be given.

Please share your successful laboratory testing techniques with others!

\section{Upcoming Events}

Mar 26-28 Road School, Purdue University

West Lafayette, Indiana

Apr 1-3 Superpave Binder Training

Indianapolis, Indiana (Binder Branch) TENTATTVE

Apr 8-11 Superpave Mix Training for Experienced Marshall

Mix Designers

Indianapolis, Indiana (Binder Branch) TENTAJTVE

Apr 16 Meeting of NCSC Lab Personnel

Kansas City, Missouri

Apr 17 North Central Asphalt User-Producer Group Meeting Kansas City, Missouri

Apr 18 North Central Superpave Center Steering Committee Meeting

Kansas City, Missouri

Jul 11-12 Superpave Centers Coordination Meeting

West Lafayette, Indiana invaAToN ONLY

All meetings are open unless otherwise noted. Preregistration and/or registration fees may be required. Contact the Superpave Center for more details: NCSC, 1205 Montgomery Road, Posi Office Box 2382, West Lafayette, Indiana 47906. Please notify the Superpave Center of your upcoming meetings and conferences.

\section{Until the staff of the NCSC move into their permanent offices later this Spring, please send your faxes clo Julie Smith to (317) 496-1364. Written correspondence can be sent to the address listed below.}



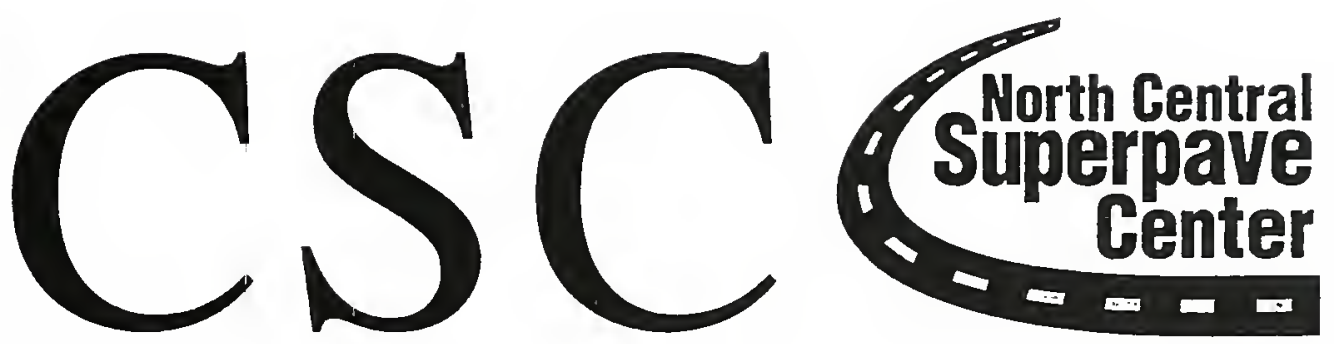

Volume 1, Number 2

Summer 1996

\section{Industry Shares in Superpave Implementation}

P artnership is one of the key buzzwords of the 1990's. Far from being a cliché, however, the concept of partnership is crucial to the improvement in quality that all of us are seeking. In this era of partnership, the involvement of the highway industry in Superpave implementation is recognized as essential to the successful application of the new technologies. The North Central Superpave Center (NCSC) was established with the goal of involving industry. The Steering Committee comprises both state and industry representatives from each state and province in the region. Currently, the industry members of the Steering Committee represent the asphalt pavement associations of their respective states or contractors in the region. Those members are shown in the have asphalt pavement organizations. The Technical Committee, which is called on to address specific technical issues, will consist largely of experts from industry, academia and government.

Industry involvement in the NCSC has been discussed at previous meetings of the Steering Committee. The state members of that committee expressed their recognition of the need for industry participation, but did not feel industry groups should be required to assist in funding the NCSC's operation. (The NCSC will be funded in large part by the states paying an annual base fee. Additional funding will be provided by the states for research projects, some training programs and other auxiliary activities.) Various facets of industry already provide support for many other organizations, such as the National Asphalt Pavement Association, Center for Aggregate Research, Asphalt Institute, etc. Therefore, at this time, the industry groups are not being asked to pay a membership fee to participate in the NCSC.

Industry participation is, however, being sought in other ways. Incustry is weicome and encouraged to share in the exchange of information that is one of the NCSC's primary functions. Of more than 500 people who receive copies of this newsletter, well over 80 percent of them represent industry in one way or another. Of 40 people trained to date in courses taught by NCSC personnel, half have been contractors. The industry representatives on the Steering Committee have equal voices with their state counterparts in guiding the NCSC's operations and priorities. Each study advisory committee that is formed to oversee particular research projects conducted by the NCSC will include industry representation.

Industry representatives are considering ways they can voluntarily participate in the financial support of the NCSC. Mr. Lloyd Bandy, Executive Director of the Asphalt Pavement Association of Indiana, is working with his counterparts in other states to identify particular functions or activities they can sponsor. Funding of the printing and distribution of this newsletter, hosting meetings, financing research projects and other items are being discussed.

Industry is also involved in the NCSC through the North Central Asphalt User/Producer Group (NCAUPG). The NCSC staff is currently working with the NCAUPG Executive Committee on ways to strengthen those ties and coordinate activities.

The NCSC staff gratefully acknowledges the support and active participation of industry in the Center. Without the backing of industry, Superpave implementation cannot be successful. Without the involvement of industry representatives, the Superpave center cannot fulfill its mission.

\section{NCSE Steering Committee Industry Representatives}

\section{ILLINOIS Mr. Marvin Traylor}

Illinois Asphalt Pavement Association

Springfield (217) 523-2241

INDIANA Mr. Lloyd Bandy

Asphalt Pavement Association of Indiana

Indianapolis (317) 632-2441

IOWA Mr. Gail Jensen

Mathy Construction Company

Onalaska, WI (608) 783-6411

KENTUCKY Mr. Dean Blake

Plantmix Asphalt Industry of Kentucky

Frankfort (502) 223-3415

MICHIGAN Mr. John Becsey

Michigan Asphalt Paving Association

Lansing (517) 882-6555

MINNESOTA Mr. Gene Skok

Minnesota Asp balt Pavement Association

New Brighton (612) 636-4666

MISSOURI Mr Wayne Muri

Missour Asphalt Pavement Association Jefferson City (314) 635-6071

OHIO Mr. Cliff Ursich

Flexible Pavenents, Inc.

Colinmbus (614) 22 I -5402

OKLAHOMA Mf al Lombert Oklahoma Asphalt Pavement Assoctation Oklahoma City (405) 947-7675

WISCONSIN MT Enin Benish Payne \& Dolan, Inc.

Waukesha (414) 524-1753 


\section{Superpave 2000 Open House}

1 National Superpave 2000 Open House being hosted by the Indiana Department of Transportation (DOT) is scheduled to be held in Indianapolis, Indiana, August 21-22, 1996. This Open House will showcase Superpave implementation efforts by the Indiana DOT and other states, provide updates on Superpave software, and Westrack validation work. In addition, there will be discussions on the use of reclaimed asphalt pavement (RAP), Superpave aggregate specifications, industry perspective on Superpave implementation, and the use of Superpave mix design and analysis procedures on a hot mix asphalt (HMA) warranty project. Attendees of the Open House also will have the opportunity to visit Superpave construction projects and a Superpave laboratory. The Open House is directed to state and local agencies, asphalt and aggregate representatives, and contractors. The Open House is being sponsored by the Federal Highway Administration, Indiana Deparment of Transportation, Asphalt Pavement Association of Indiana, Indiana Mineral Aggregates Association, and the North Central Superpave Center.

For more information about the Open House or to be included on the mailing lists for registration information, please contact Sandi Robles or Mary Huth of "Accent on Indianapolis" at (317) $632-8687$ or (317) 632-5848 (fax). When you call, be sure to refer to Superpave 2000.

\section{JHRP Tradition Continues}

0 ne thing that the FHWA looked for when selecting sites for the regional Superpave Centers was a good working relationship between the potential host state DOT and an engineering university in that state. While many states in the North Central region have established effective and productive arrangements with their universities, the relationship between the Indiana DOT and Purdue University is distinguished by its longevity and efficiency. Their venture, the Joint Highway Research Project (JHRP), has long been recognized as an outstanding example of how states and universities can pool their resources to mutual benefit.

That long-standing partnership was expanded to include industry in 1992 when four industry representatives were added to the governing board. The industry members of the board represent the aggregate, hot mix asphalt, concrete and construction industries. Industry representatives are also included on each study advisory committee to guide research on particular problems.

The JHRP was established by the Indiana State legislature in 1937. The program is govemed by the Joint Highway Research Project Board, which is currently chaired by Mr. David $M$. Pluckebaum, Indiana DOT Deputy Chief Engineer. Professor Kumares C. Sinha, Head of the Transportation Area at Purcue, serves as the Director of the Board.

Through the JHRP, the State can utilize the resources of the University for transportation-related research and development, implementation and technology transfer. Over 500 research projects have been completed by the JHRP since its inception. The $82^{\text {nd }}$ Annual Purdue Road School was held in 1996; this meeting of state and local highway personnel is one of the major technology transfer activities of the JHRP.

The NCSC is currently being overseen by JHRP. This allows the NCSC to operate through the University with no overhead being charged, at least for the first two years of operation. University resources are being used to handle accounting, payroll, procurement and other functions. The University connection also allows the NCSC to make use of University services at greatly reduced fees. This newsletter, for example, is printed by Purdue Printing Services. Also, the WWW page we are establishing will operate through the Purdue Engineering Computer Network (see page seven for our new WWW address). These are just a few of the ways that the NCSC can take advantage of the benefits of working through the JHRP.

\section{State Support for Superpave}

T he AASHTO Standing Committee on Highways of the United States unanimously approved a resolution in support of the five regional Superpave Centers at its meeting in April. The resolution cites recommendations from the AASHTO Task Force on SHRP Implementation which strongly encourage states to take an active role in their regional Centers. The resolution also acknowledges the backing of the FHWA and states that the FHWA has determined that support of the Centers is in the national interest and has authorized states to use 100 percent SPR (State Planning and Research) funds to participate in their respective Superpave Center.

The Committee on Highways resolved that each state should be encouraged to participate in their regional Superpave Center through funding support, oversight of operations, and through supplying loaned staff in order for the nation's highways in every region to be benefitted by the maximum possible advancement of the Superpave system.

The five regional Superpave Centers appreciate the strong support demonstrated by this resolution. We are all committed to belping to achieve the goal of successful implementation of the Superpave system to improve the performance of our nation's highways. The support of the states, other government agencies and industry is essential to making Superpave work.

\section{A full copy of the text of this resolution is available upon request from the NCSC.}

\section{Equipment News}

B oart Longyear demonstrated a new gyratory compactor at the Asphalt Institute last month. The hydraulic device was designed to meet the Superpave specifications and weighs about 490 pounds. A built-in sample ejector is included. The Asphalt Institute plans to test the compactor for conformance to the specifications. Pending favorable results of that testing, the device may be on the market in a few months. 


\section{North Central Region Moves Toward Superpave Implementation}

T he 12 states and two Canadian provinces of the North Central region are making the commitment to implement the Superpave specifications. Most states report that they will be adopting the Superpave binder specifications effective January 1, 1997, and have set target dates for instituting the Superpave volumetric mix design procedure as well. The status of implementation varies widely across the region, however. State Steering Committee members outlined the status of implementation in their states for this article. The summary of their responses is presented in the table on pages four and five of this Newsletter. More detailed comments related to implementation in each of the states are given below. Please keep in mind that these plans and proposals are evolving and are subject to change.

The Ilinois Department of Transportation (DOT) is one of the leaders in the implementation of the Superpave Gyratory Compactor (SGC); their investment in the SGC and training was summarized in the January 1996 issue of FOCUS, the FHWA's newsletter on SHRP implementation. Illinois will not adopt the binder specification entirely in 1997, but will have nine demonstration projects in 1997. In 1996, the Mlinois DOT will require the use of Superpave binder and the asphalt ignition oven on four demonstration projects.

The Indiana DOT will construct seventeen projects using the Superpave binder and mix specifications in 1996; three of these projects will involve mix analysis procedures (formerly known as Superpave Level 2). The Indiana DOT plans to implement Superpave mix design for all major interstate projects in 1997, all secondary roads in 1998 , and all projects in 1999. Two regional binder laboratories will assist with production testing of Superpave binders.

The Iowa DOT will implement the binder specification in 1997 and is discussing the possibility of implementing the volumetric mix design procedure in 1998 or $1999 . \quad$ Last year's Superpave projects used the Marshall hammer for field control, a practice that may continue for some time because contractors in Iowa were recently required to buy Marshall hammers for Iowa's Quality Management program. The Superpave designs are done cooperatively by the State and contractors.

The Kansas DOT will be working to implement both the Superpave volumetric mix design procedures and a Quality Control/Quality Assurance program by 1999. Contractors in Kansas are getting with the program as well; one has a full lab up and running, and two others will probably get set up this summer. Kansas has also been researching some test methods, including fine aggregate angularity and microwave binder aging.

The Kentucky Transportation Cabinet is placing $\mathrm{mix}$ for a research project this year which requires the use of several different binder modification techniques to meet the same PG grade. The project will include the use of an air oxidized asphalt and in-line polymer modification. Kentucky is also working on instituting a Quality Management specification on about 50 jobs this year and all jobs next year.

The Manitoba Department of Highways is in the midst of a transition to Superpave, but does not yet have firm deadlines for their shift. They are working closely with asphalt suppliers on binder implementation. Low temperature issues continue to be of great interest. They are currently looking at the conventionaily graded materials their suppliers produce and determining what PG grade those materials meet. Manitoba is looking to the SPS-9 projects for verification of the mix design procedures. They are also experimenting with the SGC.

The Michigan DOT is planning many projects using the Superpave binder specification in 1996 and will adopt the specification in 1997. They plan to implement the mix design specification no later than the year 2000 . One of Michigan's projects this year will include the use of RAP. Materials from that project will likely be used in a regional pooled fund study on the use of
RAP planned to begin this summer.

The Minnesota DOT has used mixture volumetrics for years, but they will be changing their specifications to include more rigorous VMA requirements and will institute the moisture sensitivity test. A proposal is under discussion to institute the Superpave mix design as early as 1998. Minnesota is working with Iowa and Wisconsin to select standard PG grades to use consistently in the region. The three states share common suppliers and have similar environmental conditions. Two grades for new construction and one grade for use with RAP or over jointed or cracked pavement will likely be selected.

The Missouri Highway

Transportation Department has found that contractors are having to be more selective in the aggregates that they use for Superpave mixtures. The State does all of the mix designs and shares the information with contractors. Missouri is implementing a QC/QA plan this year on two Superpave projects.

The Nebraska Department of Roads wants to implement Superpave but was one of the last states to receive all their pooled fund equipment. This is also the first full-fledged year using QC by the contractors. Contractors just purchased Marshall hammers, so it will be some time before the state requires them to purchase SGC's. Even if Superpave mix desigo is adopted by 2000 , field control still may be by Marshall.

The Ohio DOT has formed a Superpave evaluation team including the State, FHWA, and hot-mix, aggregate and asphalt industry representatives to look at Superpave's potential effects on Ohio asphalt pavement longevity. The DOT is letting several projects that allow some modifications to the Superpave specs and include quality control testing with both the Marshall hammer and SGC. The specs also allow mixes designed for roads with heavy traffic to pass through the restricted zone if satisfactory results are obtained from Loaded Wheel testing.

(contimued on page 6) 


\section{Superpave Implementation Survey}

\begin{tabular}{|c|c|c|c|c|}
\hline \multirow{2}{*}{ STATE/PROVINCE } & \multicolumn{3}{|c|}{ BINDER SPECIFICATIONS } & SP VC \\
\hline & $\begin{array}{l}\text { Implementation } \\
\text { Plans }\end{array}$ & $\begin{array}{l}\text { \# Projects } \\
1995\end{array}$ & $\begin{array}{l}\text { \# Projects } \\
\quad 1996\end{array}$ & $\begin{array}{l}\text { Implementation } \\
\text { Plans }\end{array}$ \\
\hline ILLINOIS & $1997^{*}$ & & 4 & 1996 \\
\hline INDIANA & 1997 & 6 & 17 & $1997-99$ \\
\hline IOWA & 1997 & 4 & 1 & $1998-95$ \\
\hline KANSAS & 1997 & $\therefore \quad 1+$ & 3 & 1999 \\
\hline KENTUCKY & 1997 & 3 or 4 & 2 or 3 & 2000 (Tentative) \\
\hline MANITOBA & Uncertain & 1 & 1 & Uncertain \\
\hline MICHGAN & - 1997 & $6-7$ & 10 & No later than \\
\hline MUNNESOTA & 1997 & 1 & 4 & $998^{*}$ \\
\hline MSSOURI & 1997 & Several & $\because$ & 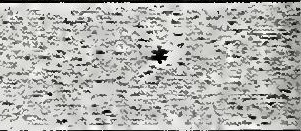 \\
\hline NEBRASKA & Uncertain & 0 & 0 & Uncertain \\
\hline $\begin{array}{l}\mathrm{OHIO} \\
\mathrm{OH}\end{array}$ & 1997 & \pm 5 & $6^{*}$ & $+* *$ \\
\hline SASKATCHEWAN & Uncertain & 0 & 1 & Uncertain \\
\hline SOUTH DAKOTA & Uncertain & 0 & 1 & Uncertain \\
\hline $\begin{array}{l}\text { WISCONSIN }\end{array}$ & 1997 & 0 & 2 or 3 & 2000 \\
\hline
\end{tabular}




\section{ITRIC MIX DESIGN}

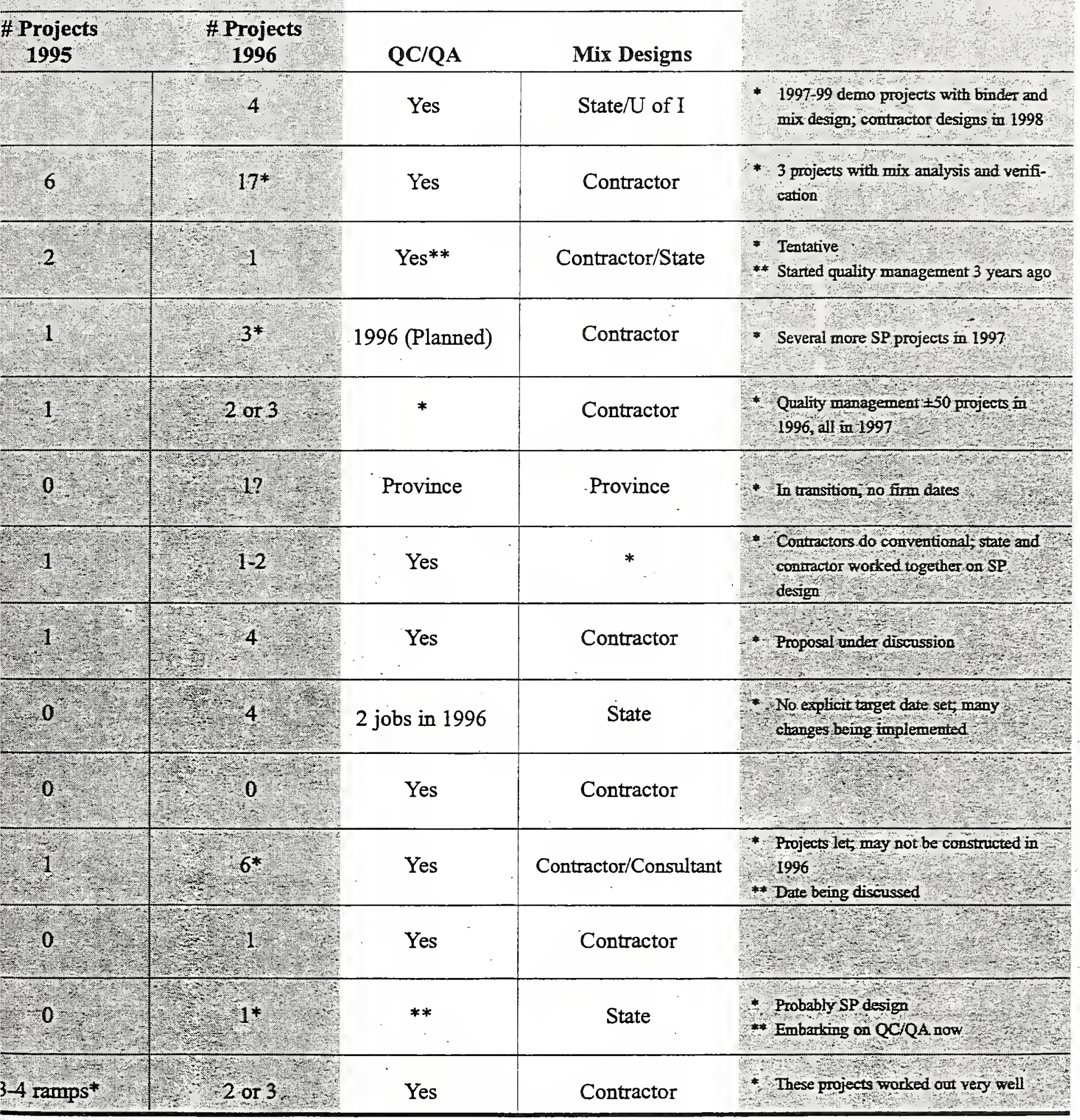

\section{CURRENT PRACTICES COMMENTS} mix design; contractor designs in 1998 


\section{National Pooled Fund Study on Superpave Validation Begins}

T wenty-three states have committed well over $\$ 500,000$ to a national pooled fund study directed at Validation of the Superpave Asphalt Mixture Specification Using Accelerated Testing (FHWA Pooled Fund Study 176). Representatives of the participating states met in West Lafayette in May to discuss the experimental design for the program.

The recommendations of the Accelerated Pavement Testing (APT) Expert Task Group (ETG) served as the starting point for the deliberations. After much discussion, the group identified a short list of factors to study, including:

Sensitivity of Mix Performance to Voids in the

Mineral Aggregate (VMA)

Effect of Fine Aggregate Angularity (FAA) on

Mixture Performance

Performance Comparison of Gradations Finer

and Coarser than Superpave Gradations

Effect of Binder Grade on Rut Depth

Principal investigator Mr. Brian Coree, Materials Research Engineer with the Indiana DOT, will develop an experimental design for the study focusing on the first three factors above. Work at Tumer-Fairbank is addressing the binder issue.

Additional work elements may be added as the study proceeds.

The NCSC will cooperate with the research by performing Superpave mix designs and analysis on the experimental mixtures. The NCSC will also coordinate a regional study on FAA with this project.

The study will be conducted at the APT facility in West Lafayette. Mixtures are placed and compacted in the APT using full-sized construction equipment. The facility, deveioped under the direction of Dr. Thomas D. White, Professor of Civil Engineering at Purdue University, can accelerate loading damage by 1,000 times.

\section{Mix ETG Recommendations}

T he Mixture Expert Task Group (ETG) met in March to discuss any outstanding issues related to Superpave implementation. Discussions focused primarily on refinement and standardization of testing. Mr. Jim Gehler of the Illinois DOT reported on the results of a round robin conducted in Illinois using the Superpave Gyratory Compactor (SGC). Ilinois is the leader in the adoption of the SGC for field compaction. Results of testing using 13 different gyratories showed standard deviations of the bulk specific gravity of 0.025 at $\mathrm{N}_{\mathrm{ini}}, 0.010$ at $\mathrm{N}_{\text {des }}$ and 0.005 at $\mathrm{N}_{\max }$.

Mr. Bob McGennis, Director of the Superpave Center at Austin, reported on a draft of the Ruggedness Evaluation on TP4, Standard Method for Preparing and Determining the Density of Hot Mix Asphalt (HMA) Specimens by Means of the SHRP Gyratory Compactor. McGennis presented the results from four aboratories; data for a fifth lab will be added before the final report is released. Results to date indicate that the tolerance on the compaction angle $\left( \pm 0.02^{\circ}\right)$ is reasonable; a transfer bowl is preferable, but not necessary, for mold loading; the tolerance on compaction pressure $( \pm 18 \mathrm{kPa})$ is too high; precompaction using a blunt-nosed rod is ineffectual; the tolerance on equiviscous compaction temperature $( \pm 0.030 \mathrm{~Pa}-\mathrm{s})$ is reasonable; the tolerance on specimen height $( \pm 1 \mathrm{~mm})$ is too narrow; and, for binders similar to those used in this evaluation, the 30-minute compaction temperature equilibrium period can be included in the four hour aging period for mixture volumetrics determinations.

The group discussed a comparison of short-term aging times at different material thicknesses. Based upon the results of a study using 11 mixes with varying degrees of absorption, the ETG is recommending that short term aging be changed to two hours at $50 \mathrm{~kg} / \mathrm{m}^{2}$. A note will suggest using four hours for highly absorptive aggregates.

In other business, the group also formed a subcommittee to look into the use of solid additives with the binder and how these fit into the Superpave system; discussed the need for research on the test for moisture sensitivity; reviewed progress of several efforts investigating the use of a mixture strength test/proof test for volumetric mix design; reviewed the N-Design experiment; and considered issues related to fine aggregate angularity, the provisional standards, test standardization, the restricted zone and control points, and the use of RAP.

\section{Implementation (continued from page 3)}

Saskatchewan Highways \& Transportation is working with Manitoba on the design of an SPS-9 this summer, which will include a section with recycled mix. Saskatchewan has an SGC in operation, but does not yet have the binder equipment. Implementation of the binder specification will take some time and some convincing-suppliers are having a hard time meeting the low temperature grades. They hope that the SPS- 9 experiment will give confidence in and understanding of the process.

The Sonth Dakota DOT has not yet developed a plan for Superpave implementation. They just recently received their last piece of binder equipment. Therefore, they will not fully implement the binder specification next year, but will likely allow AC or PG grades. They have specified one small, highly modified job this year.

The Wisconsin DOT should be well into Superpave volumetric mix design by the year 2000 . They are currently planming to place about 800,000 tons of Superpave mix between now and the year 2000. An SPS-9 project scheduled for 1997 will include different cross sections and different PG grades.

Please remember that the NCSC welcomes contributions to or suggestions for the newsletter. Please send your upcoming events, calendar dates, tips and techniques, etc., to the NCSC, clo Julie Smith, 1205 Montgomery Road, P. O. Box 2382, West Lafayette, IN 47906. 


\section{Tips and Techniques}

$M$

r. Pat Jacomet of CSR American Aggregates responded to our request for information on laboratory tips and techniques for Superpave testing. Jacomet reports on a device called the Gyro Loader, which they developed to load a gyratory compaction mold in one lift with reduced segregation. Jacomet says, "Early in our experiences with the gyratory compactor, we felt there was a need to develop an apparatus for loading the asphalt mix into the compaction mold after the short term aging period. We wanted an apparatus that would allow us to load the mold in one continuous motion without segregation. It had to be quick and easy (to reduce temperature loss and time spent by the technician) and it had to reduce the segregation that occurs during scooping (the fines tend to stick to the curing pan and thus end up on the top of the specimen). Finally, and most importantly, it had to conform to the AASHTO TP4 mold-loading procedure."

The Gyro Loader is the result of their experimentation and innovation. Jacomet describes the Gyro Loader as a self-stand- ing, wing-shaped piece of rolled stainless steel with a tapered discharge end to fit into the top of the mold. The device allows the technician to transfer material from the aging pan into the loader, level the sample and distribute it evenly, then load the mold in one motion.

Preliminary results of the ruggedness testing of AASHTO TP4, Standard Method for Preparing and Determining the Density of Hot Mix Asphalt (HMA) Specimens by Means of the SHRP Gyratory Compactor, indicate that the Gyro Loader and scoop methods can both be used without causing significant effects. Use of the scoop, in at least one case, apparently had a significant effect on the results because the operator took a long time and meticulous care in avoiding segregation during loading. With timely loading of the mold, however, such effects should not occur. These results indicate that the Gyro Loader is an acceptable method for loading the mold. In some cases, at least, the method may be preferred in some labs or by particular operators. If you would like more information about the Gyro Loader, please contact the NCSC.
For your convenience, we have printed roladex cards that you can cut out and keep at Your desk

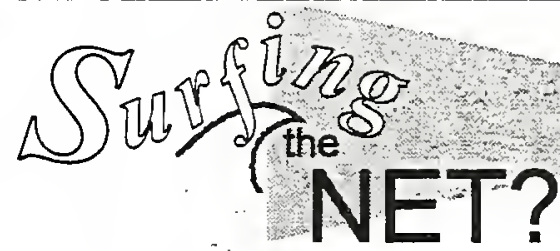

Our new WWW site should be ready around July $1,1996$. Check it out!

http://ce.mww.ecn.purdue, odufCEI Research/SUPERPAVE/superhome.htrn (type exactly as shown, respecting case)

\section{Jan Olek}

Director

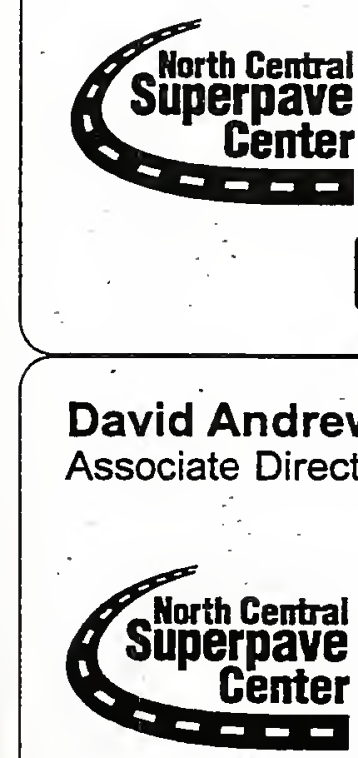

Purdue University 1284 Civil Engineering Building West Lafayette, IN 47907-1284 (317) 494-5015 phone (317) 496-1364 fax olek@ecn.purdue.edu

\section{Rebecca McDaniel}

Technical Director

\section{Mixture Branch}

1205 Montgomery Road

P. O. Box 2382

West Lafayette, IN 47906

(317) 463-2317 phoneffax

rsmcdani@ecn.purdue.edu

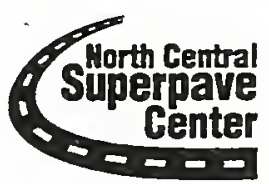

Travis Lovvorn Technician

Julie Smith Secretary

julie@ecn.purdue.edu
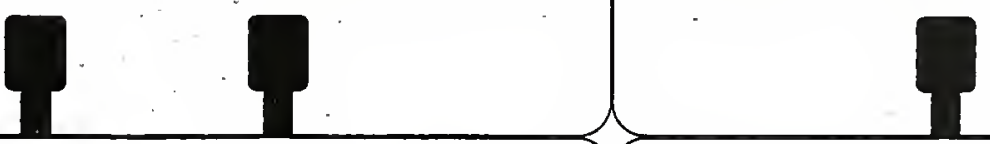

Rhonda Richardson Laboratory Manager

\section{Mike Prather Engineer} 120 S. Shortridge Road Indianapolis, IN 46219 (317) 232-5280 phone (317) $356-9351$ fax
Binder Branch North Central Superpave Center

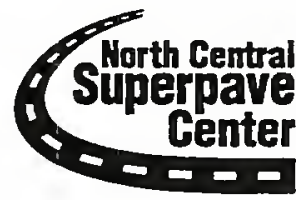

Shortridge Road 120 S. Shortridge Road
Indianapolis, IN 46219

(317) 232-5280 phone (317) 356-9351 fax

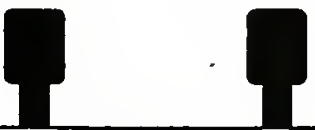




\section{NGSE Announces Course Schedule for 1996}

he NCSC has planned a number of training courses to be offered through the remainder of 1996. Planned courses include binder training and mix design training. The training schedule, shown to the right, is subject to change depending on demand.

The Binder Course is designed to provide classroom overviews of the binder specification and test methods followed by hands-on laboratory work with all of the binder test procedures except direct tension. The course is based on materials developed by the National Asphalt Training Center. This threeday course is primarily for binder lab technicians who will be performing these tests on a routine basis. Course size is limited to twelve people.

The Mix Design Course offers a thorough presentation of the Superpave mix design system and includes overviews of the binder specification and mix analysis. The majority of this threeand-a-half-day course focuses on the Superpave Gyratory Compactor (including hands on work), mixture volumetrics and the mix design procedure. The course concludes with a workshop session on the calculations used in the mix design process. For new mix design technicians, an additional half-day can be provided to detail measuring specific gravities, mixing samples, and other steps that are only reviewed during the primary course. Course size is limited to twelve people.

Additional courses can be scheduled based on demand. The NCSC staff is also available to travel to your facility to provide training for groups. If your organization needs customized training or envisions courses other than those outlined here, please contact the NCSC to discuss your ideas. We would be happy to

work with you to meet your needs.

For registration information, contact Julie Smith at the NCSC Mixture Branch. Before July 1, please call (317) 494 5025 or fax (317) 463-1364; after July 1, call or fax (317) 4632317. Registrations will be accepted for specific course dates, but it is recommended that you indicate a second choice in case the class you prefer is full. Registration will be closed three weeks prior to the class date to allow confirmations to be sent to attendees.

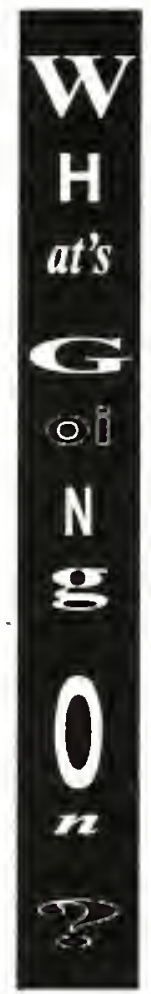

\section{NCSC 1996 Calendar}

\section{Training Courses}

\author{
Ientative Date \\ September 16-19 \\ October 21-24 \\ November $18-21$ \\ December 2-5
}

\author{
Course Title \\ Binder \\ Mix Design \\ Mix Design \\ Mix Design
}

\section{Meetings/Conferences}

JL 11-12 Snperpave Centers Coordination Meeting West Lafayette, Indiana anrration ONLY

AUG 21-22 Snperpave 2000 National Open House Indianapolis, Indiana

OCT 23-24 North Central Asphalt User/Prodncer Group Meeting The University Inn, West Lafayette, Indiana

OCT 24-25 NCSC Steering Committee Meeting The University Inn, West Lafayette, Indiana

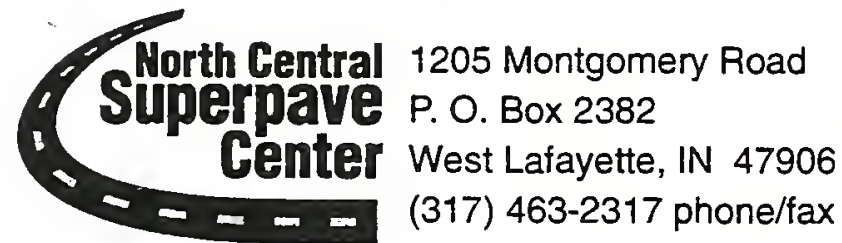

Non-Profit Organization

U.S. Postage

PAID

Purdue University 

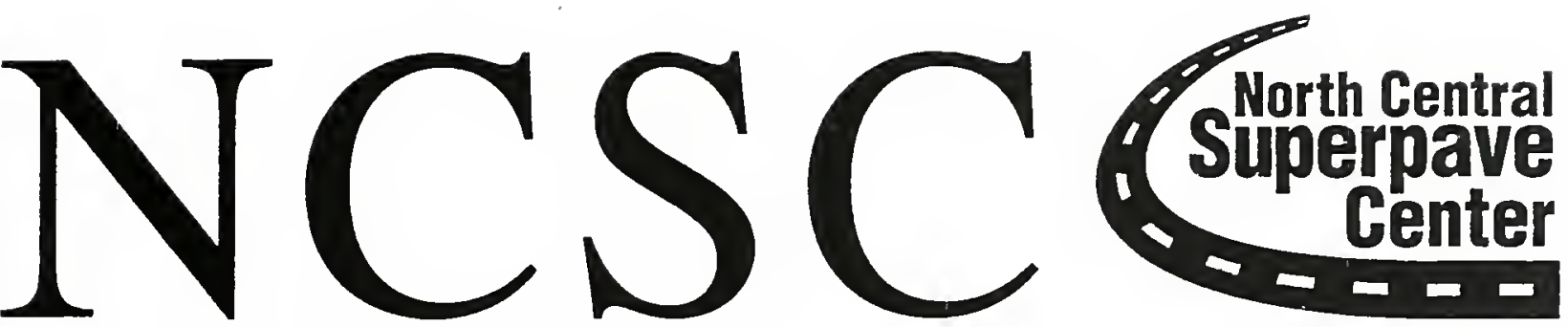

Volume 1, Number 3

Fall 1996

\section{Enthusiastic Response to Superpave 2000}

O ver 250 people attended the Superpave 2000 National Open House held in Indianapolis, Indiana, on August 21-22, 1996. Arthur Fendrick, FHWA Indiana Division Administrator, called the meeting a "major success." According to Fendrick, "This national meeting should go a long way towards better understanding and the ultimate implementation of the Superpave concept in the next century...The challenges that we face towards implementing the technology can only be negotiated together and [with the Open House] we displayed a true partnering effort to achieve this."

NEED FOR CHANGE. Don Lucas, Indiana Department of Transportation (INDOT) Chief Engineer, fired up the audience by showing his now-famous chart demonstrating the dramatic increase in traffic loadings on our highways. Lucas asserted that our old ways of doing things are no longer adequate to cope with the tremendous growth in loadings. Now is the time to start using Superpave, averred Lucas. Superpave does not bave to be a perfectly-finished product before the nation can benefit from the improvements it offers; "look bow long we've been working on Marshall," he pointed out. Lucas concluded his speech by quoting an uniknown source: "In times of change, the learners inherit the earth while the "learned find themselves beautifully equipped for a world that no longer exists."

RAP \& PG GRADES. John D'Angelo, FHWA Senior Technology Engineer, then took the podium to discuss $P G$ asphalt and reclaimed asphalt pavement (RAP) effects on grading. D'Angelo aimed to answer the question "can RAP be used in Superpave?" The short answer is yes-although RAP is not specifically addressed in Superpave, it is not excluded. D'Angelo stressed that RAP represents a valuable resource that should be reused whenever possible. The binder grade typically changes one or two grades depending on the amount of RAP used. Several issues remain, including blending RAP with modified asphalts; compatibility will have to be checked. Recycling agents and their effects on PG grades also need to be evaluated. How RAP mixtures will perform will depend on handling the RAP properly in terms of grading and stockpiling, operating the plant properly, watching moisture and overbeating, and placing and compacting the mix properly-just like with virgin mixtures.

AGGREGATE INDUSTRY CONCERNS. David Jahn, Vice

Chairman of the National Stone Association's Technical

Committee, enumerated three issues of concern to the aggregate industry: VMA, the restricted zone and fine aggregate angularity. Jahn reported that the current Superpave VMA requirements, when combined with other requirements on gradation, etc., can be impossible to meet with some previously successful aggregates, especially 100 percent crushed stone. He asserted that VMA requirements based on maximum aggregate size may not be appropriate since surface area decreases as aggregate size increases, thereby decreasing the need for VMA. Jahn also described a highly rut-resistant mixture widely used by the Georgia DOT that passes right through the restricted zone; Jahn contends that this

continued on page four

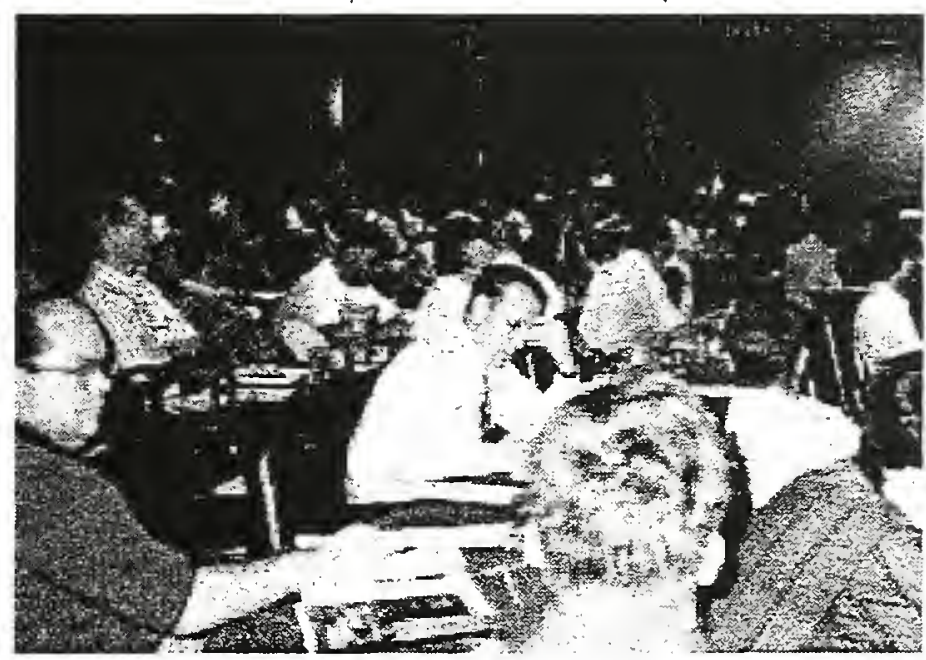

Organizers were pleased with the large turnout for the Superpave 2000 National Open House in Indianapolis

Enthusiastic Response to Superpave 2000 1

$2^{\text {sid }}$ Superpave Center Coordination Meeting 2

North Central States Estimate Binder Usage _.._____._. 3

Mix ETG Identifies, Discusses Issues ............... 5

Superpave Gyratory Compactor Update _.............. 6

FHWA/AASHTO Organize Lead States _....... 6

Nort Central Region Works Toward Reciprocity........ 7

Regional Binder Round Robin _................... 8

Upcoming NCAUPG \& NCSC Metings ............. 9

Calendar of Events 


\section{Second Superpave Center Coordination Meeting}

T he five regional Superpave Centers met for the second time on July 11-12, 1996 at the North Central Superpave Center in West Lafayette, Indiana. The meeting attendees included representatives of the South East Superpave Center, the 1 North Central Superpave Center, the Westem Superpave Center, the North East Superpave Center, the Superpave Center at Austin, the FHWA, University of California-Berkeley, the University of Maryland/Models Group and the Asphalt Institute.

The Centers met to update each other on their progress over the six-month period since the first meeting, and to share experiences and suggestions to make the next six months better. The spirit of the meeting was cooperation among the Centers, with the Centers performing supportive and sometimes complementary roles vis-à-vis the other Centers. The group also toured the North Central Superpave Center and Accelerated Pavement Testing Facility, both housed within the Indiana Department of Transportation building, which served as an occasion for the Centers to discuss and compare their respective progress toward setting up their labs and offices.

ADMINISTRATION. The group discussed the relationship between the Centers, the State DOT's and the FHWA. Each center outlined their status, organization and current funding.

Training was an important topic. The Centers have been charged with providing training at various levels in order to disseminate Superpave expertise. Training materials will be shared among the Centers so that we are providing uniform instruction. FHWA is considering using the Centers to provide training courses through the National Highway Institute (NHI). Training barriers such as out-of-state travel, were considered. Byron Lord, of

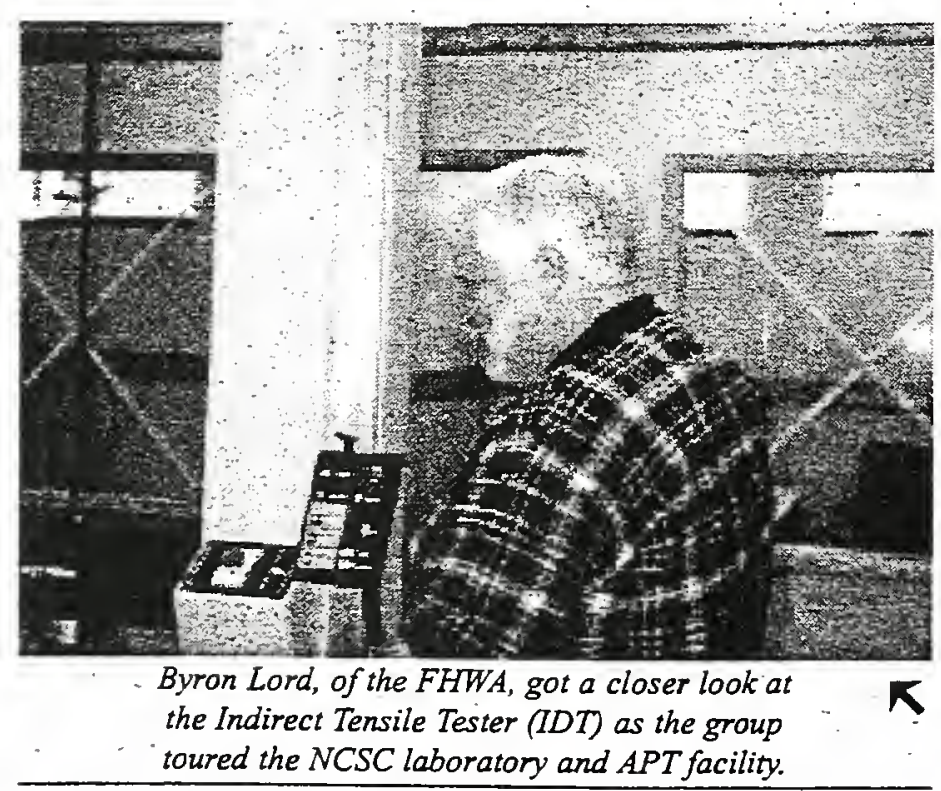

FHWA, encouraged the loaned staff concept to provide in-depth, hands-on training to a limited number of people. The Centers will continue to work together on training and certification.

TECHNICAL. The group discussed the need for uniformity in specifications and how states can be encouraged to resist modifying the system. Sharing data representing successes and failures openly with the states may help to build confidence in the system. Bob McGennis, of the Superpave Center at Austin, outlined the first phase of ruggedness testing on the Superpave Shear Tester (SST) and Indirect Tensile Tester (IDT) that the Centers will begin in October. Chuck Schwart, of the University of Maryland, updated the group on the status of the Models Contract. Adam Hand, of the Western Superpave Center, mentioned some of the problems they have been having with getting their equipment up and running; the Centers agreed to share their equipment problems and fixes to avoid repeating them.

COMMUNICATION. Rebecca McDaniel, of the North Central Superpave Center, discussed the enthusiastic reception of the first two editions of the NCSC newsletter. The newsletter has increased visibility for the Center and served as a vehicle for sharing information. The NCSC plans to publish four editions a year.

The other Centers are considering or working on their own newsletters to be distributed two to three times per year.

The WWW is also being used as a means of communication; several of the Centers have or will soon have a WWW site. The group discussed linking their sites for mutually increasing visibility.

To maintain communication between the five Centers, the Center representatives plan to continue meeting every six months or so. The next Superpave Center coordination meeting is scheduled for December 16 and 17, and will be hosted by Mr. Bob McGennis of the Austin Superpave Center.

$*$

\section{Mixture Branch Status Report}

W $T^{e}$ are very pleased to announce that the Mixture Branch is now up and running. Installation of the Indirect Tensile Tester (IDT) and Superpave Shear Tester (SST) was completed by late August and final training and fine tuning of the equipment was completed by the end of the first week of September.

The first order of business with the new equipment is to participate in the ruggedness testing of the IDT and SST test procedures with the FHWA and other regional centers. This testing will examine the sensitivity of the test procedures to changes in the test parameters, such as temperature, loading rate, specimen height, order of testing, etc.

All those who attend the North Central Asphalt User Producer Group meeting are welcome to attend the Open House at the NCSC from 10:00 a.m. to 12:00 p.m. (E.S.T.), October 23rd. 


\section{North Central States Estimate Binder Usage}

T he chart below shows the performance graded binders most likely to be used by the states in the North Central region for different applications. Responding states indicated the binders they would routinely specify for surface and binder courses on overlays, surface and base courses for full depth asphalt pavements, and special grades for occasional use. Where states identified more than one option for a given application, without specifying a geographical region for its use, the option is shown in parentheses.

This survey was conducted by Rick Smutzer and his staff at the Indiana Department of Transportation as was suggested at the last meeting of the North Central Asphalt User Producer Group. The questionnaire was sent to all of the states and provinces represented on the North Central Superpave Center Steering Committee; ten of 14 states/provinces responded.

\section{NCSC Courses}

The NCSC will be offering the following training courses through March 1997:

\section{Superpave Binder Course}

(3 days)

February 17-19, 1997

\section{Superpave Volumetric Mix Design Course (3 days) \\ November 18-20, 1996 \\ December 2-4, 1996 \\ January 27-29, 1997 \\ March 17-19, 1997}

If you would like to register for one of the courses, or to receive a copy of our course brochure, please call Julie Smith at (317) 463-2317.

\section{Anticipated Performance Grades for Different Applications}

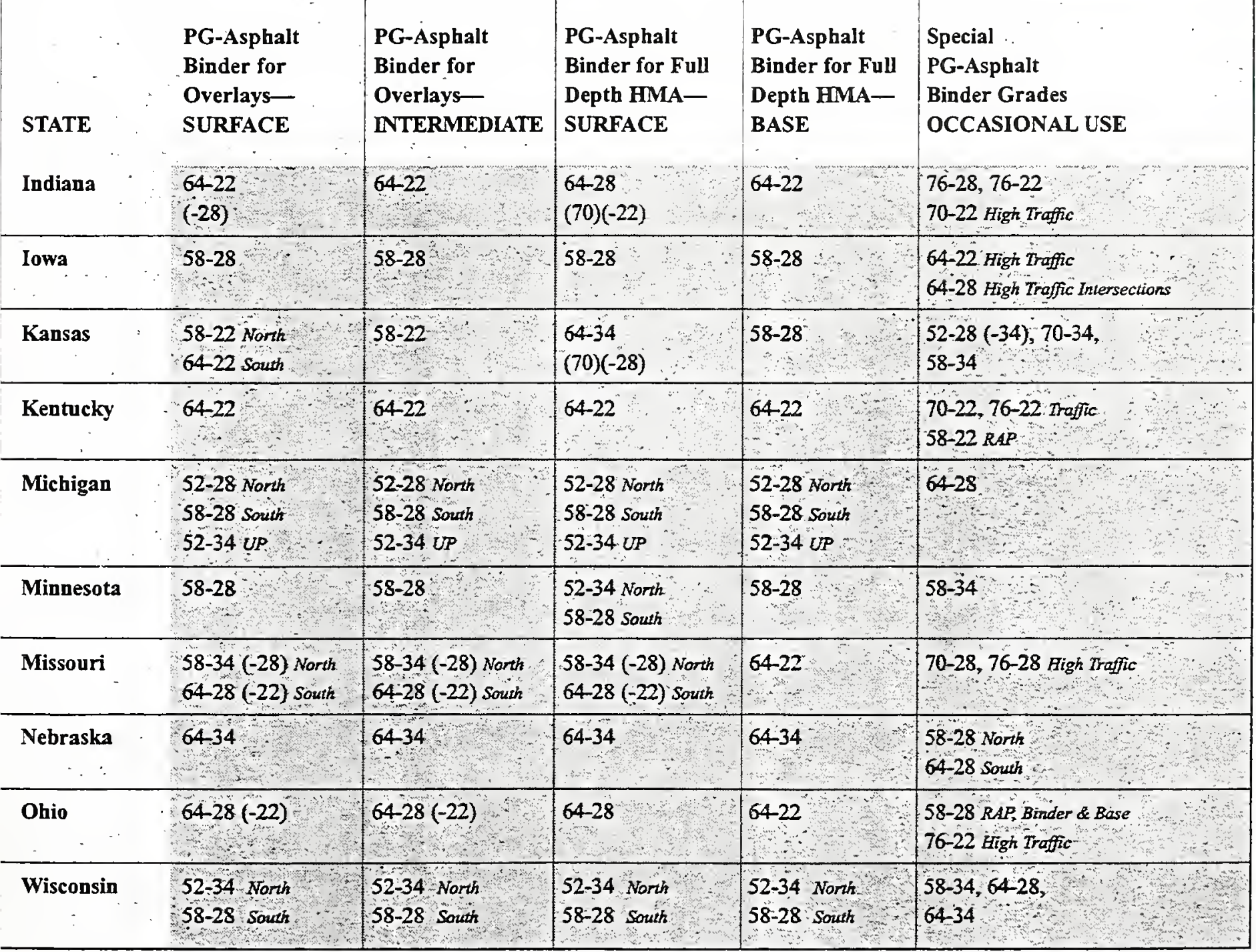




\section{Superpave 2000 continued from cover page}

casts doubt on the validity of the restricted zone as an overall requirement. Jahn concluded that the crushed stone industry thoroughly supports and endorses Superpave, but feels some refinements are necessary.

John Yzenas, of The Levy Company, continued the aggregate discussion by focusing on fine aggregate angularity issues.

Yzenas reviewed the different test methods (A, B and C) and pointed out the difficulties in accurately measuring the bulk specific gravity of fine aggregate. According to Yzenas, there is another problem with the test method. Specifically, flat and elongated particles can increase VMA; this is contrary to the direction we want to go. Cubical particles can test as spherical and some "knobby" uncrushed materials have high angularities.

Running fine aggregate angularities on extracted aggregates is also questionable since only a small amount of rounding, which may occur during the extraction process, may be enough to knock the sample out of specifications.

Tony Kriech, of Heritage Research Group, supported the increased coarseness of Superpave mixes and the increased film thickness they afford. He also supported moving away from weaker sands. He recommended using performance and accelerated tests to examine VMA, the restricted zone and fine aggregate angularity. Kriech stated that future trends may be towards more one-sized and cubical aggregate.

Tom Kennedy, of the University of Texas and one of the key Superpave developers, stated that "the system really does work" and urged people to give it a chance. He acknowledged that there will be changes and improvements, but urged moving forward with implementation of the existing system rather than waiting for more research. Kennedy then outlined some of the remaining questions people have about

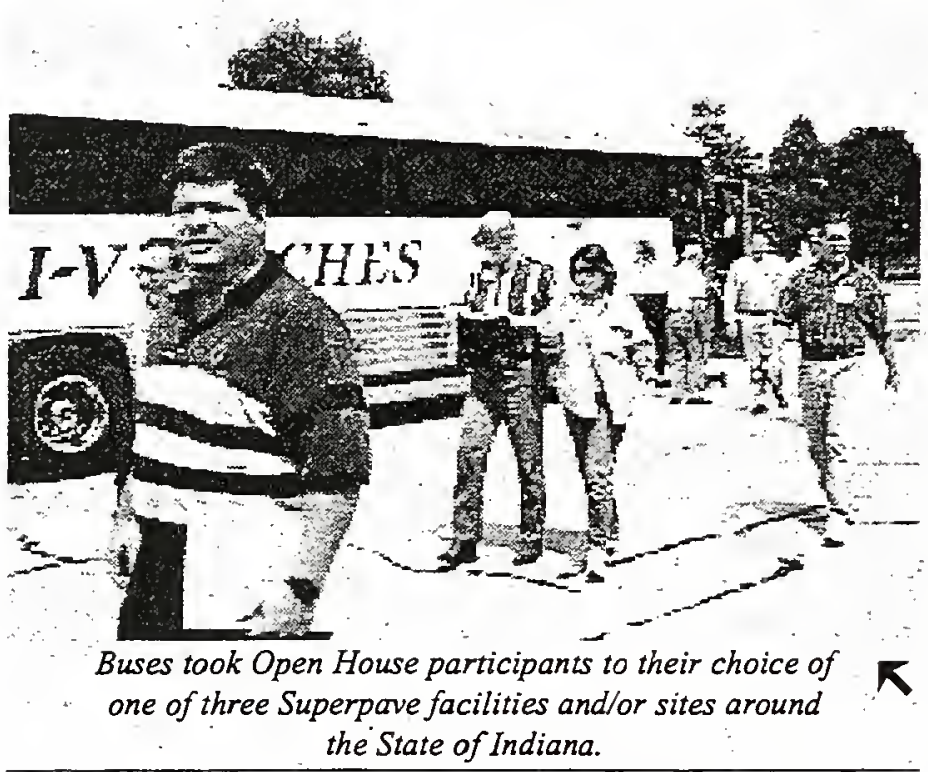

Rebecca McDaniel, Technical Director of the North Central Superpave Center, gave participants a demonstration of the Indirect Tensile Tester (IDT) at their new laboratory.

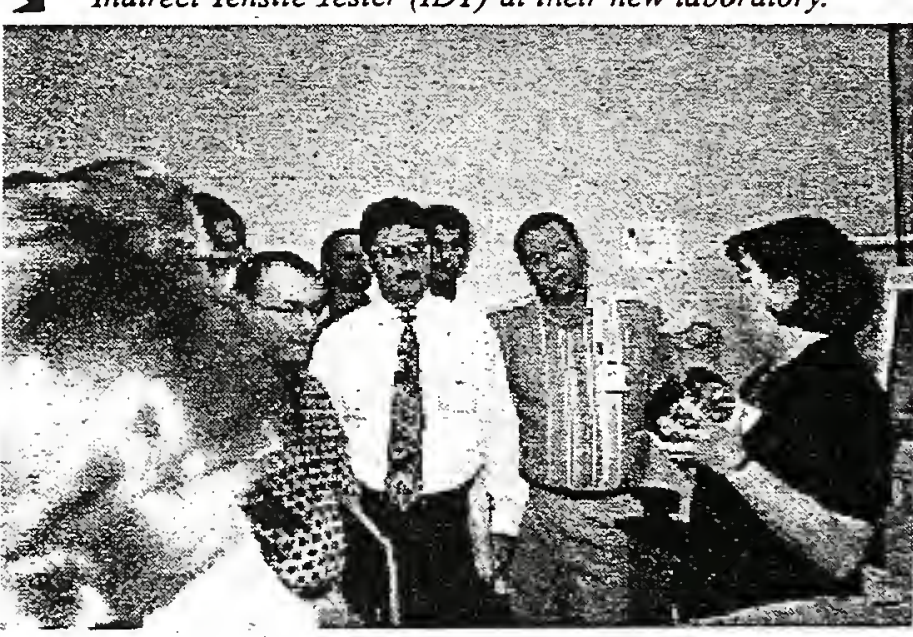

agency must make a policy decision; "what do you do now?" Kennedy countered the claim that sorne good mixtures violate the Superpave restrictions by asking the audience to consider how long those mixtures perform; even though they may be a state's best mixes, they may only perform for five years or so.

Superpave will afford them good performance for a longer time.

INNOVATIONS. Jon Epps, of the University of NevadaReno, then described the facilities at Westrack where 21 mixes placed in 26 test sections are undergoing accelerated loading by innovative, driverless, triple trailer rigs. Westrack is designed for validation of Superpave and evaluation of issues such as performance-related specifications, field/plant control, pay adjustment factors, etc. Samples from Westrack are being tested around the country in a myriad of accelerated testing devices. Some of the early performance results are surprising-"non-critical" mixtures which were expected to perform well are exhibiting more rutting than "super-critical" mixes that were expected to rut. Time will tell if this unexpected performance continues. Gerry Huber, of Heritage Research Group, and John Spangler, of Milestone

Contractors, L. P., then described an innovative INDOT warranty contract in which they were involved. Huber outlined the specifications for the contract which require a five-year warranty on ride quality, friction, longitudinal cracking and rutting. The contract also included consideration of contract time in determining the successful bidder $(A+B+C)$. Milestone Contractors, the successful bidder, chose to place a Superpave mix on the project; Heritage Research developed the mix design and performed an intermediate mix analysis (formerly Level 2). Spangier stated that the intermediate mix analysis provided the "insurance" his company felt it needed. He believes that warranties will cause contractors to becorne more intelligent about their business because someday their competitiveness will depend on how mixtures perform. "You can't afford to base your future on your past," said Spangler.

SOFTWARE. The open bouse continued the next morning with an update on the Superpave software by Matt Witczak, of the University of Maryland. Witczak reviewed the software that has been released and that which is planned. blend of old and new materials should meet the same requirements as a virgin mix. Kennedy described how the aggregate specifications were arrived at by a panel of experts using a Delphi process. He admitted that some of the values could perhaps be improved upon, but urged changes should only be made nationally after due consideration. Kennedy is frequently asked if gradations can "nick" the restricted zone: His answer is that each 


\section{Mix ETG Identifies, Discusses Issues}

$t$ its recent meeting in Seattle, the Superpave Asphalt Mix Expert Task Group (ETG) identified 16 to 20 issues that members felt needed work. The list included such items as Reclaimed Asphalt Pavement, aggregate requirements, field management, uniformity of implementation, training and certification, a strength/proof test for volumetric mix design, equipment issues, field compaction and more. The group then went on to discuss many of these items, review new data and make recommendations, where possible.

Compaction was the first item on the agenda. Tom Harmon, of FHWA, provided an update on the Superpave Gyratory Compactors (see Superpave Gyratory Bompactor Update, page six). Maryland, New York and Kentucky reported having no problems with compacting large stone mixes $(37.5 \mathrm{~mm})$ in the SGC. Mike Anderson, of the Asphalt Institute, then presented some data he had collected on using the slope of the compaction curve as a tool to analyze mixes. Compaction slope has been used to detect changes in mix properties. In one case, a change in the slope pinpointed a fine mix that occurred when there was improper feed of crushed sand in a plant. Anderson's data was intriguing but not conclusive; some of the performance test results (SST) were counterintuitive. More work is needed.

Gerry Huber, of Heritage Research, then reported on progress on the $\mathrm{N}_{\text {design }}$ experiment. This study is aimed at fine tuning the relationship between traffic and design gyrations. Using field cores and estimates of traffic, four sites have been analyzed to date. Preliminary data shows that $\mathrm{N}_{\text {dss }}$ should be much lower and is not very traffic sensitive, but there are some inconsistencies in the data; some of the problem may be with the accuracy of the traffic estimates. More sites will be analyzed to determine if this perceived trend continues.

The group then discussed some reported field compaction problems. Ron Sines, of the New York State DOT, recounted experiences on one project (out of 11) where they had difficulty compacting. The binder and top courses showed severe displacement under the roller. Numerous attempted fixes did not work. Switching to a Marshall mix design with the same materials aiso did not correct the problem, therefore Sines does not think the problems are necessarily related to Superpave.

Bob Briggs, of the Washington State DOT, analyzed 163 previous mix designs to see if they would meet Superpave specifications. With the exception of the restricted zone and, to a lesser extent, the coarse aggregate crushed content, most of their mixes did comply. Their work bas revealed a potential source of error when the Rice densities are done on Friday but the bulk specific gravities are not done until Monday; continued absorption over the weekend car possibly lead to errors.

Dale Decker, of NAPA, then led a discussion of issues associated with reclaimed asphalt pavement (RAP). The group agreed in principle that mixes containing RAP should meet the same requirements as virgin mixes. There may be some threshold limit, however, below which the RAP can be assumed to have no effect on the mix and may not require extensive testing. There is a need for an interim policy decision regarding RAP usage and testing that can be used until conclusive research is done on the issue. NCHRP is beginning such a study now. Decker and his subcommittee will prepare a draft recommendation for ETG review by October 1 .

The first draft of guidelines on the use of solid mixture additives was presented by John D'Angelo, of FHWA. The draft is very preliminary and will be revised by the subcommittee by December 1 .

Eileen Connelly, of the New Jersey DOT, led discussion of suggested revisions to the AASHTO specifications for PP28, Standard Practice for Superpave Volumetric Design for HMA, and MP2, Standard Specification for Superpave Volumetric Mix Design. Balloting by the AASHTO states will occur very soon on these changes.

Connelly also initiated discussion of fine aggregate angularity testing. She presented some data on New Jersey fine aggregates and on determining the bulk specific gravities of blended sands. The group debated the rationale between using Method A vs. Method C in TP-33. David Jahn, of American Aggregates, presented some data showing that flat and elongated particles give higher angularities than cubical particles. Jahn will write up a draft document on fine aggregate angularity, including a definition of mechanically crushed, by October 1 .

Bob McGennis, of the Superpave Center at Austin, reviewed the efforts planned for the ruggedness testing of the SST and IDT, which will begin very soon.

Frank Fee, of Koch Materials, reported on the results of a comparison of several types of rut tester. The data is somewhat confounded by variations in the air void contents of the samples tested, but some of the devices may have potential as a strength test for volumetric mix design. John Bukowski, of FHWA, summarized the field shear tester developed under NCHRP 9-7 and John Harvey, University of California-Berkeley, showed some SST data they had collected.

Tim Aschenbrener, of the Colorado DOT, recounted the long saga of getting some research done on the moisture sensitivity test, T-283. NCHRP is in the process of selecting a researcher now for an in-depth study.

The group then discussed communicating changes in specifications to the users. Jahn reviewed a very successful type of mix used in Georgia which passes right through the restricted zone. D'Angelo pointed out that the wording of MP2 has been changed so that gradations are not recommended to go through the restricted zone. Gradations may be allowed to pass through the zone if there is performance data to support continued use of a mix. People need to be made aware of changes such as this. A FOCUS (Federal Highway Administration) article highlighting some of the recent developments will be prepared.

The next meeting of the group will be held in San Antonio in March 1997. 


\section{Superpave Gyratory Compactor Update}

H

ave you been hearing about possible problems with the Superpave Gyratory Compactor? This update, based on information presented at the recent Mix ETG meeting and conversations with FHWA, Troxler, Pine, Heritage

Research and other Superpave Centers, should clarify the situation. Tom Harman, of FHWA, reported at the Mix ETG meeting that some correctable problems with the angle measurement bad been noted with both the Troxler and the Pine SGC's. Users of these devices should be aware of these problems and contact the manufacturers for more details or to get retrofits to correct the problems.

Early Troxler SGC's had a problem with the screws that secure a plate in the bottom of the machine. Reportedly these screws could work loose and cut a groove in the plate below them. This may result in a change in the angle or a change in the pressure. The result is that the compactive effort may be incorrect and may result in a change in voids. In addition to the density problem, the cutting of this groove will result in metal shavings that may get into the bearings. Ken Brown, of Troxler Electronic Laboratories, has stated that their production records show this problem was limited to four units from the very first production of the compactors. Troxler further indicates that all of the units have been repaired. If you would like to verify that your machine has the self-locking screws installed, you need to open the bottom panel and look at the bottom of the machine. If you do not know if your compactor has the potential for this type of problem, contact Troxler's customer service department at (919) 549-8661.

Harman also discussed the Pine Instruments SGC. On early production units, mixtures with coarse gradations can bend the halo that holds the angle and allow the angle to increase. The problem, which showed up only on some mixtures, can result in densities that are too high. Pine has developed a stiffer mechanism. Roger Pyle, of Pine Instruments, reports that the updated system will hold the angle to 0.01 degrees for all mixtures tested, which is within the specification of 0.02 degrees. All owners of the early machines have been notified and the units are being updated. Also, Pine recently suggested that the lubrication of the bearings needs some attention. It appears that some users have gone overboard and are now over-lubricating the bearings.

Harman did emphasize that these problems do not mean the devices are not doing a good job of compacting. Users do, bowever, need to be aware of the service/maintenance issues. These isues do underscore the need to check the compaction angle on a regular basis (at least once a week) and make sure that the bolts are securely tightened. The Mixture ETG will continue to follow this issue.

Discussion then turned to potential brands of SGC coming on to the market. FHWA does not and will not have an approved list. SGC's will have to be tested by an independent lab to determine if they meet specifications. The Mixture ETG recommended establishing a protocol for testing compactors to determine speci-

fication compliance.

FHWA and the Mixture ETG will be pursuing these items and we will try to keep you informed.

\title{
$\%$
}

\section{FHWA/AASHTO Organize Lead States}

\begin{abstract}
$t$ the urging of the AASHTO Task Force on SHRP
1 Implementation, the Federal Highway Administration has coordinated the establishment of seven Lead State Teams to assist other states, local agencies and industry with implementation of selected SHRP projects, including Superpave.
\end{abstract} At a recent meeting in St. Louis, these teams met to develop missions statements, goals, strategies and action plans to promote implementation of these products.

The Superpave Lead State team consists of representatives of the states of Florida, Indiana, Maryland, New York, Texas and Utah, plus industry representatives from those states and a representative of the North Central Superpave Center.

The Superpave Lead State team will be working in the immediate future to designate a pool of technical and management expertise within the lead states to be available to assist other states with implementation issues. A list will be developed and distributed by January 1997. This list will include contact people in the DOT's, industry and Superpave Centers who are available to answer questions, offer experiences and provide guidance on testing, design, construction, contracting and other implementation issues.

The team will also be working on getting management to buy-in to the Superpave system, encouraging each state to develop a plan for Superpave implementation, establishing lines of communication between the states, documenting and sharing Superpave experiences, and more. These efforts will be coordinated with other ongoing activities at the Superpave centers, FHWA, AASHTO, etc. As work progresses, we will attempt to keep you informed.

$$
\text { \%. }
$$

Check it out! Our WWW site now has an easier address:

http://ce.ecn.purdue edu/ spave/ (tope exactly as shown, respecting case)

Please keep in mind that our site is a work in progress. 


\section{North Gentral Region Works Toward Reciprocity}

$T_{1}^{\mathrm{h}}$

he Iowa Department of Transportation and the Federal Highway Administration hosted the third Training and Certification Workshop for FHWA Regions 5 and 7 in Des Moines, July 2325,1996 . The group of people involved in administering and 1 putting on training and certification programs first met in 1994 with the goal of leaming and benefitting from other programs. The ultimate goal is to achieve some measure of reciprocity across state lines. Chris Anderson, of the Iowa DOT, welcomed the participants. Word of the group and its goals has spread beyond Regions 5 and 7. This meeting was attended by 61 people representing 20 states from Alaska to Rhode Island and Massachusetts. Attendees represented State DOT's, colleges and universities, and industry.

Haleem Tahir, of AASHTO, reported on AASHTO and AMRL activities, especially those related to Superpave and other SHRP products.

Patrick Bauer, of FHWA, discussed the National Quality Initiative (NQI) and its requirement that states use "qualified" sampling and testing personnel by June 29,2000 . The meaning of "qualified" is left undefined. FHWA initiated a contract to develop generic training manuals which has since been canceled. Headquarters is discussing what to do next and welcomes any and all comments.

The North Central Asphalt User-Producer Group's efforts on test procedure standardization were described by Rich Wolters, of the Minnesota Asphalt Paving Association. Key issues, according to Wolters, include uniformity, reciprocity, technology exchange, continuous quality improvement, unresolved Superpave issues (RAP, precision and bias, etc.), and field management. Having well-trained people "in the trenches" with the authority to make changes is vital.

Each state outlined their overall training and certification programs. There was a wide range of differences in approaches and experiences. We are all at different starting points in most cases.

The group discussed the future of training and certification uniformity and reciprocity. Superpave presents a real opportunity to achieve uniformity since we are all starting at about the same level of experience. The North Central Superpave Center will work with the region to establish what should be accomplished through Superpave training programs-what key concepts people should learn.

The group will also work on gathering information from the participating states and putting together generic training materials that could be used by any state.

The next meeting will be held in Kansas City in 1997. $*$

\section{SUDetpaye 2000 continued from page four}

An all-new, Windows-based Version 2.0 to be released in January 1997 will be for volumetric mix design only. Version 2.1, due out in September 1997, will add some performance models. The final models will be included in Version 3.0, due in February 2000. Witczak also mentioned the Superpave Software User software and planned training workshops on Versions 2.0, 2.1 and 3.0.

INDUSTRY. Dale Decker, of the National Asphalt Pavement Association (NAPA), followed with an "Industry Perspective on Superpave." Decker applauded many features of Superpave, including choosing asphalt by climate, the Approved Supplier Certification Process and Best Management Practices guidelines. Field management, according to Decker, is critical today without Superpave and will be critical tomorrow with Superpave. Making the contractor responsible for his product and implementing a gradual change to Superpave are appropriate moves, in Decker's estimation. Decker cautions, however, that training will be a herculean effort-thousands need training. The implementation issues are not fatal flaws by any means-the overall concept is very good-but a public/private partnership is vital to resolving the remaining issues.

SUPERPAVE CENTERS. Rebecca McDaniel, of the North Central Superpave Center, gave a general overview of the activities in which the five regional Superpave Centers will be involved. The Centers were established by the FHWA to serve as regional sources of expertise to promote the successful implementation of Superpave. The Centers are also involved in such things as ruggedness testing of the SST and IDT, training, SPS-9 testing, mix designs and analysis for experimental or pilot projects, forensic analysis, referee testing and proficiency testing. One of the primary functions of the North Central Superpave Center, as established by its Steering Committee, is communication. To that end, the NCSC publishes this quarterly newsletter and has established a WWW site; the page can be found at http://ce.ecn.purdue.edu/ spave/. Other Centers are considering or have similar methods of communication. McDaniel urged the audience to participate in their regional Centers to help ensure that the implementation of Superpave suits their needs.

The conference continued with updates on Superpave implementation from the States' perspectives. Gale Page, of the Florida DOT, stated that beginning in 1997 all Interstate projects in Florida will use Superpave specifications and mix designs including up to 20 percent RAP. He went on to state that the only risk is that Superpave mixes will outperform their existing mixes. Larry Michael, of the Maryland DOT, related that Hal Kassoff, Maryland's State Highway Administrator, asked "why wait until the year 2000?" Maryland is already using Superpave on their major projects, including their SMA mixes throughout the State. Don Corum, of the Arizona DOT, described Arizona's cold temperature cracking problems and temperature algorithms to more accurately determine which binder grades to use. Corum believes Superpave technology is definitely an improvement. Dave Andrewski, of the Indiana DOT, outlined Indiana's history of Superpave, starting in 1993 with their first SPS project (that has virtually no rutting to date) up to the planned 1997 program which consists of 40 to 50 Superpave projects. He did emphasize the importance of the Contractors "doing their homework" with their aggregates during the off-season in preparation for the upcoming season.

Rick Smutzer, of the Indiana DOT, outlined the activities of the North Central Asphalt User-Producer Group; specifically, with the development and implementation o the Approved Supplier Certification project and the Manufacturers' Quality Control Plan (TP26-96). Indiana is willing to accept ASC certifications approved in other States as if they were approved in Indiana.

Lee Gallivan, of the FHWA-Indiana Division, provided a summary of the high points of the Superpave 2000 Open House, and stressed to all that "we are all in this together" and with the States and Industry working as partners, we can do more than just implement Superpave, we can fully address our needs for the next century. 


\section{Regional Binder Round Robin}

1 t the request of the North Central Asphalt User Producer Group, the NCSC coordinated a binder round robin testing program to investigate the amount of variation in binder testing from different labs under normal testing conditions and to identify lab results to allow comparison of one lab to another. Test results were returned by 25 labs which tested 26 sets of samples. Four asphalt cements, including one polymet modified binder, were tested for compliance with known grades in the rotational viscometer, bending beam rheometer (BBR) and dynamic shear rheometer (DSR).

Test conditions were not rigidly controlled in order to see the amount of variation that could occur under normal testing conditions. Labs were told to follow the latest AASHTO provisional methods, but were given no further instructions on material handling, test temperatures, equipment calibration or other parameters. Technicians were not required to meet any sort of eligibility requirements either, some had done very little or no previous testing. Three of the materials were sampled without NCSC staff there to witness the sampling due to time, distance and union restrictions. All the asphalts were sampled from storage tanks except the modified asphalt (C), which was laboratory fabricated in five gallon batches.

The results revealed relatively high amounts of variation in some tests. Figure 1 shows a typical graph of the data for one asphalt and one test. Table 1 shows the coefficients of variation achieved for the different test methods on different asphalts. The data generally shows that higher amounts of variation seem to be associated with testing aged asphalt. This is logical since the aging processes introduce more chances for variation to occur and the aged binder is stiffer and therefore harder to test.
Other, more closely controlled round robin programs, such as those by AMRL, show less variability in the results. This data, then, underscores the need to follow the standardized procedures closely to eliminate sources of error. Care needs to be exercised in preparing the samples, maintaining equipment calibration, properly equilibrating temperatures, etc. The Binder Expert Task Group will continue to look at round robin results and potential sources of variation. Equipment differences and glitches may also account for some of this variation. In several cases, people who provided data have informed the NCSC when they found equipment problems that contributed to the variation and retested the samples.

The full report on the binder round robin will be distributed to the participating labs prior to the October NCAUPG meeting. Additional copies will be available at the meeting or by request.

Table 1. Coefficients of Variation

\section{Asphalt}

Test

Rotational Viscosity

Original $G^{*} / \operatorname{Sin}$ Delta

RTFO G*/Sin Delta

PAV G*Sin Delta

BBR Stiffness

BBR Slope

\begin{tabular}{cccc}
$\mathrm{A}$ & $\mathrm{B}$ & $\mathrm{C}$ & $\mathrm{D}$ \\
\hline $6 \%$ & $8 \%$ & $17 \%$ & $-9 \%$ \\
$11 \%$ & $11 \%$ & $15 \%$ & $10 \%$ \\
$13 \%$ & $19 \%$ & $9 \%$ & $15 \%$ \\
$22 \%$ & $18 \%$ & $22 \%$ & $13 \%$ \\
$9 \%$ & $8 \%$ & $9 \%$ & $11 \%$ \\
$5 \%$ & $4 \%$ & $3 \%$ & $5 \%$
\end{tabular}

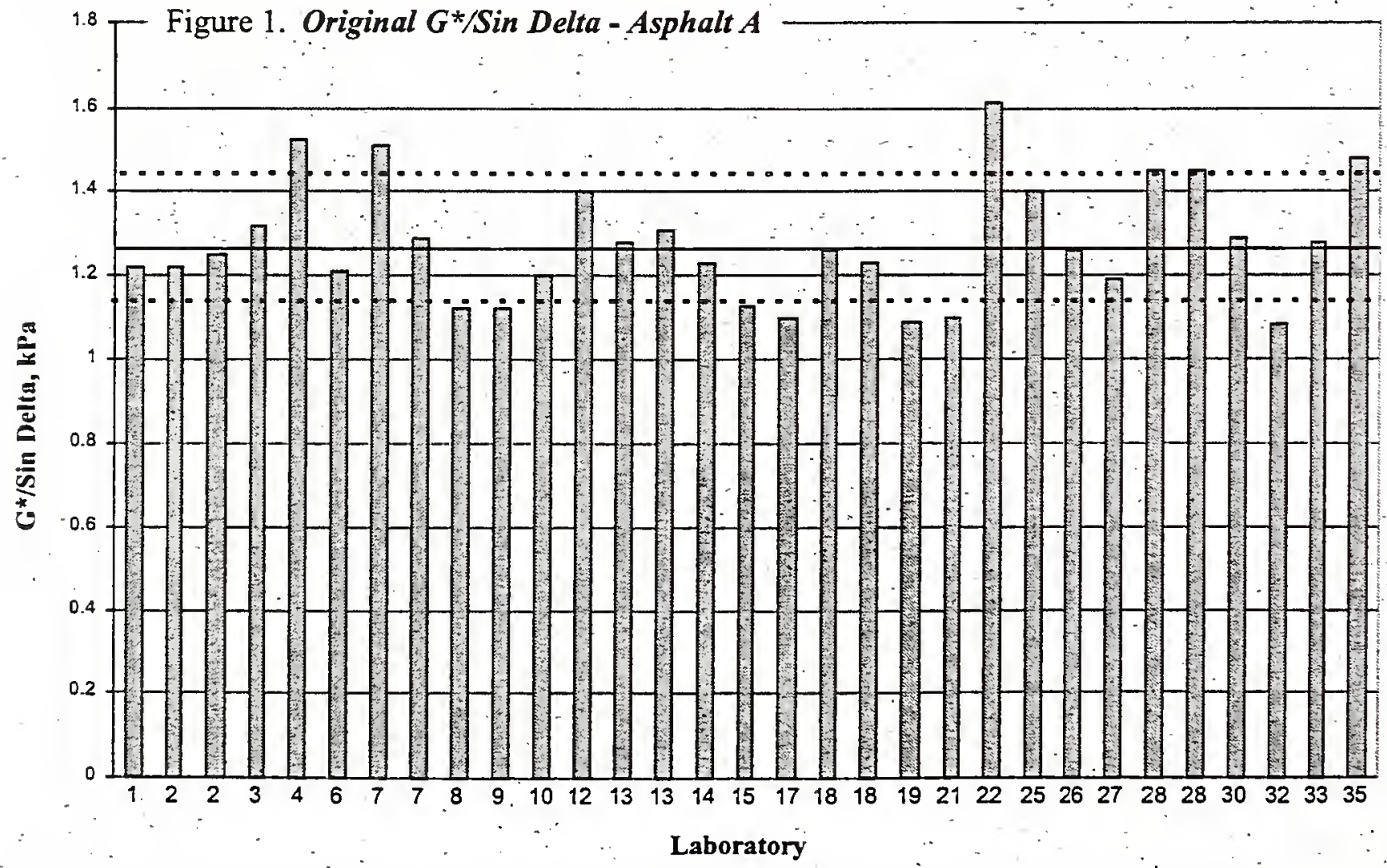

+1 Standard Deviation

Average

-1 Standard Deviation 


\section{Upcoming KCAUPG and NGSE Meetings}

Tust a reminder regarding the fast approaching NCAUPG meeting, which will take place October 23-24, 1996, at the University Inn \& Conference Center in West Lafayette, Indiana. You should have received a meeting agenda and registration form in the mail recently. If you are interested in attending one or both of the meetings, and do not have a registration form, please call Julie Smith at (317) 463-2317. If you are not registered by the early deadline of October 11 , you can also register at the meeting. Also, please remember to register at the hotel as soon as possible. To reserve a room, call the University Inn at (800) $777-9808$ and refer to the NCAUPG and/or Superpave meeting(s).

The meeting is particularly important because there will be a discussion regarding the future of the NCAUPG. Some of the other highlights of the Agenda are as follows:

- Contracting Futures

- National Perspectives Update

- FHWA

- AASHTO

- NAPA/Industry

- North Central Superpave Center

- Binder Update

- Survey of anticipated agency PG grades

- Method of handling test reproducibility

- NCSC binder information transfer

- Update on Recycling

- Superpave Mix Design and Implementation

- SPS-9A Research

- Missouri Pilot Projects on Superpave QC/QA

- Resolution on Test Procedure Standardization

- Superpave Volumetric Mix Design Manual

- Coordination of Superpave Activities

For those who arrive early, the NCSC will be hosting an Open House from 10:00 a.m. to noon on October 23. Transportation will be available from the hotel, although the Center is only a few blocks away. At the Open House, participants will be able to tour the facilities, meet the staff, and learn more about the Superpave Shear Tester (SST) and Indirect Tensile Tester (IDT).

A working meeting of the NCSC Steering Committee immediately follows, from October 24-25.

If you need more information about either of the . meetings, please call Julie Smith at the NCSC.
University Inn \&

Conference Center

3001 Northwestern Avenue

(317) 463-5511

\section{Getting to West Lafayette}

There are three ways to get to West Lafayette besides driving.

1. Fly in to Purdue/Lafayette Airport via Northwest Airlink from Detroit or United Express from Chicago O'Hare.

2. Fly in to Indianapolis, then

- rent a car and drive to West Lafayette (1-11/2 hours); or

- take the Lafayette Limo (317-497-3828) which-for $\$ 29$

round trip-runs every two hours and can bring you directly to the hotel.

3. Fly in to Chicago, then rent a car and drive (21/2-3 hours).

\section{Directions}

From Indianapolis or Chicago, take I-65 to SR-25 at Lafayette. Take SR-25 South 1.5 miles to US-52 West; turn right. Take US-52 West 3.8 miles across the Wabash River to West Lafayette and the University Inn \& Conference Center.

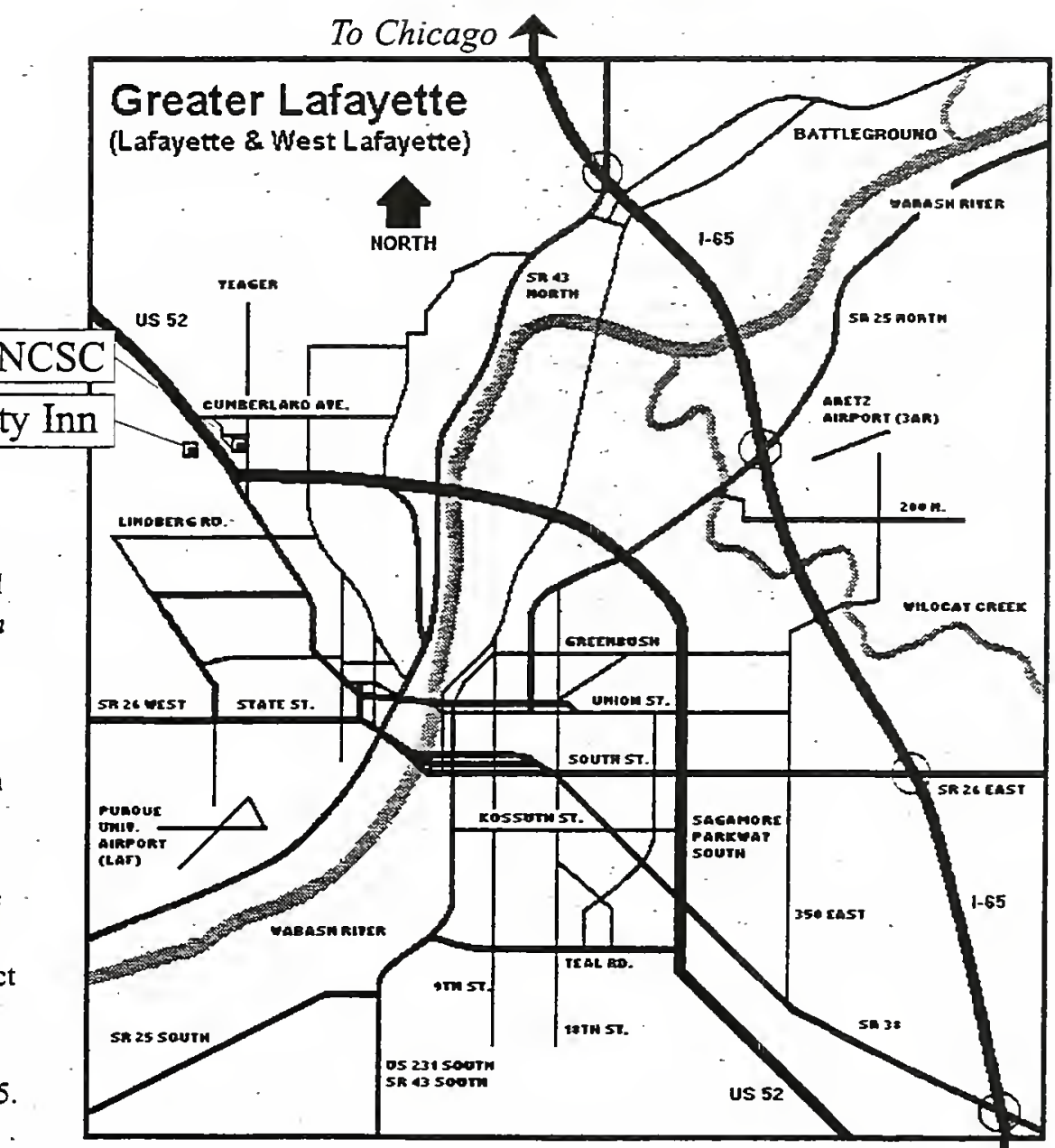

To Indianapolis 


\section{Calendar of Events}

October 10-11 NAUPG (Northeast Asphalt User/Producer

Group) Meeting

Burlington, Vermont

For details, call Jim Dunne at (410) 962-6644

October 23-24 NCAUPG Meeting

West Lafayette, Indiana

For details, see page seven

October 24-25 NCSC Steering Committee Meeting

West Lafayette, Indiana

For details, see page seven

October 28-30 $4^{\text {th }}$ Annual U. S. Hot Mix Asphalt Conference East Rutherford, New Jersey

For details, call NAPA at (301) $731-4748$ or

visit their WWW site at http://www.hotmix.org

November 13 ... Indiana User-Producer Group Meeting

Indianapolis, Indiana

For details, call INDOT at (317) 232-5280

November 20-21 $39^{\text {th }}$ Annual UMR Asphalt Conference

Rolla, Missouri

For details, call UMR at (573) 341-4461

November 25-26 43 ${ }^{\text {rd }}$ Annual Asphalt Conference

Brooklyn Park, Minnesota

For details, call the Minnesota Association of Asphalt Paving Technologists at (612) 631-0156
December 10-12 Pennsylvania Asphalt Pavement Association $37^{\text {th }}$ Annual Paving Conference

Hershey, Pennsylvania

For details, call PAPA at (717) 657-1881

December 16-17 $3^{\text {rd }}$ Superpave Center Coordination Meeting Austin, Texas mvtraton onLY

December 16-18 Pacific Coast Conference on Asphalt Specifications

Reno, Nevada

For details, call Joe Massucco at (415) 744-2662

January 12-16 Transportation Research Board

$76^{\text {th }}$ Annual Meeting

Washington, District of Columbia

For details, call the TRB at (202) 334-2934

See page three for a listing of binder and mix design courses offered by the North Central Superpave Center through March 1997.

If you have upcoming meetings, conferences or other events you would like to put on our calendar, call Julie Smith at (317) 463-2317.
North Central 1205 Montgomery Road

Superpave P. O. Box 2382

Center West Lafayette, IN 47906

- - - (317) 463-2317 phone/fax
Non-Profit Organization U. S. Postage

PAID

Purdue University 

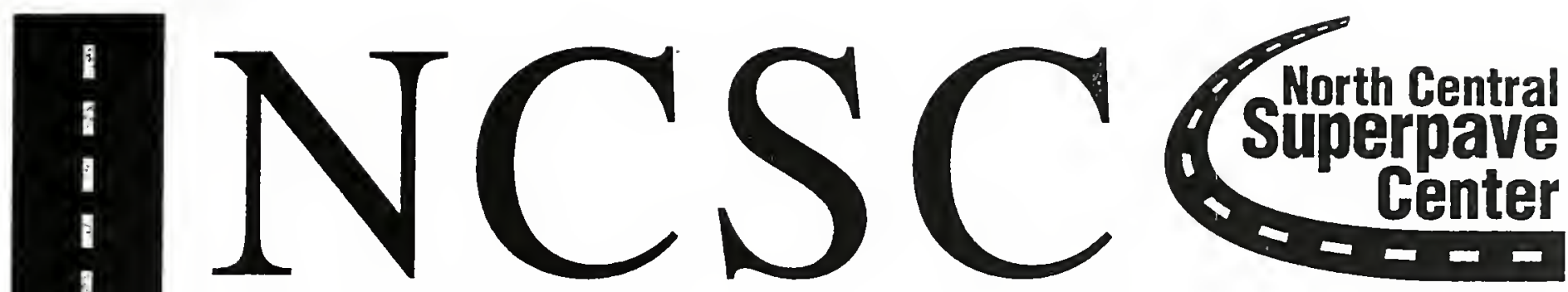

Volume 1, Number 4

Winter $1996 / 7$

\section{North Gentral User-Producer Group Meets}

$\pi$ he Fall meeting of the North Central Asphalt UserProducer Group (NCAUPG) was held in West Lafayette, Indiana, October 23-24, 1996. An open house at the North Central Superpave Center (NCSC) 1 preceded the official opening of the NCAUPG meeting. Over 70 people toured the facility and saw the recent remodeling, Indirect Tensile Tester (IDT), Superpave Shear Tester (SST), Superpave gyratory and mixing shed, and the Superpave binder equipment. The NCSC staff was on hand to answer questions.

Over 140 people from state DOT's, contractors, material and equipment suppliers, consulting firms and academia attended the NCAUPG meeting. $A r t$

Fendrick, Division Administrator of the FHWA Indiana Division, opened the meeting and welcomed everyone to Indiana. Don Lucas, Indiana DOT and co-chair of the NCAUPG, reviewed the purpose of the meeting, then provided a look at the future of contracting and paving. Lucas summarized numerous changes in progress that will have major impacts on the way states and industry do business. Among the changes are such innovations as Superpave, warranty contracts, partnering, and quality control/quality assurance (QC/QA).

A series of updates on Superpave implementation from the national level followed. Tom Bryan, from the FHWA Regional Office, reviewed the FHWA initiatives towards Superpave, including the Superpave Centers, National Asphalt Training Center II, the Lead State Team, etc. Haleem Tahir reported on the status of implementation in AASHTO, which is putting an emphasis on communication. Tahir announced the AASHTO web site at http://www.aashto.org/main. The provisional standards keep getting improved and fine-tuned. A recent AASHTO survey found that 39 states have used or are using the PG binder specifications and 34 have used or are using the volumetric mix design procedures. Tahir also reported on an assessment study that the Texas Transportation Institute (TTI) is doing. Texas says they will save $\$ 2.2$ billion by using PG binders. Maryland has reported saving $\$ 5$ per ton of mix by specifying a $P G$ binder versus using a named proprietary binder.

Don Brock, Astec, highlighted recent and upcoming developments in paving and testing equipment for the asphalt industry. He noted that the general public wants higher quality products at no higher cost, while also demanding that they be environmentally sound. He stressed that premature failures, like segregation and joint deterioration, must be remedied. Test results must be obtained faster and more reliably. Equipment needs to change to meet all of these demands.

Jan Olek, Director of the NCSC, provided an update on the status and activities of the North Central

Superpave Center. The Steering Committee of the NCSC met after the NCAUPG meeting (see accompanying article).

A binder update followed. Rick Smutzer, Indiana DOT, reported on a survey of the binder grades state agencies anticipate using (see the Fall issue of this newsletter for details). April Swanson, Amoco Oil Company, reported on test reproducibility problems and the need to determine and control the sources of this variability. Gerald Reinke, MTE, then reported on work he had done with recent developments with Bending Beam Rheometer testing and comparisons between the ATS and Cannon devices. Rebecca McDaniel, NCSC, distributed a questionnaire asking for input regarding the proposed North Central Binder Information Exchange program. This program, conceived by the Kansas DOT, continued on page three North Central User-Producer Group Meets NCSC Steering Committee Sets Policies

Superpave Updates

Digesting the Alphabet Soup

FHWA Contact/Resource Directory 3

Fatl Conference Highlights 4

Indiana Discusses Specification Changes 5

U.S. Hot Mix Conference 7. (n) Hot 7

Superpave Binder ETG Continues Efforts 8

NCSC Staff Recent Speaking Engagements 8

Binder ETG Makes BBR Recomendation

Lead State Pool of Expertise Announced

Calendar 10 


\section{NCSC Steering Committee Sets Policies}

he NCSC Steering Committee met after the NCAUPG meeting October 24-25, 1996. One of the committee's major actions was to elect Laird Weishahn, Nebraska DOR, as the new chairman. Weishahn will serve a two year term as head of the committee 1 beginning January 1, 1997. He replaces David Andrewski, Indiana DOT, who guided the Center through the difficult start-up period. Andrewski's efforts are greatly appreciated. Among the many other items of business discussed, the Steering Committee:

> Voted to allow the Director of the NCSC to recommend to the Chairman that ad hoc Expert Task Groups be formed as needed to address issues related to the center.

$>$ Reviewed current committee membership and established a procedure to add members in the funure if approved by the Chairman and a two-thirds vote of the committee.

$>$ Reviewed long-term center funding and the SPR Pooled Fund process.

$>$ Discussed industry participation in the center and agreed to accept industry contributions for support of the newsletter and other communications-related activities, plus optional support of research projects of interest.

$>$ Discussed the long-term vision for the center.

$>$ Outlined existing training being offered or proposed by the NCSC and set pricing policies.

$>$ Decided to continue piggy-backing Steering Committee meetings on the NCAUPG meetings.

\section{Superpave Updates}

Mesion LX ANALYSIS TRANNING. If you wart to get a bead start on the implementation of Superpave mixture analysis, the University of California-Berkeley is offering a course entitled Superpave Mix Design and Analysis February 3-7,1997, at the University of California Richmond Field Station. The course is intended for pavement and materials engineers responsible for hot mix asphalt designs who want to learn more about mixture performance testing and interpretation of test results. The course will focus on the Superpave Shear Tester (SST) and Indirect Tensile Tester (DT), but will also discuss other performance tests. such as beam fatigue, the thermal stress restrained specimen test (TSRST), and moisture sensitivity tests. The course will be taught by Dr. Rita B. Leaby, Dr. Carl L. Monismith, Dr. John T. Harvey and Mr. Lawrence E. Santucci. For additional information on the course, contact UCB at (510) 642-4111.

A course on Mixture Analysis will also be offered at the Asphalt Instinute's National Asphalt Training Center in Iexington, Kentucky, April 14-18, 1997. Contact Mandee Hall at (606) 2884964 for more information.

MODELS SOFTWARE. The University of MarylandCollege Park continues to work on refining the Superpave performance models. In a draft report submitted to FHWA in September, the Models Team recommends some corrections and enhancements to make the performance prediction models and analysis software reliable and suitable for general use by the industry. The Superpave Models Expert Task Group (ETG) met in October and was supportive of the proposed changes. The anticipated work to calibrate and validate the revised models will extend the time line a couple of years beyond the current five-year estimate. In the meantime, most agencies and the industry will be involved in implementing the volumetric mix design procedures and the mix analysis models will only be used on a small percentage of projects, notably those where pefformance is critical. A decision on approval of the additional work entailed in refining, calibrating and validating the performance models is expected by mid-January. At that time, a better estimate of the time line for completion of the models refinement will be available.

SUPERPAVE MIX DESIGN SOFTWARE. A WIndowsbased version of the Superpave volumetric mix design is now scbeduled to be available in April 1997. A DOS-based prototype version has been distributed to state materials engineers by AASHTO. When the Windows version is available, it will be reviewed by the AASHTO Special Committee on Software Systems (SCOSS) and appropriate subcommittees or task forces. Following this review, the software may be distributed and licensed by AASHTO.

\section{MOBILE ASPHALT TRAIIERS ON THE ROAD}

AGAN. The FHWA has two mobile asphalt trailers each ourfitted with a gyratory compactor, dynamic shear rheometer, rotational viscometer, and everything needed to $\mathrm{rin}$ the consensus aggregate tests. Tom Harman has indicated that FHWA is now scheduling these trailers to bead out to construction sites beginning in Spring 1997. Typically, the trailers set up at an asphalt plant producing Superpave mix and stay on-site for about six weeks. The trailer personnel then do companion tesing along with the state and/or contractors personnel. Experienced Superpave technicians and engineers with the trailer can help to answer questions about Superpave and work out mix design, testing and construction bugs. Any state interested in having the trailers set up on a Superpave project should initiate a request through their FHWA Division Office. Requests should be submitted soon, as the schedule is filling up rapidly.

One trailer is equipped with a Troxler gyratory and the other with a Pine. Samples of the Superpave mix collected by one trailer are sent to the other trailer for compaction. These data are belping to resolve questions about the possible differences in compaction with the different brands of gyratory. To date, the FHWA data indicate that there is not a significant difference between the two primary brands.

ANOTHER SOURCE OF INFORMATION. A new quarterly publication is being distributed nationally from Ohio. Testing News Digest is a "comprehensive informational news source for test and quality assurance professionals in the asphalt industry." The publication will feature summaries of changes in specifications and standards, a calendar of events, new product briefs and more. For information, write Testing News Digest, P.O. Box 2626, Westerville, OH, 43086, fax (614) 794-3050 of e-mail testnews@aol.com. 


\section{Digesting the Alphabet Soup}

G etting up to speed with Superpave requires learning many new or unfamiliar acronyms. There are so many letters

floating around, it sometimes feels as if we are staring into a bowl of alphabet soup. This summary of the organizations active in Superpave implementation, what they are doing and how their activities are coordinated, may help you develop a taste for the broth!

First, you need to remember that Superpave is a product of the Strategic Highway Research Program (SHRP). The trend towards catchy abbreviations may have started there.

The Federal Highway Administration (FHWA) is responsible for overall coordination of Superpave activities and is working closely with all the other groups. FHWA assumed the central role when it took over the Long Term Pavement Performance Program (LTPP) from SHRP; LTPP is aimed at determining how various pavement features, including Superpave mixtures, perform over a long time span by observing real, in-service pavements. FHWA is actively promoting Superpave through its Asphalt Delivery Team, Superpave Centers, National Asphalt Training Center (NATC) at the Asphalt Institute (AD), research contracts, FOCUS Newsletter, ETG's and TWG's, and more.

ETG's are Expert Task Groups. There are Superpave ETG's for Binder, Mixture and Models. These groups are composed of industry, state and academic representatives knowledgeable about the subject area. They work on resolving issues related to the implementation of the various specifications, tests and programs. Each Superpave Center is represented on the Mix ETG and most are on the Binder ETG, providing another point of contact and coordination for the centers. When the ETG's recommend changes to the specifications or tests, those recommendations are forwarded to AASHTO for consideration.

The TWG of interest for Superpave is the Asphalt Technical Working Gronp. This group generally oversees the work of the three ETG's in the Superpave area.

The American Association of State Highway and Transportation Officials (AASHTO) is comprised of representatives of each state agency and is very active in Superpave. The Subcommittee on Materials (SOM) reviews, votes on and publishes the AASHTO Standards and Test Methods [the Provisional Practices (PP's), Provisional Tests (TP's) and Provisional Methods (MP's)] related to Superpave. The AASHTO Task Force on SHRP Implementation is charged with moving the results of SHRP into practice. The Task Force is establishing Lead State Teams, for Superpave and other SHRP products, to help "jump start" implementation. The AASHTO headquarters team tracks the status of Superpave and coordinates activities between the SOM and other interested committees (Maintenance and Design, for example). AASHTO will also be responsible for managing and distributing Superpave software.
Other active groups include the User-Producer Groups (UPG's) which are working on a regional level. Their efforts are coordinated with the Superpave Centers, FHWA and AASHTO. As an example, the AASHTO Provisional Practice for Approved Supplier Certification for Binder largely came from work by the North Central Asphalt User-Producer Group. Advantages of the UPG's include the state-industry partnerships and wide audience that they reach.

The efforts of these diverse groups are largely coordinated through cross-membership of many people on several of these organizations and by the oversight provided by FHWA. We are truly working together to make Superpave work.

\section{MCAUPG}

continued from page one

would allow states to share binder information results and reduce duplication of effort. A question and answer period concluded this session.

Doug Coleman of the Michigan DOT gave an update on recycling of old asphalt pavements under the Superpave specifications. He pointed out that the gradation and volumetric properties must be met by the blended aggregate including the RAP. Coleman outlined the Superpave Binder ETG recommendations for blending binders. Michigan checks the recovered binder after plant mixing to see if the recovered blended materials meet the specifications.

On the second day of the meeting, Gerry Huber of Heritage Research Group gave an overview of the implementation of Superpave mix design summarizing pending and potential changes or adjustments in the process. Jim Campbell of the Missouri DOT reported on Missouri pilot projects using Superpave QC/QA (see article on the 39th Annual Missouri Asphalt Conference). Rich Wolters and Gerry Huber summarized the work on test procedure standardization.

Wayne Murphy, Minnesota DOT, discussed the proposed Superpave Volumetric Mix Design, or "one-stop" manual. This would be a very large undertaking and it is hard to make much headway. John Heggen, Iowa DOT, suggested distributing an outline of the proposed manual to the states to see if they already have documentation addressing some aspects that could be used. Kansas and Missouri, for example, have already development training manuals.

Lucas and Dave Holt, also co-chair of the NCAUPG, then led a discussion of the future directions of the group. Both are stepping down from their positions to bring some new blood into the organization. Lucas stressed that they are still committed to the organization and its goals, but feel that the time has come for others to take the lead. Work is underway to identify new candidates for the co-chairs from the states and industry.

The next meeting of the NCAUPG will be held in Madison, Wisconsin, in April and will include a technician meeting as was held in Kansas City last Spring. The Fall meeting will include an extended session examining repeatability of test results. 


\section{Directory of FHWA Contacts and Resources}

\begin{abstract}
For your convenience, we have reprinted this current directory of FHWA contacts and resources.
\end{abstract}

\section{General}

AASHTO Task Force on SHRP Implementation

Bobbie Templeton, Texas Department of Transportation

(512) 305-9504 phone $\cdot$ (512) 463-0283 fax

\section{SHRP Coordinators}

Mike Halladay, FHWA Headquarters

(202) 366-6503 phone - (202) 366-7909 fax

Margie Sheriff, FHWA Headquarters

(202) 366-1747 phone - (202) 366-7909 fax

Haleem Tahir, AASHTO

(301) 975-6704 phone - (301) 330-1956 fax

Doug Shaffer, Transportation Research Board

(202) 334-1430 phone - (202) 334-3471 fax

FHWA Regional Offices

Kathryn Harrington-Hughes, FOCUS Newsletter

(202) 347-1414 phone - (202) 347-6938 fax

Neil Hawks, Transportation Research Board SHRP Committee

(202) 334-1430 phone - (202) 334-3471 fax

Transportation Research Board SHRP Research Reports

(202) 334-3214 phone $\cdot$ (202) 334-2519 fax

SHRP Information Clearinghouse

http://www.hend com/shrp/shrp (dial-up service requires special

software and 9600-bps or faster modem; call Henderson Associates at

(202) $682-3739$ to request a copy of the free software)

\section{Asphalt}

\section{Asphalt Technical Working Groups}

Don Steinke

(202) 366-0392 phone - (202) 366-9981 fax

John D'Angelo, Binder Expert Task Group

(202) 366-0121 phone - (202) 366-7909 fax

John Bukowski, Mix Expert Task Group

(202) 366-1287 phone • (202) 366-7909 fax

Katherine Petros, Superpave Models/Software Expert Task Group

(202) 366-1340 phone - (202) 336-9981 fax

Ray Bonaquist, Accelerated Pavement Testing Expert Task Group

(703) 285-2629 phone - (703) 285-3105 fax

Asphalt User-Producer Groups

Frank Fee, Northeast Region

(609) 428-8808 phone - (609) 963-0111 fax

Jill Baumgardner, Southeast Region

(601) 956-3017 phone - (601) 956-4021 fax

Dick Ingberg, North Central Region

(612) 429-2955 phone \& fax

Bob Rask, Rocky Mountain Region

(303) 798-1950 phone - (303) 794-5205 fax

Rick Holmgreen, Pacific Coast Region

(713) 544-8257 phone - (713) 544-8150 fax
Mobile Asphalt Laboratories

Tom Harman, FHWA

(202) 366-0859 phone - (202) 366-7909 fax

National Asphalt Training Center

Mandee Hall

(606) 288-4964 phone - (606) 288-4999 fax

Snperpave Models and Software

Katherine Petros, General Information

(202) 366-1340 phone - (202) 336-9981 fax

$U$ of Maryland Project Team, User Support

(301) 405-0305 phone - (301) 405-6230 fax

\section{Long Term Pavement Performance [LTPP]}

\section{LTPP Program}

Charlie Churilla, FHWA

(703) 285-2355 phone $\cdot$ (703) 285-2767 fax

Transportation Research Board LTPP Committee

Rob Raab, TRB

(202) 334-1430 phone - (202) 334-3471 fax

LTPP Product Implementation Team

Bob Hathaway, FHWA

(503) 326-2071 phone $\cdot$ (703) 326-3928 fax

LTPP Regional Coordination Offices

Ivan Pecnik, ITX Stanley (North Atlantic Region)

(716) 631-5205 phone - (716) 632-4808 fax

Morris Reinhardt, Brent Rauhut Engineering (Southern Region)

(512) 346-0870 phone - (512) 346-8750 fax

Dick Ingberg, ERES Consultants (North Central Region)

(217) 356-4500 phone - (217) 356-3088 fax

Cal Berge, Nichols Consulting Engineers (Western Region)

(702) $329-4955$ phone $\cdot$ (702) $329-5098$ fox reprinted from the October 1996 FOCUS Newsletter

\section{NHI Offers Superpave Course}

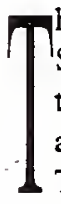
he National Highway Institute will be offering a course on Superpave for field engineers. The two-day course will be taught by the regional Superpave Centers. The course materials are currently being revised by the National Asphalt

Iraining Center following a pilot course reviewed by the centers and other state, federal and academic reviewers.

The course provides an overview of the Superpave process so that field personnel will understand the similarities and differences between Superpave mixes and conventional mixes, the concepts behind Superpave, and the impacts of changes in the mix, among other issues.

The course should be ready for presentation in the Spring. Courses are also in development for local agencies and for upper management. For more information, contact the NCSC. 


\section{North Central Region Fall Conference Highlights}

\begin{abstract}
I the construction season winds down, the conference season picks up. This section of the NCSC newsletter contains highlights of two area asphalt conferences; elsewhere are highlights from the Superpave Binder Expert Task Group Meeting 1 and the Fourth Annual U.S. Hot Mix Conference. The calendar, shown on page 10, lists upcoming conferences of interest.
\end{abstract}

\section{TH ANNUAL MISSOURI ASPHAIT CONFER-} ENCE. The 39th Annual Missouri Asphalt Conference was held in Rolla, Missouri. The attendees represented state DOT's, contractors, equipment and materials suppliers, consultants, cities and counties, federal agencies and others.

Superpave was a major topic of discussion. Ron Netemeyer, Missouri DOT, and Jerry Riley, Hall and Riley Paving Company, discussed their experiences with Missouri's 1996 Superpave projects. Some problems were experienced with getting densities and VMA's. They are looking into why this was the case with some input forthcoming from the Superpave Center and the FHWA. St. Louis County is also working with Superpave; Ted Medler of the St. Louis County Highway Department summarized their experiences on three overlay projects. In general, the contractors seemed to support Superpave, but were concerned about costs and tender mixes. Roger Brown of Pace Construction said that Missouri needed to make sure there were enough Superpave projects to justify contractors investing in gyratories; he urged setting a deadline for switching to Superpave on all projects.

Dave Richardson, University of Missouri-Rolla, gave an overview of the Superpave laboratory and field testing equipment. A display of much of the equipment was set up for meeting participants to view. Wayne Muri spoke on behalf of the Missouri Asphalt Pavement Association, National Asphalt Pavement Association and North Central User-Producer Group. He expressed support for Superpave and stressed the need for training in Superpave and QC/QA. The training, communication, research and other activities of the North Central Superpave Center were outlined by Rebecca McDaniel.

Richard Meininger of the National Stone Association gave a presentation on the use of natural aggregates in hot mix asphalt that focused on the Superpave specifications. He expressed his viewpoint that a performance test is needed as part of the volumetric mix design process, so the aggregate tests can be used for guidance, not as controls.

On a related topic, Jim Campbell, Missouri DOT, recounted experiences with the use of QC/QA specifications in Missouri in 1996. Three Superpave projects with QC/QA have been contracted. The contractors results are accepted for payment if they agree reasonably well with the state results. Payment is based on gradation, asphalt content (by nuclear gauge), VMA and air voids at $\mathrm{N}_{\text {des }}$, and mat density. Missouri will be looking at their pay factors in the future. Roger Brown of Pace Construction added that everyone, from the plant operator to the paving crew to the testing people, needs to know what is going on, which will result in higher quality and more consistent results. He fully supports the QC/QA concept and said Superpave is a great product, though we are still on a learning curve.

Other topics of discussion during the 11/2 day conference included an update on changes and developments within the Missouri Department of Transportation, hot mix asphalt plants, an update on changes and activities at the Asphalt Institute, asphalt ignition ovens, and more.

The conference was hosted by the University of MissouriRolla, Asphalt Institute, Missouri Asphalt Pavement Association and Missouri Department of Transportation.

43RD ANNUAL MINNESOTA ASPHALT CONFERENCE. The 43rd Annual Minnesota Asphalt Conference opened with a series of roundtable discussions on a range of topics including the Minnesota DOT Mobile Superpave Lab, metrication, work zone safety, technician certification/recertification, asphalt content by incineration, cold weather paving, $\mathrm{MnROAD}$ research and more. The roundtable technology exchange was followed by the business meeting of the Minnesota Association of Asphalt Paving Technologists.

Most of the afternoon of the first day was spent discussing various items related to Superpave. Shawn Anderson of Shell Oil gave an informative presentation entitled "Asphalt and the Global Refining Outlook, making sense of a very complicated business. A number of issues are active or potentially active that will have an effect on petroleum prices across the board. Regarding Superpave specifically, the costs for binder will increase due to the need for specific crudes to meet some binder grades, changes in refinery optimization to produce specific grades and the need for more tanks to store various grades. Anderson said that Superpave is a "great program" that will lead to improved products for the driving public. The more demanding specifications tied to specific temperature regimes put a twist in the suppliers' logistics; they will need to use specific crudes to meet some grades and will need to have pipelines and refinery capabilities to handle the new grades. In general, performance grades higher than 64 and lower than -22 will be tougher to supply than other grades.

Mike Kamnikar, Minnesota DOT, described the varied geology of Minnesota and its impacts on aggregate resources.

Superpave may require coarser gradations than have been used in Minnesota in the past. In the near future, more information will be needed/demanded on sources, there will be a need for increased knowledge of where to look for aggregates to meet requirements and there may be a need to look farther afield to find good aggregates. Other speakers discussed the availability of aggregates in the Twin Cities area and county aggregate maps for the rest of the state.

Wayne Murphy, Director of Construction and Materials Engineering for Minnesota DOT, then described the DOT's Superpave implementation plan. Minnesota will be adopting PG binders on schedule January 1, 1997, and adopting the Superpave volumetric mix design procedures January 1, 1998, when the 20year design lane ESAL's are greater than 3 million. There will be 


\section{Highlights}

continued from page five

some pilot projects in 1997. Murphy outlined research needs related to Superpave, including the appropriate temperatures for selecting performance grades, RAP and its effects on binder selection, use of modified binders, aggregate angularity and design compactive effort. On related topics, Minnesota bas developed a draft QC/QA specification; pilot projects may be let in 1997. Also, Minnesota will begin requiring VMA type specifications on a large majority of projects.

Jim Lilly, also of Minnesota DOT, outlined the use of PG binders in more detail. In 1997, Minnesota will be selecting equal or better binders than currently used, but they will atternpt to minimize the initial cost increase by focusing on binders that can be produced using existing capabilities and avoiding the use of polymers. The Department will then look at the cost/benefit ratio and review developments from the Superpave Binder ETG. Minnesota has less dependence on the thermal crack resistance of asphait mixes due to their widespread use of sawing and sealing joints in asphait pavements and high proportion of overlay projects. Lilly also noted that Minnesota is working with Wisconsin and Iowa on selecting certain work horse grades of binders they will be specifying.

\section{Rebecca McDaniel spoke on behalf of the North Central} Superpave Center (NCSC), summarizing what the center is and bow it can assist contractors, state and local agencies and others with Superpave implementation issues. She described the types of training available, discussed the methods of communication the NCSC is establishing, and outlined the current and proposed research efforts, many of which address issues on Murphy's list of research needs. McDaniel aiso provided a list of other types of activities the Superpave Centers will be undertaking cooperatively.

The second day of the conference concurrent sessions focused on local issues, research, Minnesota Superpave experiences and construction issues. During the session on Superpave, the Minnesota DOT, a contractor and two county engineers talked about their experiences with Superpave. Mike Rief of the DOT reported that, on one project on I-34, the contractor had to go farther away to get suitable aggregate for the Superpave mix that was added to the project through a supplemental agreement. Among Rief's other comments, he noted the following considerations for Superpave mixes: segregation was not a problem; the coarser Superpave surface took more paint, sand and salt than conventional surfaces, but the Superpave surface held salt longer resulting in fewer applications; road spray and pavement noise were decreased; and cracks that appeared in the surface healed themselves during warmer weather.

Doug Weiszhaar, Stearns County Engineer, indicated they tried Superpave due to concerns about stripping, durability, thermal cracking and rutting in the county. They did one experimental project and are very happy with the results. Time will tell if it was worth the additional cost, but at this point they would probably use Superpave specifications again. The contractor on the project, Harris Duininck, Duininck Brothers, Inc., reported having no trouble achieving 92 to 94 percent of maximum density in the field and overall did not experience any laydown difficulties. He also noted that the Superpave mix gradations are similar to an old mix that was formerly used in Minnesota; many of those old mixes are still in place and performing well.

Al Forsberg, Blue Earth County Engineer, then summarized their use of the full Superpave system-binder, aggregate structure, volumetrics and moisture susceptibility. Their first project, in 1995, went on the fine side of the maximum density line; their second project, in 1996, went on the coarse side. It needed more quartzite and a thick aspbalt film, and was therefore more expensive, but led to a very stable mix. In short, Forsberg said it "worked great!" The costs increased 25 percent over the cost of conventional mix per ton, but only 12 percent more for the entire pavement. Forsberg said it would not take a great increase in service life to justify the added cost.

John Isackson then presented Minnesota's history with Superpave and plans for the future. He indicated that all projects would use the binder specifications beginning January 1, 1997, using supplemental agreements to change the binder on existing contracts. Minnesota had three Superpave volumetric mix design projects in 1996, will have six to eight in 1997 and approximately 20 percent of all projects by 1998 . Isackson related problems meeting fine aggregate angularity on the planned SPS-9 project in Minnesota; they learned from that project that fine materials must be angular and clean to pass the test. Isackson presented preliminary results on two experimental projects comparing Superpave mixtures to other mixes, like SMA's, and comparisons of different binder grades. Isackson concluded by observing that Superpave is "here to stay."

Other topics presented at the conference included saw and seal, MnROAD research, SHRP maintenance and rehabilitation projects, mixture durability, Ohio's use of asphalt ignition ovens, and more.

The conference is sponsored every year by the Minnesota Association of Asphalt Paving Technologists in cooperation with the American Society of Civil Engineers, Asphalt Institute, FHWA, Local Road Research Board, Minnesota Asphalt Pavement Association, Minnesota City Engineers Association, Minnesota DOT, Minnesota Street Superintendents Association, and University of Minnesota.

\section{$\%$}

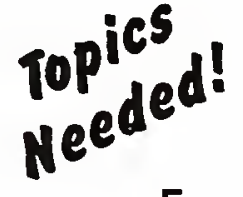

\section{Topics are needed for discussion at the next Superpave Technicians'}

Forum, for example: binder and gyratory equipment, and testing issues. Please submit your topic ideas to the NCSC on or before January 31, 1997. The topics will be used to develop a survey for distribution prior to the meeting in April. 


\section{Indiana Industry, DOT Discuss Superpave and Specification Changes}

T he Asphalt Pavement Association of Indiana (APAI) hosted its annual meeting in Indianapolis in December. Superpave and changes in the Indiana 1 DOT (INDOT) specifications were the major topics of discussion. $B o b$ McCormick, President of APAI, noted that his organization and INDOT have worked on these changes together.

Mike Acott, President of the National Asphalt Pavement Association (NAPA), congratulated the group in Indiana on their efforts toward Superpave implementation, partnering and warranties. Acott then summarized the major areas NAPA is actively pursuing.

Superpave is one of those areas. Acott said that NAPA is "very supportive" of Superpave and believes it is a "powerful tool," but that many issues still need to be resolved, including modifiers, aggregates and a strength test for the volumetric mix design. Acott was concerned that many people may have a knee jerk reaction to reported failures at Westrack; he said that the results may support Superpave and the need to pay close attention to aggregate properties. Acott also mentioned that a new asphalt textbook would be published soon, and offered the NAPA web page (www.hotmix.org) and toll free number (1-888HOTMIXX) as information sources.

Don Lucas, INDOT Chief Highway Engineer, spoke on the future of highway construction in the year 2000 . He stressed that our customers are better informed than ever before and are demanding better quality for less money.

Art Fendrick, FHWA Indiana Division Administrator, noted that many things are changing, but the need for quality and integrity will not change. He then spoke about the reauthorization of the Intermodal Surface Transportation Efficiency Act (ISTEA) or highway funding bill.

Andy Brooks, of Advancing Indiana, spoke on the efforts of that group to build grass roots support for improving the infrastructure in Indiana. He indicated that the general public does not realize that funding for needed road and bridge projects is not available.

Rick Smutzer and Dave Andrewski of INDOT spoke on the Approved Supplier Certification Program for PG binders and Indiana's Superpave implementation schedule. Indiana will be using PG binders in 1997 and will have at least 33 Superpave mix projects. In 1998, all major projects will use Superpave mixtures and the goal is to use Superpave on all projects beginning in 1999.

Other presentations reported on Indiana's work establishing a Hot Mix Asphalt Certified Producer Program, contractor acceptance testing, computerized control charts for HMA production, and revisions to the bituminous section of the Standard Specifications.

\section{Users, Producers Meet at U.S. Hot Mix Conference}

he Fourth Annual Hot Mix Asphalt
Conference was beld in East
Rutherford, New Jersey on October 28-
30, 1996. The conference was attended
by over 200 asphalt users and producers from across the country. The objective of the conference was to present and discuss issues related to quality and performance of HMA pavements. Various technical sessions specifically related to heavy duty HMA, Superpave implementation, current pavement construction issues, and pavement rehabilitation were discussed.

The North Central Region was well represented on the agenda with $A p r i l$ Swanson of Amoco presenting the results of a recent round robin in the North Central Region regarding binder certification, background information, selection of PG's, certification and test precision results. AASHTO initiated the development of PG binders to improve the performance and durability of HMA pavements. PG binder characteristics are much better than the old penetration and viscosity specifications. It was reiterated that selection of the PG should be based on performance, PG availability, volume of the roadway and costs of the PG. The large asphalt suppliers need time (a year or more) to make the change over to PG wholesale. Test reproducibility results are a thorny issue. The North Central Region round robin results were variable when testing the same materials. The TP26-96 Asphalt Supplier Certification Program is good and suppliers are looking forward to it.

Dudley Bonte of Rieth-Riley Construction discussed various construction issues with Superpave projects. He also coined a new acronym, "TATO," the Trial and Tribulation of Superpave, which all contractors will experience. All contractors will go through a learning curve with mix designs. On RiethRiley's first project there were $22 \mathrm{mix}$ design trials before one worked. The current project using PG58-34 is experiencing trouble obtaining density on the mix. Bonte believes that the contractor should evaluate his base materials so that he is experienced with the use of Superpave requirements before bidding on projects.

A presentation on activities of the user-producer groups from around the country was given by Dave Holt of the Minnesota Asphalt Pavement

Association. Holt spoke on how each of the five user-producer groups is working together with industry and the DOT's in the areas of implementation of Superpave. User-producer groups are made up of multiple disciplines including asphalt contractors, asphalt suppliers, and state and government agencies. The major issues at this date are the quality control process for implementation of the TP26 Asphalt Supplier Certification program, recycling, fine aggregate angularity, and the Superpave Centers.

Other topics discussed included New continued on page eight 


\section{Superpave Binder Expert Task Group Continues Efforts}

he Superpave Binder Expert Task Group (ETG) met in September to continue its work on resolving issues with the Superpave binder specifications and test equipment. Some of the items discussed at the last meeting are summarized 1 here.

The discrepancy between test results obtained using the Cannon and ATS Bending Beam Rheometers (BBR) was discussed at length. The ATS BBR gives a slope value that is about 0.01 lower than the Cannon BBR. The reason for this difference may be related to the way the different devices define the 0 time of loading. The Superpave Binder ETG will continue to investigate the source of the discrepancy with the cooperation of the manufacturers. In the interim, the ETG is recommending that the slope value (m) determined by the AIS BBR be increased by 0.01 .

A prototype of the new design for the Direct Tension Device (DT) is being readied. The new design uses a borizontally mounted specimen in a fluid bath instead of an air-cooled chamber to control the temperature. Preliminary test results indicate that some changes in the test protocol may be advisable. When ruggedness testing has been completed, the FHWA plans to purchase these new devices for the states under the pooled-fund equipment purchase.

A task group has been formed to look at how fatigue influences binder characteristics. The group will review data from California pavements and other sources.

The Superpave Binder ETG continues to follow the work of the National Cooperative Highway Research Program (NCHRP) Project 9-10, which is developing Superpave protocols for testing modified binders. This research will likely lead to changes in the AASHTO Provisional Standard PP6, "Standard Practice for Grading or Verifying the Performance Grade of an Asphalt Binder."

The Superpave Binder ETG has recommended that the use of up to 15 percent Reclaimed Asphait Pavement (RAP) should not require a change in the binder grade and that over 15 percent, blending charts be used to determine a trial RAP percentage. This requires testing both the virgin and recovered binder grades, then preparing the blend to verify the resulting grade. A new NCHRP project will be looking at the effects of RAP on both binder and mixture properties in more detail.

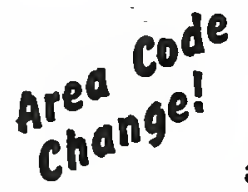
In February, the NCSC's area code will change from 317 to 765 . Our new phone and fax number will be (765) 463- Please make a note in your records! 2317. The Spring edition of the NCSC Newsletter will reflect the new area code.

\section{NCSC Staff Recent Speaking Engagements}

he NCSC Steering Committee has requested that every issue

of the newsletter include a listing of recent speaking engage-

ments to show the types of audiences NCSC staff are reaching

and to show others that the Superpave Center is a resource

they can use when putting together programs.

During the months of October, November and December, the NCSC personnel spoke on the following occasions:

> North Central Asphalt User-Producer Group Meeting

$>$ North Central Superpave Center Steering Committee

$>$ 39th Annual Missouri Asphalt Paving Conference

> 43rd Annual Minnesota Asphalt Conference

> Indiana University_Purdue University Physics Seminar

$>$ Civil Engineering Professional Development Seminar

$>$ Superpave Center Tour for Disadvantaged High School Students

Details on some of these meetings can be found elsewhere in this newsletter.

\section{Superpave Binder ETG Makes BBR Recommendation}

$\overbrace{}^{2}$

he Superpave Binder ETG has recommended that Bending

Beam Rheometer (BBR) results be adjusted to bring results collected with the Cannon and AIS bending beams closer together. Specifically, the ETG is recommending that the m-

1 values reported by the ATS BBR be increased by 0.010 . This is an interim measure until the cause for the discrepancy between the two devices is found and corrected.

This recommendation is based on a detailed evaluation by the Asphalt Institute, which revealed that the test data produced by the two devices typically differed by 0.01 . This finding was confirmed by analysis of the AMRL round robin data. The Binder ETG will continue to work to resolve the discrepancy.

\section{Hot mix}

continued from page seven

York and New Jersey Port Authority experiences; heavy traffic on the New Jersey turnpike and their exclusive use of asphalt pavements; design of heavy pavements with asphalt; aggregate issues; segregation; building good longitudinal joints; pavement smoothness; Westrack; pavement preparation prior to overlay; $\mathrm{PCC}$ rehabilitation using HMA; thin surfaces; and rehabilitation of HMA with pulverization.

Dale Decker of the National Asphalt Pavement Association provided closing remarks and indicated that a site for the Fifth Annual Hot Mix Asphalt Conference has not been finalized at this time. It was rumored without confirmation that the conference will be in Phoenix, Arizona next year.

by V. Lee Gallivan 


\section{Lead State Pool of Expertise Announced}

7 he last issue of this newsletter summarized the goals of the FHWA/AASHTO sponsored Superpave Lead State Team. This team is composed of state, industry and academic representatives from Florida, Indiana, Maryland, New York, Texas and Utah. One of the goals of this team was to assemble a pool of experts in various areas of Superpave who could be available to share their expertise with others.

The people shown in the list below are willing to share their experiences and knowledge. You can also contact the NCSC, of course, and we will help you get the information you need.

\begin{tabular}{|c|c|c|c|c|c|}
\hline STATE & EXPERTISE & ORGANIZATION & CONTACT & PHONE & FAX \\
\hline \multirow[t]{4}{*}{ FL } & Binder \& Mix Design & Florida DOT & Glenn Shiller & (352) $337-3203$ & (352) 334-1649 \\
\hline & Binder \& Mix Design & Florida DOT & Gale Page & (352) $337-3208$ & (352) $334-1648$ \\
\hline & Mix Design & Florida DOT & Toby Dillow & (352) $337-3189$ & (352) 334-1644 \\
\hline & Mix Design \& Construction & Florida DOT & Jim Musselman & (352) $337-3150$ & (352) 334-1648 \\
\hline \multirow[t]{3}{*}{ IN } & Mix Specifications & $\begin{array}{l}\text { Indiana DOT } \\
\text { Materials \& Tests Division }\end{array}$ & David Andrewski & (317) $232-5280$ & (317) $356-9351$ \\
\hline & Binder Specifications & $\begin{array}{l}\text { Indiana DOT } \\
\text { Materials \& Tests Division }\end{array}$ & Richard Smutzer & (317) $232-5280$ & (317) 356-9351 \\
\hline & Binder Testing & $\begin{array}{l}\text { Indiana DOT } \\
\text { Materials \& Tests Division }\end{array}$ & Rhonda Richardson & $(317) 232-5280$ & (317) $356-9351$ \\
\hline \multirow[t]{6}{*}{$\mathbf{M D}$} & General & $\begin{array}{l}\text { Maryland State Hwy Admin } \\
\text { Western Regional Lab }\end{array}$ & Larry Michael & (301) 678-6134 & (301) 678-5190 \\
\hline & Mix Design \& Analysis & $\begin{array}{l}\text { Maryland State Hwy Admin } \\
\text { Western Regional Lab }\end{array}$ & Bill Wells & $(301) 678-6134$ & $(301) 678-5190$ \\
\hline & Spec Writing, Equipment & Maryland State Hwy Admin & Gloria Burke & (301) 678-6134 & (301) 678-5190 \\
\hline & $\begin{array}{l}\text { Purchasing \& Implementation } \\
\text { Plan Development }\end{array}$ & Western Regional Lab & & & - \\
\hline & Binder Testing & $\begin{array}{l}\text { Maryland State Hwy Admin } \\
\text { Western Regional Lab }\end{array}$ & Jitesh Parikh & (410) $321-3431$ & (410) 321-2208 \\
\hline & Binder Testing & Maryland State Hwy Admin & Ricky Finney & (301) 678-6134 & $(301) 678-5190$ \\
\hline Mo & Lead State Team Facilitator & Missouri DOT & Jeanne Fuchs & (314) $340-4167$ & (314) $340-4193$ \\
\hline \multirow[t]{4}{*}{ NY } & $\begin{array}{l}\text { Mix Design, Analysis \& } \\
\text { Construction }\end{array}$ & New York DOT & Ron Sines & (518) $457-4582$ & (518) $457-8171$ \\
\hline & Binder Testing & New York DOT & Jeff Groff & $(518) 457-3113$ & (518) 457-4171 \\
\hline & Mix Design & Materiais Testing Laboratory & Marisa Kalinowski & $(516) 354-6600$ & (516) $354-6690$ \\
\hline & Mix Design \& Construction & Advance Testing Company & James Smith & (914) 496-1600 & (914) 496-1398 \\
\hline \multirow[t]{3}{*}{ TX } & Binder Testing & Texas DOT & Darren Hazlett & (512) $232-1900$ & (512) 232-1939 \\
\hline & $\begin{array}{l}\text { Mix Design, Analysis \& } \\
\text { Construction }\end{array}$ & Texas DOT & Maghsoud Tahmoressi & (512) 232-1903 & $(512) 232-1939$ \\
\hline & Mix Design \& Analysis & Austin Superpave Center & Bob McGennis & (512) 475-7912 & (512) $475-7914$ \\
\hline \multirow[t]{8}{*}{ UT } & $\begin{array}{l}\text { Leadership, Funding \& } \\
\text { Coordination }\end{array}$ & $\begin{array}{l}\text { Utah DOT } \\
\text { Materials Division }\end{array}$ & Gerald Bartett & (801) $965-4328$ & (801) $965-4796$ \\
\hline & $\begin{array}{l}\text { Mix Design, Specifications } \\
\text { \& Analysis }\end{array}$ & $\begin{array}{l}\text { Utah DOT } \\
\text { Materials Division }\end{array}$ & Howard Anderson & (801) $965-4616$ & $(801) 965-4796$ \\
\hline & Mix Testing & $\begin{array}{l}\text { Utah DOT } \\
\text { Materials Division }\end{array}$ & Steve Niederhauser & $(801) 965-4294$ & (801) 965-3843 \\
\hline & Binder Testing \& Analysis & $\begin{array}{l}\text { Utah DOT } \\
\text { Materials Division }\end{array}$ & Cameron Peterson & (801) $965-4296$ & (801) $965-3843$ \\
\hline & Binder Testing & $\begin{array}{l}\text { Utah DOT } \\
\text { Materials Division }\end{array}$ & Roy Ulibarri & (801) $965-4295$ & (801) $965-3843$ \\
\hline & Construction & Staker Paving Company & Mike Worischeck & (801) 298-7500 & (801) 295-7440 \\
\hline & Construction & Staker Paving Company & Loyd Lefevre & $(801) 298-7500$ & $(801) 295-7440$ \\
\hline & $\begin{array}{l}\text { Binder Formulation \& } \\
\text { Supply }\end{array}$ & $\begin{array}{l}\text { Koch Materials Company } \\
\text { Western Region } \\
\text { Technical Laboratory }\end{array}$ & Tim O'Connell & (801) 292-1434 & (801) 292-1346 \\
\hline
\end{tabular}




\section{Galendar of Events}

January $?$

Iowa Superpave Workshop

Ames, Iowa

For details, call the Aspahlt Pavement

Association of lowa at (515) 222-0015

January 12-16 Transportation Research Board 76th Annual

Meeting

Washington, District of Columbia

For details, call the TRB at (202) 334-2934

January $27-29$

Superpave Volumetric Mix Design Course

Indianapolis, Indiana

For details, call the NCSC at (317) 463-2317

February 3-5 Plantmix Asphalt Industry of Kentucky

Winter Training SchooI

Louisville, Kentucky

For details, call Dean Blake at (502) 223-3415

February 3-7 Superpave Mix Design and Analysis

Richmond, California

For detaits, call the University of California-

Berkeley at (510) 642-4111:-

$\therefore \sin x=$

February 4-5

Missouri Asphalt Pavement Association

Annual Conference

Jefferson City, Missouri

For details, call MAPA at (573) 635-6071

February 11
Ohio Asphalt Paving Conference

Columbus, Ohio

For details, call the Ohio Department of

Iransportation at (614) 275-1387
February 11-12 Nebraska Asphalt Paving Conference Kearney, Nebraska

For details, call the University of Nebraska Lincoln at (402) 472-2844

February 17-19 Superpave Binder Course

Indianapolis, Indiana

For details, call the NCSC at (317) 463-2317

March 3-5 Flexible Pavements, Inc. Annual Meeting

Columbus, Ohio

For details, call Cliff Ursich at (614) 2215402

March 11

41st Annual Asphalt Paving Conference and

Equipment Show

Lansing, Michigan

For details, call the Michigan Department of Transportation at (517) 882-6555

March 17-19 Superpave Volumetric. Mix Design Course Indianapolis, Indiana

For details, call the NCSC at (3I7) 463-2317

April

North Central Asphalt User-Prodncer Gronp Spring Meeting, North Central Superpave Center Steering Committee Meeting and

Laboratory Technicians' Forum

Madison, Wisconsin

Dates yet to be finalized; for details, call Dick Ingberg of LTPP North Central Region at (800) 344-7477 
Binder ETG Meeting

NCSC Lab Construction

Winter Conference Season

Lead State Update

Your NCSC as a Resource

5

NCSC Speaking Engagements

6

NCSC's New Phone Numbers

7

Superpave in the News

WWW Site Improvements

back

Spring 1997 Calendar

back

S O D

Volume 2, Number 1

Spring 1997

\section{Superpave Aggregate Gamble Pays Off}

1 eridian Aggregates, in St. Cloud, Minnesota, took a gamble on Superpave that paid off. When Stearns County, Minnesota, was looking into the possibility of using Superpave for the reconstruction of one of its more heavily traveled roads, Meridian Aggregates guaranteed that they could

supply the combined aggregate for the project at a fixed cost. This was a gamble since Steams County and Meridian had no prior Superpave experience and the mix designs had not yet been completed.

By taking advantage of their high quality aggregate source and using good quality assurance procedures, Meridian was able to provide a consistent supply of aggregate to the project and meet the agreed upon price. Mieriaian quarries granize from a nuge batholith with a radius of about 50 miles and a depth of 13 miles. So many granite-related businesses operate in the area that St. Cloud has long been known as the Granite City. The quarry has been in operation since it was opened by Burlington Northern in 1947 to supply railroad ballast.

In order to meet tight contractual deadlines and even the playing field for this first use of Superpave in the county, the contract specified that granite be used in the mixes and the same mix designs were provided to all bidders. Granted, Meridian can take advantage of a reserve of high quality aggregate. The aggregate met all the consensus and source properties quite easily.

Because the granite is so hard, they do not use jaw or impact crushers; cone crushers provide more rock-onrock crushing action. Not many aggregate suppliers have such high quality sources, but all can learn from Meridian's experiences with this project and subsequent Superpave jobs in the area.

Dan Bokinskie, Technical Support Manager for Meridian, indicates they were able to provide such a uniform supply of aggregate to the project that no adjustments of asphalt content or gradation were required in the three days of paving on the job. They did this without any special processing or changes in typical operations, though they did set aside stockpiles specifically for the project. They advise not to try to take products out of production, but to take materials from stockpiles that they uniformly blend to meet the desired gradation.
They use the Shilstone program for blending. They also stress that materials need to be removed from stockpiles properly and good handling procedures need to be followed at the HMA plant as well.

Bokinskie indicated that the county went into this project with the attitude that they wanted to have a durable road built. Superpave materials and mixtures, supplemented by good quality management practices, helped the county achieve that goal.

This project is described in more detail in the Winter 1996-97 issue of Asphalt Magazine. *

\section{Technician Joins MESE Staff}

\author{
he NCSC is proud to announce that Stephen P. \\ Bowman has joined the staff as the main laboratory \\ technician. He replaces Travis Lovvorn, who \\ 1 resigned in August. Bowman has over 13 years of
} experience as an electronics technician working with the Indiana

Department of

Transportation, Division of

Research, where he gained an appreciation of asphalt pavements, research and sophisticated testing equipment. Bowman's electronics background is already being put to good

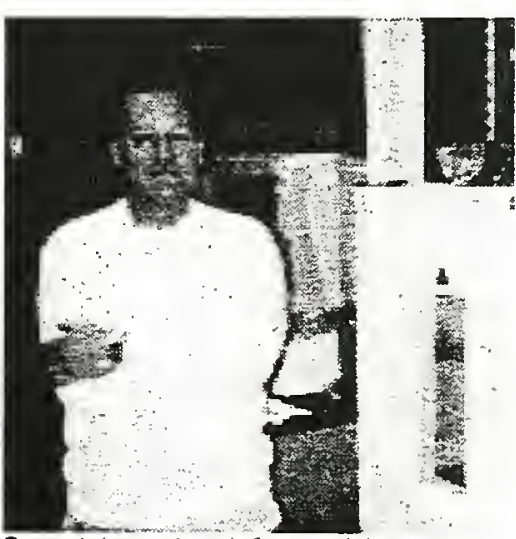

Steve takes a break from training on the Indirect Tensile Tester. use as he learns the operation and complexities of the Superpave Shear Tester (SST) and Indirect Tensile Tester (IDT).

As the lab technician, Bowman will be responsible for operation of the SST and IDT, overseeing the lab, supervising graduate and undergraduate students working in the lab, and assisting with training. He is already riding hard on the contractors as installation of the air handling system nears completion-no small job! * 


\section{Superpave Mixture Expert Task Group Meets}

Tos he Superpave Mixture Expert Task Group met March 3-4, 1997, in San Antonio, Texas. John Bukowski (FHWA) started off the meeting by providing an update on the status of Superpave-related research ongoing through the National Cooperative Highway Research Program (NCHRP). See the sidebar to the right for more details regarding the NCHRP research. Listed below are some other key points discussed during the meeting.

- The AASHTO provisional standards will be published again in June or July and will include many of the ETG recommended revisions.

- The test procedure for fine aggregate angularity (AASHTO TP33) bas been accepted as a full standard and will be published with the other standards in June 1997. AMRL is now set up to begin including this test method in its lab inspections and to conduct a round robin experiment to establish precision and bias statements for the test.

- There is a need to clarify the process involved in establishing or revising a standard through AASHTO. Just because the ETG recommends a change, that does not make it official. Recommendations must be forwarded to AASHTO and approved by a balloted vote of the responsible committee.

- Several groups are working on documenting what Superpave projects have been or will be placed around the country. Asphalt Institute field engineers are visiting their states to document 1996 Superpave projects. FHWA will be trying to keep track of projects in 1997 and beyond. The Lead State team has developed a form to use for trouble-shooting problems on Superpave projects in 1997 and beyond. These efforts are being coordinated and do not duplicate each other.

- The Florida DOT will be increasing lift thicknesses for coarse mixtures to four times the nominal maximum aggregate size and increasing the density requirement to 94 percent of Rice, among other things, in response to observations of permeable mixtures on some of their Superpave projects. They attribute the permeability to compaction difficulties during construction.

- In Florida and elsewhere, there have been reports of an interim temperature range where densification cannot be achieved. This range varies depending on the mixture and binder used, but is generally reported to be in the range of about $240-260^{\circ} \mathrm{F}$ down to $190-200^{\circ} \mathrm{F}$. With mixtures exhibiting this behavior, it may be most efficient to try to get compaction at high temperatures right behind the screed, then lay off the mix for a while, removing roller marks only when the mix has cooled sufficiently.

- The group reviewed research into fine aggregate angularity ongoing or planned in the North Central Region, by Couch, Inc. and Heritage Research Group, and by CSR/American Aggregates.

- The ongoing FHWA comparison of 18 mixtures compacted in both the Pine and Troxler gyratory compactors shows that there is no statistical difference between the two devices. If you have problems correlating with another lab, check for uniformity of lab procectures and for proper calibration of equipment.

- A protocol for evaluating new Superpave gyratories is being reviewed by the ETG and should soon be ready for use.

Eventually this will likely be an annex to TP4, the AASHTO standard for preparing specimens in the gyratory.

- The group discussed the possibility of eliminating or revising the lower control point on the $2.36 \mathrm{~mm}$ sieve. The ETG recommendations will go to the Asphalt Technical Working Group (TWG) in May for further action.

- The Mix ETG is finalizing interim guidelines on the use of Reclaimed Asphalt Pavement (RAP) to present to the Asphalt TWG in May. These recommendations would be available for use until derinitive research under NCHRP 9-12 is complete in 1999.

- Ruggedness testing is underway at the Superpave Centers and associated labs. Urethane samples are being used as a confidence check on the shear testing.

- The $\mathrm{N}_{\text {design }}$ experiment is being reviewed for a possible shift in focus to relating the engineering properties of lab compacted mixtures to permanent deformation resistance required under various traffic levels.

continued on page six

\section{HGHRP Superpave Research Hews}

9-7. Field Procedures and Equipment to Implement the SHRP Asphalt Specification

Contractor: BRE

Principal Investigator: Ron Cominsky

Draft Final Report Completed

9-8 Designing SMA Mixtures

Contractor: Auburn University

Principal Investigator: Ray Brown

Looking at binder/modifier/fiber mastic through

Superpave binder tests

9-9 Refinement of the Superpave Gyratory

Compaction Procedure

Contractor: Auburn University

Principal Investigator: Ray Brown

Second phase to begin soon

9-10 Snperpave Protocols for Modified Asphalt Binders Contractor: Asphalt Institute

Principal Investigator: Hussain Bahia

First interim report submitted; second phase to begin soon

9-11 Verification Test Procedures for QC/QA

Programs for HMA Construction Using

Contractor QC Testing

Agency selection in process

9-12 Incorporation of Reclaimed Asphalt Pavement

(RAP) in the Superpave System

Agency selection in process

9-13 Evalnation of Moisture Sensitivity Tests

Agency selection in process 


\section{Superpave Binder ETG Meets in San Antonio}

he SHRP Binder ETG met in San Antonio, Texas, February 26 and 27, 1997. Major discussion items included the binder test equipment: Bending Beam Rheometer (BBR), Pressured Aging Vessel (PAV), Direct Tension Tester (DTT) and Dynamic Shear Rheometer (DSR). The group also discussed binder specifications, the low temperature algorithm, NCHRP 9-10 Superpave Protocols for Modified Binders, fatigue criteria, low temperature properties, aging, and rolling flasks in place of rolling thin film bottles.

Dave Anderson, of the North East Superpave Center, summarized the findings concerning the ATS versus Cannon BBR, concluding that using 50 percent load as the zero time reference is not achievable with existing hardware; that 50 percent load does not ensure that the rise line is acceptable and will have to be done on averaged or filtered data; that zero loading should be the time the signal is sent to the pressure regulator and rise time is checked at 0.5 seconds; and that the margin of error ( 0.5 seconds) can have significant effect on the eight second loading time. No decisions have been made and the topic will be discussed at the next ETG meeting.

Studies on AC30 and PG70-22 after PAV aging at 100 and $110^{\circ} \mathrm{C}$ indicate that aging of asphalts was significantly affected if the temperature was out of specification for 90 minutes and 120 minutes. Prior results combined with the above indicate that 60 minutes is a reasonable limit for total time that the vessel is not at temperature versus the present 10 minutes. A specification allowing for this is currently being written.

The second round of Direct Tension equipment has developed repeatability problems. Work is continuing.

Anderson reported that on the last DSR round robin, all outliers but one came from the same equipment, a recent additional DSR model.

LTPP has developed a new low temperature algorithm that compares favorably with several instrumented pavements throughout the country. High temperature is currently under review. Both high and low temperature criteria will be implemented simultaneously.

A Fatigue Task Group has started a study to develop a performance based specification for intermediate temperature load induced fatigue. Currently, it is planned to have all data compiled and results available for the next ETG meeting in June.

An update on NCHRP 9-10 regarding classification of modified binder was given. Research has been formulated to address testing of all binders including modified binders. The vision is to develop screening tests to rank binders as simple or complex, a complex binder being defined as a modified asphalt today as well as a binder with additives. Complex binders would be required to pass supplementary tests but the grading would still be based on existing Superpave parameters.

Gerry Huber, of Heritage Research, discussed air oxidized asphalts. Huber stated that the research by the Asphalt Institute showed air oxidized asphalts to be equal or better than neat asphalt of the same grade. Conclusions of studies of mixtures containing air oxidized, neat or polymer modified binders were presented that showed that oxidized asphalt mixtures have more desirable properties than unmodified asphalt mixes, that fatigue properties of oxidized asphalt mixtures were better than modified or neat asphalt mixtures, and that binder findings agree with Hussain Bahia's TRB 96 paper.

The next Binder ETG meeting is scheduled for June 4 and 5, 1997, in Kansas Ciry.

by David H. Andrewski

\section{HCSC Construction Status Updated}

7 he NCSC Mixture Branch is still waiting for the final connection of our air handling system, but with the beginning of nice spring weather, it is easier to take the lack of heat and air con1 ditioning! The final details should be completed within the next few weeks. The electrician, plumbers, insulators, sheet metal workers and others are essentially out of our way now and are working outside the building.

We are fully operational, except for the connection of our three fume hoods to the air handling system. Our SST and IDT are in use for the ruggedness and proficiency testing all five Superpave Centers are conducting. Now that work has progressed to the outside of the building, we have been able to clean and organize the lab. Feel free to stop in a visit if you are in the area; call us before hand so we can be sure someone is on hand to show you around. We are proud of the way things have come together.

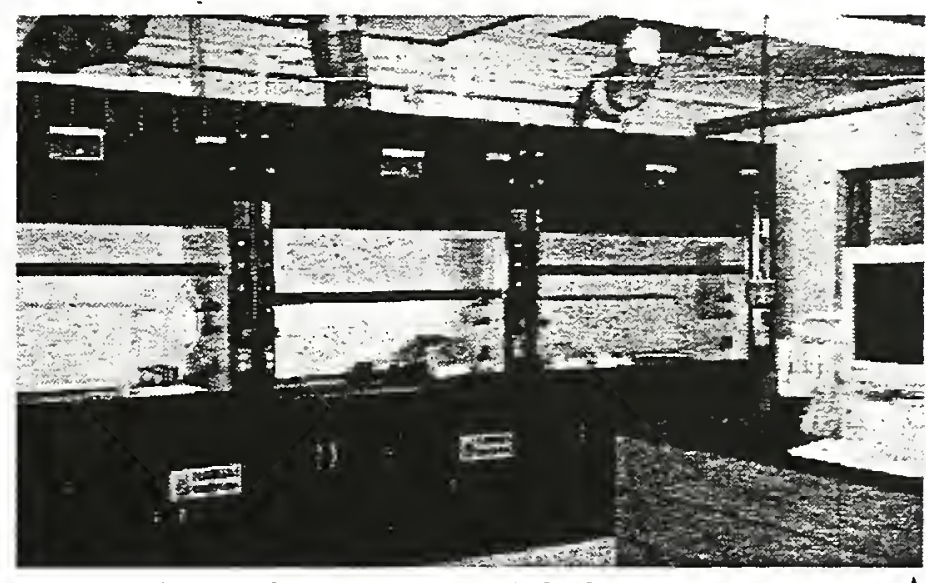

Three top of the line fume hoods are ready for Superpave testing.

$V$ The IDT, long since up and running, now has a lab space worthy of it!

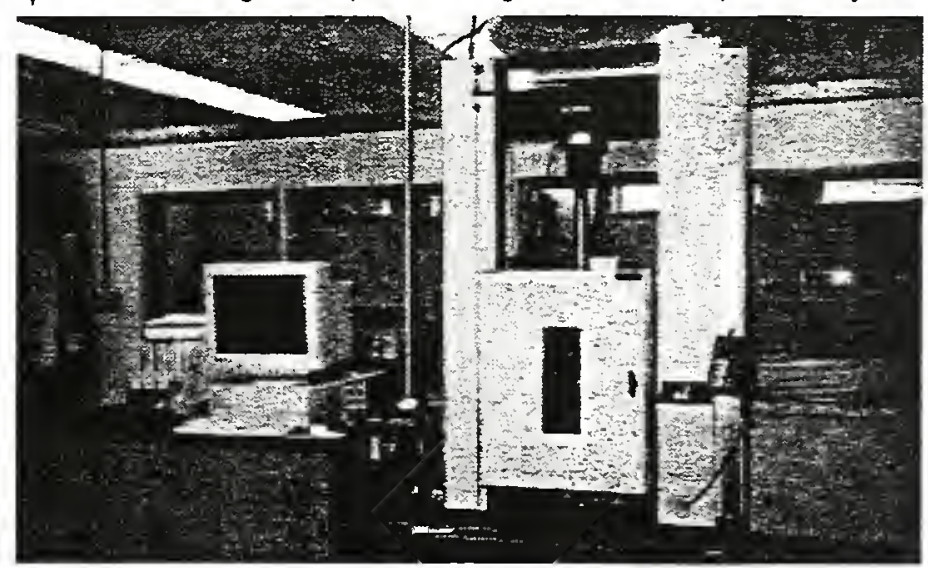




\section{Winter Conference Season Winds Down}

fter a few frenzied months of Winter paving conferences, workshops and training courses, things are slowing down as the paving season approaches. Representatives of the NCSC attended a few major conferences in the last few months, helping to spread the word about Superpave and what the Superpave Centers are all about. Highlights of two of these meetings follow.

\section{THE FUTURE OF ASPHALT MIX DESIGN}

The Asphalt Institute and Asphalt Pavement Association of Iowa (APAI), in cooperation with the Iowa DOT, presented The Future of Asphalt Mix Design, a workshop on Superpave, in Ames, Iowa, on January 7, 1997. The morning was spent discussing Superpave binder issues and the afternoon focused on mixtures.

Don Jordison (APAI) introduced the workshop by recounting some of the history of asphalt contracting in Iowa. The state largely ran the show prior to the implementation of quality management (QMA). Since then, contractors bave assumed more responsibility for mix designs and field control. What has gone before with QMA is a lead-in to Superpave. Bruce Matzke (FHWA) reviewed national initiatives in Superpave implementation, including FHWA efforts and the Lead State team. Matzke discussed a national assessment study which estimated a savings of over $\$ 2.8$ billion could result from the adoption of Superpave specifications.

Al Palmer (Asphalt Institute) then gave an overview of asphalt binder behavior and Superpave. Dan Wegman (Koch Materials) described the Superpave binder tests. The Superpave binder specification was outlined by Ray Hogrefe (Jebro). Hogrefe also summarized care and handling tips for Superpave binders. Some of the handling keys include:

- avoiding contamination;

- avoiding overheating during storage and properly handling material during shutdowns;

- providing agitation in tarks, if needed; and
- watching mixing and compaction temperatures.

Hogrefe stressed that QMA, the National Quality Initiative and other quality programs require each of us to hold up our end and to do our jobs conscientiously.

Rebecca McDaniel (NCSC) summarized how the NCSC can help states and industry as they implement Superpave through training, technology transfer, technical assistance and continued research and development work to meet the needs of the region. Jobn Heggen (lowa DOT) outlined the Iowa DOT impiementation plan, test and production tolerances, pay factors and testing frequencies. Heggen noted that production tolerances will be dropped after 1997 and testing tolerances are expected to decrease. He also mentioned that RAP will be allowed at up to at least 15 percent with no change in the binder grade.

In the afternoon, Palmer continued with a review of asphalt mix behavior and Superpave materials/aggregate selection. Dave Humphry (Martin-Marietta Aggregates) discussed aggregate processing for Superpave. He commented that although there are still lots of unanswered questions, they are not a major cause for concern; aggregate producers make aggregate that will meet the new specifications every day. Some changes may be required to achieve consistency and possibly to make cleaner aggregates. He advised that "the more you know your product, the better off you're going to be," and to work closely with the DOT and HMA producer. Palmer then reviewed the principles of the gyratory compactor.

John Hinrachsen (Iowa DOT) summarized the lowa implementation plan. Six Superpave projects will be constructed in 1997 by letting, 25 percent of primary and interstate projects will be Superpave in 1998 , increasing to 100 percent in 2000. City and county implementation will likely occur around 2002.

Hinrachsen cited four examples of excellent pavements that were placed in the 1980 's that would meet the Superpave gradation requirements, showing that this type of mix can be designed and built to last. He also reviewed the Superpave pro- jects placed in lowa by extra work order in 1995 and 1996.

Champ Narotam (lowa DOT) discussed national issues, including testing modified binders, $\mathrm{N}_{\text {design }}$ values, ramifications of the restricted zone, precision and bias on test protocols, RAP usage and more. He concluded that if we use Superpave as a system, we should have more durable asphalt pavements.

\section{PAIKY WINTER TRAINING SCHOOL}

The Plant Mix Asphalt Industry of Kentucky (PAIKY) held a training program covering all aspects of HMA production on February 3-5, 1997, in Louisville. Topics on the first two days included Kentucky DOT plans for training, metrication, QC/QA, specifications and more. Breakout sessions dealt with basic paving principles, asphalt plant operations, advanced paving and compaction, basic compaction principles, advanced job situations and analysis.

The final moming focused on Superpave, the future for HMA. Dean Blake (PAIKY) opened the session by stressing that knowledge is essential, and preparation and training are absolutely the key. Tom Harmon (FHWA) gave an overview of Superpave, summarizing similarities to and differences from past practices. He also outlined the parallel activities going on to implement and further refine Superpave by the FHWA, Expert Task Groups and Asphalt Technical Working Group, User-Producer Groups, Superpave Centers, Lead State Teams and others. Harmon warned that in the field, some Superpave mixnures are proving to be harder to compact than conventional mixtures; the old rules of thumb relating lift thickness to aggregate size may no longer work.

Roger Hayner (Ashland Oil) reported on Superpave from the perspective of a liquid asphalt producer. He noted many changes related to Superpave implementation, including increased testing time; costs for training, equipment, software, certification, etc.; and the need for increased tankage at refinery and plant 


\section{What Are The Lead States Up To?}

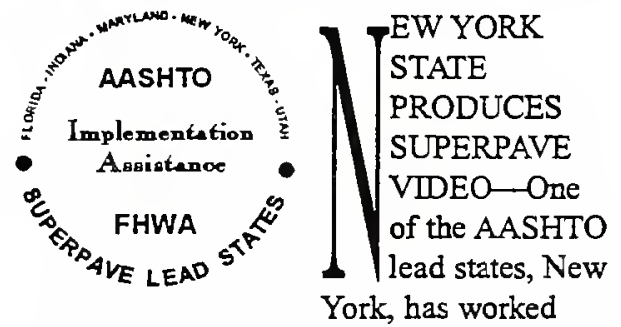

with the Federal Highway Administration to produce an excellent video on Superpave implementation. The video, called Superpave: Tomorrow's Pavements Today, runs a little over nine minutes.

The tape outlines New York's aggressive Superpave implementation schedule and how industry is reacting to it. The main focus of the video is on interviews with various industry representatives, including aggregate and hot mix asphalt producers, who have worked on Superpave projects in the state. The industry people discuss the need for Superpave, changes required in their operations and costs, among other topics.

The NCSC can lend copies of the tape to interested parties or you may request a copy from the FHWA Research and Technology Report Center by faxing a written request to (301) 577-1421.

LEAD STATES SURVEY

TRAINING NEEDS-Mike Worischeck, of Staker Paving in Utah, developed a survey on training needs to which 39 states responded. Each response included an estimate of the number of people in industry and the DOT needing training in their state. The survey results estimate that over 1,000 people need binder training and nearly 4,000 need mix design and quality assurance training. A need was also indicated for other levels of training, including general overviews and programs for executives or management. When Superpave is more widely implemented at the city and county level, the training needs will increase significantly. The months of December through March were cited as the best for training programs.

The next step for the lead states in the area of training will be to provide feedback to the states and industry indicating what training is available where. The needed types of training are available from the Superpave Centers, the Asphalt Institute, the National Highway Institute, some Technology Transfer Centers, univer- sities, community colleges, etc. In this region, the NCSC is available to help put on customized training or assist other organizations with their training programs, in addition to the regularly scheduled NCSC courses.

\section{SAMPLE IMPLEMENTATION}

PLAN AVAILABLE-The New York State DOT has made available their implementation plan to serve as an example to help states that have not yet developed a plan develop a realistic one. This plan has been or will soon be provided to all states for their use. The plan is not being distributed throughout the North Central Region because the states in this region are ahead of the curve and have already developed their own strategies. If you are interested in getting a copy of the plan, please contact the NCSC.

OTHER WORK CONTINUES-The lead states will continue working on these activities and others, including establishing a forum on the World Wide Web, collecting information on past and future Superpave projects, assisting with implementation and field operations on request, and more. The next meeting of the group will be held in September.

\section{Your Superpave Genter: A Resource You Can Use}

The North Central Superpave Center is a resource you can take advantage of when you need information, training or 1 a speaker. Some recent examples may help show how we can help you as you work towards implementation of Superpave.

- The NCSC lent slides and videos and provided handouts for the Missouri DOT District 9 Flexible Pavement Quality Circle. This in-house training was designed to inform engineers and others in District 9 about what Superpave is.

- Technical Director Rebecca McDaniel and Steering Committee Chairman Laird Weishahn made individual presentations at industry meetings in Iowa, Kentucky and Minnesota within the last three months.

- The Technical Director helped provide Superpave Gyratory Compactor training to Ohio DOT and industry representatives in Columbus, $\mathrm{OH}$, in February. The training was organized by Flexible Pavements, Inc.

- We have answered numerous calls for information over the last several months. Information on fine aggregate angularity is most frequently requested by industry. States often are seeking a contact person for information on specific issues. Requests for information are typically handled through a telephone response or by faxing the pertinent information back. If we do not have the answer, we will find it or put you in contact with someone who may have the answer.

Most requests for information are free. Costs for training or presentations vary depending on location and extent; please call to discuss your needs with us.

We have added two new phone lines to handle the increasing number of calls and prevent busy signals when faxing. Please give us a call the next time you need information. :

\section{DOT Begins Binder Round Robins}

$T^{\text {he Wisconsin DOT has initiated a }}$ series of Binder round robins. Sixteen laboratories participated in the first 1 optional study at the end of 1996; 24 labs participated in the first study in 1997. Results indicate coefficients of of variation (COV's) on the different tests ranging from 3.3 percent up to as high as 30.5 percent. (Results on the mass loss test had a COV of 66.6 percent, largely because one lab showed a mass gain.) Resuits are tabulated below.

\begin{tabular}{|c|c|c|}
\hline TEST & $\begin{array}{l}96-1 \\
\text { COV }\end{array}$ & $\begin{array}{l}97-1 \\
\text { COV }\end{array}$ \\
\hline Rotational Viscosity & $6.7 \%$ & $6.9 \%$ \\
\hline DSR-Original & $6.5 \%$ & $6.1 \%$ \\
\hline DSR-RTFO & $10.2 \%$ & $8.6 \%$ \\
\hline DSR-PAV & $30.5 \%$ & $8.5 \%$ \\
\hline Mass Loss & $66.6 \%$ & $30.9 \%$ \\
\hline BBR-Stiffness & $6.7 \%$ & $8.0 \%$ \\
\hline BBR-m value & $3.3 \%$ & $4.2 \%$ \\
\hline
\end{tabular}




\section{Superpave Training Season Busy, Successful}

$T_{\text {ingen }}^{\text {he }}$ he North Central Superpave Center's first full season of training was busy and successful. Between February 1996 and April 1997, NCSC staff organized and presented nine

1 Superpave Volumetric Mix Design courses to 121 students. In February 1997, the staff presented two Superpave Binder courses to 24 students. The courses took place at the NCSC's Binder Branch in Indianapolis, Indiana, except for one specialized course sponsored by and presented at Lake Land College in Mattoon, Ilinois. There was enough demand for the courses that two additional courses were added to accommodate those on the waiting lists.

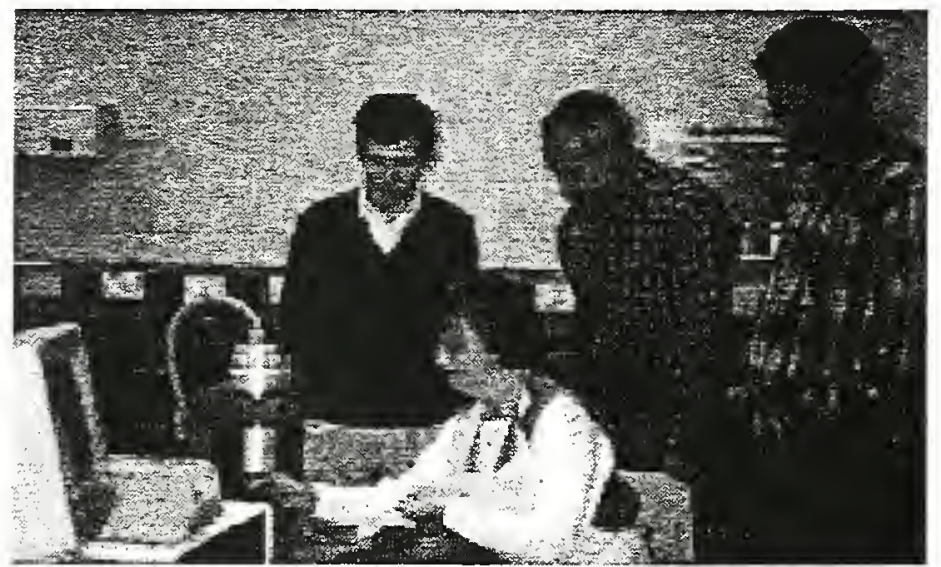

Rhonda Richardson of the NCSC's Binder Branch demonstrates the Dynamic Shear Rheometer.

A

Responses to the courses were overwhelmingly positive, and any constructive suggestions from the students were implemented in subsequent course sessions. The students reported that the courses were relevant to their jobs, and that the hands-on focus (including workshop sessions) of the courses was particularly useful.

After a hectic winter, our formal training season is coming to a close to make way for the summer construction season, but please continue to call us with your training requests. If there is sufficient interest, we will organize a mid-summer training session. As always, the NCSC staff is also available to teach Superpave courses or specialized training of your choice at our facility or yours. If you are interested in Superpave training, please contact Julie Smith at the Superpave Center (765) 4632317.

\section{NeSe Staff Continues Outreach Efforts}

\footnotetext{
$T^{n}$ keeping with our primary goal of communication, the NCSC Steering Committee has requested that we provide a list of recent speaking and training engagements in each issue Lof the newsletter to document our outreach efforts. A list of the presentations that were made during the first quarter of 1997 follows:
}

- Superpave: The Future of Asphalt Mix Design Presented by the Asphalt Institute and the Asphalt Paving Association of Iowa in cooperation with the Iowa DOT, Ames, Iowa, January 7, 1997.

- Superpave Volumetric Mix Design Course Sponsored by Lake Land College, Mattoon, IL, January 20-22, 1997.

- Plantmix Asphalt Industry of Kentucky (PAIKY) Winter Training School

Sponsored by the Plantmix Asphalt Industry of Kentucky, Louisville, KY, February 3-5, 1997.

- Superpave Gyratory Compactor Training Organized by Flexible Pavements, Inc., Columbus, $\mathrm{OH}$, February 19, 1997.

- Superpave Mixture Expert Task Gronp Meeting Sponsored by FHWA, San Antonio, TX, March 3-5, 1997.

- 41st Annual Contractors' Workshop Sponsored by the Minnesota Aspbalt Pavement Association, Minnesota DOT and FHWA, Brooklyn Park, MN, March 4-5, 1997.

\section{- 1997 Purdoe Road School}

Sponsored by Purdue University and Indiana DOT, West Lafayette, IN, March 25-27, 1997.

Please keep us in mind when planning your next conference or looking for training! If you would like a representative of the NCSC to participate in your next conference, please contact Julie Smith at (765) 463-2317.

\section{Mixture ET6 continued from page two}

- A final draft of FHWA recommendations on solid additive use in Superpave was distributed for comment. This will be forthcoming as the official FHWA response, not an ETG recommendation.

- The ETG discussed the role of rut testers as proof tests for Superpave and will be preparing a cautionary note regarding their use. Rut testers can be related to field performance, but oniy on a limited basis and must be correlated to local conditions. The results are susceptible to changes in traffic speed, temperature, loading, tire types and axle configurations.

- Matt Witczak reported on work at the University of Maryland using a simple creep test to analyze whether a mix would exhibit plastic deformation (tertiary creep). The method holds promise, but more work is needed.

- A Windows version of the Mix Design software will be available in another month or so.

The next meeting of the group will be September 22-23, 1997 in

Colorado Springs, Colorado. *

\section{Round Bobins continued from page five}

Wisconsin will require the participation of labs in round robin experiments to retain certification under the state's "Certification Method of Acceptance Program for Asphalt Cements." Five round robins are scheduled for 1997 . 


\section{Hew Telephone Numbers for the NGSE}

7 he area code for the NCSC Mixture Branch in West Lafayette, IN, has changed from 317 to 765 . Also, due to increasing phone usage, we have added a dedicated fax line. Mixture Branch employees (Rebecca McDaniel, Julie Smith and Steve Bowman) can now be reached by phone at (765) 463-2317 and by fax at (765) 497-2402. All of our new publications will reflect this change; for your convenience, we have printed new file cards that you can cut out and keep at your desk. Please note that the Binder Branch in Indianapolis was not subject to the area code change. Binder Branch employees (David Andrewski and Rhonda Richardson) can still be reached by phone at (317) 232-5280 and by fax at (317) 356-9351. We appreciate your patience as we work to serve you better!

\section{Superpave in the News}

$S^{20}$ everal recent articles have highlighted Superpave. "Superpave: Performing as Predicted," in the November 1996 issue of Better Roads, summarizes Wisconsin's experiences with Superpave to date. The article, written by Steve Shober, Chief Pavement and Research Engineer with the Wisconsin DOT, details the performance of three SPS-9 sections built in Wisconsin in 1992. Each section contains conventional Wisconsin, SMA and Superpave mixtures. The Superpave and SMA mixtures are performing comparably and both are out-performing the conventional Wisconsin mix, based on preliminary data. Shober previously reported these results at ConExpo in Las Vegas in March
1996. If you have not seen the full text of the article, you may want to check it out.

\section{PAIKY continued from page four}

Hayner concluded that not using Superpave is simply not an option for the future of the industry. Dwight Walker (a recent convert from the KYDOT to the Asphalt Institute) spoke on the Institute's belief that Superpave is the way to go. Adjusting to Superpave will take time and training, but will help achieve a better product.

Allen Myers (KYDOT), Scott Quire (H.G. Mays Corporation), and Bobby Upchurch (Mago Construction Company) summarized two Superpave jobs in Kentucky. Andrea Clifford (KYDOT) reviewed an experimental project using different modification techniques to meet a PG70-22. A final report on the experiment is due in the spring.

Following a presentation on the activities and goals of the NCSC by McDaniel, Clifford and Myers outlined Kentucky's future plans for Superpave. Kentucky has established binder warrants to provide for the consistent application of PG grades across the state based mainly on traffic volume and truck percentage. Myers noted that Kentucky is purchasing four Superpave gyratories for four districts and will have jobs in those districts in 1997. Eventually, each district will be equipped with a gyratory and the number of projects will increase as the DOT emphasizes training and promotes familiarity with the system throughout the state. Clifford concluded that the "proper use of performance graded binders will lead to better roads for the state of Kentucky." *

\section{Jan Olek \\ Director}

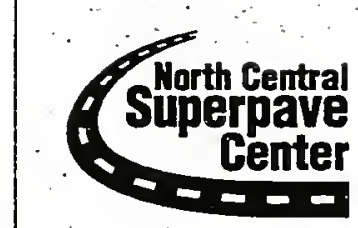

\section{Julie Smith \\ Communications}

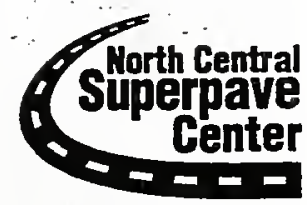

Mixture Branch 1205 Montgomery Street P. O. Box 2382 West Lafayette, IN 47906 phone (765) 463-2317 fax (765) 497-2402 o-mail julie@ecn.purdue.edu

\section{Rebecca McDaniel \\ Technical Director}

1284 Civil Engineering Building

West Lafayette, IN 47907-1284

phone (765) 494-5015

fax (765) 496-1364

o-mail olek@ecn.purdue.edu

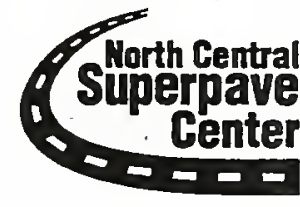

Mixture Branch 1205 Montgomery Street

P. O. Box 2382

West Lafayette, IN 47906

phone (765) 463-2317

$\operatorname{tax}(765)$ 497-2402

e-mail rsmcdani@ecn.purdue.edu

\section{Steve Bowman Laboratory Technician}

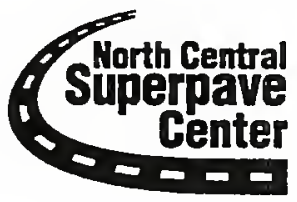

Mixture Branch 1205 Montgomery Street P. O. Box 2382

West Lafayette, IN 47906

phone (765) 463-2317

fax (765) 497-2402 


\section{Improvements Planned for the NCSE WWW Site}

(

ommunication was set forth by the NCSC Steering

Committee as the central goal and function of the center. To that end, the NCSC staff have produced this quarterly newsletter, organized and taught several training courses, and attended and/or presented at numerous other regional and national functions. Because the Internet is such a popular means of communication, we started a WWW site as well.

Unfortunately, as you avid Internet fans may already know, our site has been a bit neglected. Due to difficulties getting the NCSC hooked up to the Internet, we have been unable to spend much time updating and improving our WWW site. By early April, however, Julie Smith (our communications specialist; also responsible for The Centerline) will have access to the Internet, and she has big plans for our site! First on the agenda will be ensuring that all our printed publications (newsletter editions, training brochures and other items) are accessible and readable; second will be organizing the WWW site to make it easy to get around and find items of interest; third will be linking the NCSC site to other sites related to Superpave; fourth will be improving the appearance of the site; and fifth will be setting up discussion groups. In short, we hope to have a terrific site by the end of May. Look for us at the following address:

[http://ce.ecn.purdne.edu/ spave/]

We welcome any comments and suggestions you may have that will help us improve our site and make it useful to you. Please direct your input to Julie Smith at (765) 463-2317 or fax (765) 497-2402.

\section{Spring 1997 Calendar}

May 12-16 National Transportation Week

Check with your DOT or FHWA Division

Office for activities.

May 12-16 Superpave Binder Course

National Asphalt Training Center

Lexington, $K Y$

Call Mandee Hall for details:

(606) 288-4964

May 13-14 Snperpave: The Road to the Fnture

The University of Texas at Austin

Austin, $T X$

Call UT's Continuing Engineering Studies:

(512) 471-3506

May-August Introduction to Snperpave

The South Central Superpave Center

One day seminars at various locations in

Texas, New Mexico and Oklahoma

Call UT's Continuing Engineering Studies:

(512) 471-3506

June 1997 Snperpave Center Coordination Meeting

University Park, $P A \quad$ INUTATION ONYY

August 10-14 Eighth International Conference on

Asphalt Pavements

University of Washington

Seattle, WA

Call Engineering Professional Programs:

(206) $543-5539$ 



\section{Constructability Experiences Shared}

II

ith the construction season in full swing, reports are circulating regarding constructability issues with some Superpave mixtures. Compaction problems were noted on a few projects last year, but as the pace of implementation increases, the reports are becoming more frequent. The problems are noted on only a very small percentage of projects-say fewer than 10 percent.

The reported problems seem to consist of one or two scenarios: problems with the mix crawling or scooting under the roller and/or problems compacting in an intermediate temperature range. These problems differ from classical mix tenderness where you cannot roll the mix when it is very hot (i.e., right behind the paver). With the so-called "tender" Superpave mixes, the mix compacts well at high temperatures. There is an intermediate range of temperatures, typically reported as being between about 88 to $116^{\circ} \mathrm{C}\left(190\right.$ to $\left.240^{\circ} \mathrm{F}\right)$, where rolling either does not increase the density or can actually. decrease the density.

Jim Campbell (Missouri DOT) reported compaction problems on one of their Superpave projects last year. This year, a high profile job underway on I-70 in Kansas City is not exhibiting any tenderness or compaction problems. Missouri DOT has three other Superpave projects scheduled for this year.

There has been a

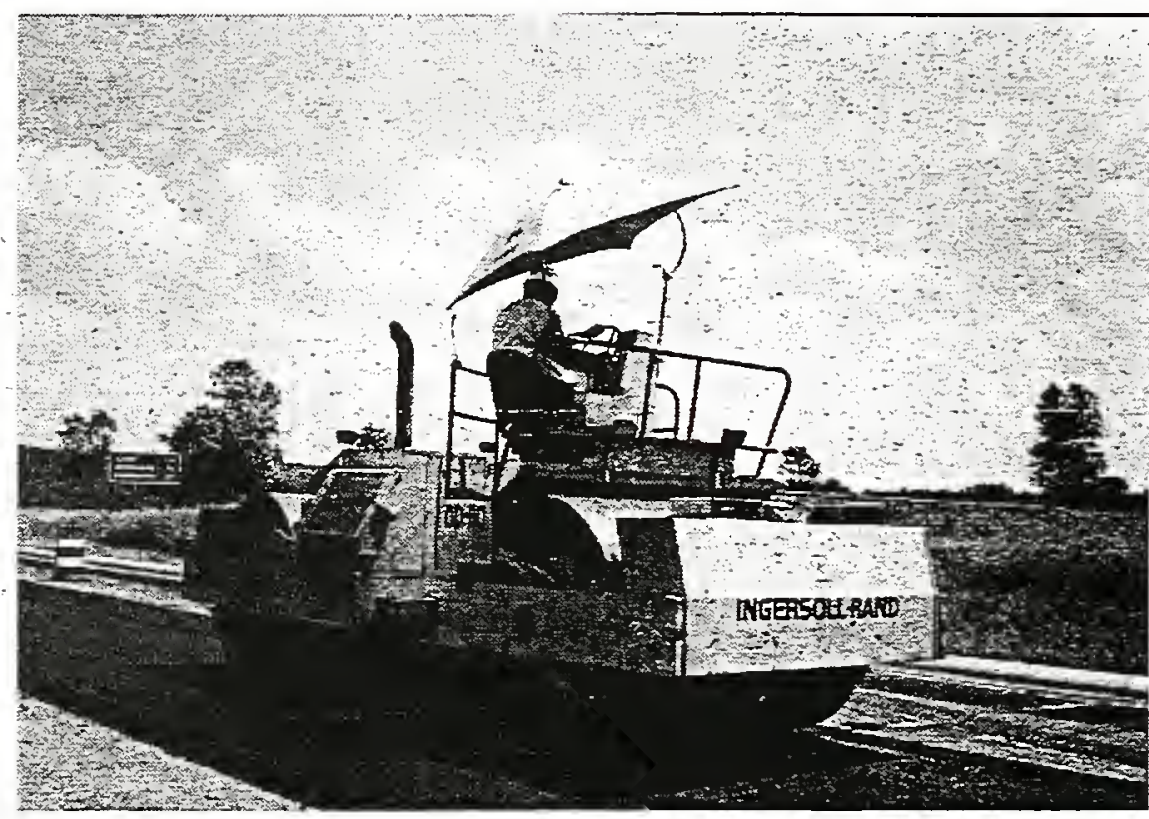

Roller pattems may need to be adjusted to get adequate compaction. New "rules of thumb" may also be needed. $\left(200^{\circ} \mathrm{F}\right)$. Dukatz also reported seeing check cracking under the breakdown roller at temperatures below $138^{\circ} \mathrm{C}\left(280^{\circ} \mathrm{F}\right)$. In both cases, according to Dukatz, the contractors were able to avoid the problems by adjusting their rolling patterns depending on the mat temperatures.

Compaction problems on a project in Pennsylvania were reportedly corrected when the gradation on the $2.36 \mathrm{~mm}$ sieve, which had been running about 3 percent low, was brought up to the job mix formula. Frank Fee (Koch Materials) reported on this project, among others, at the National Asphalt User-Producer Group meeting (see article on page three).

At this point, we are not sure what is causing these difficulties. We are implementing a new system and will need to learn to adjust our operations to achieve a quality product. Old techniques that worked with Marshall mixes were developed through trial and error and may not be appropriate for all Superpave mixes. If you experience difficulties, please share that information with the Superpave Center by phone, fax or e-mail. We need to collect. information from many projects with a range of materials and conditions to learn what is causing these problems and how to correct them. We would aiso like to hear what is working well for you. The recommended course of action if you are on a job that is experiencing a problem flurry of comments about compaction difficulties on the Internet recently. Gerry Huber (Heritage Research Group) reported that they had seen this problem on one $19 \mathrm{~mm}$ mix out of about $25 \mathrm{mix}$ designs. The plant-mixed material conformed to the mix design and everything looked good at the plant. On the road, however, the mix "crawled all over and density was not achieved." They changed the gradation to bring it closer to the maximum density line, achieved adequate voids and VMA, and were able to achieve compaction on the road.

Ervin Dukatz (Vulcan Materials) reported seeing the same type of mix "tenderness." The temperatures he noted in Texas were somewhat higher than typically reported. Dukatz reported that optimum compaction was achieved between 135 and $140^{\circ} \mathrm{C}$ ( 275 and $285^{\circ} \mathrm{F}$ ). Compaction could resume once the mat cooled to below $121^{\circ} \mathrm{C}\left(250^{\circ} \mathrm{F}\right)$. Finish rolling could begin around $93^{\circ} \mathrm{C}$ in achieving density is to keep the rollers up close to the paver. Get as much compaction as you can while the mixture is hot, then lay off until the mat has cooled somewhat. The finish roller can then take the marks out. FHWA suggests that a heavier initial breakdown roller may be needed right behind the paver.

Suggestions for what may cause these types of compaction problems include the thicker binder film thickness on the aggregates typical of Superpave mixtures. Jim Warren (Asphalt Contractors Association of Florida) theorizes that the increased film thickness may lower the temperature at which the binder stops acting like a lubricant and begins acting like a glue.

Florida has started using thicker lifts in the field and have found they have more success achieving density and reducing the permeability of the mat: They have also had some success with using a rubber-tired roller in that temperature zone. 


\section{National Asphalt User-Producer Group Meets}

T he National Asphalt User-Producer Group, chaired by Frank Fee (Koch Materials), held a meeting in conjunction with the Asphalt Technical Working Group in June. The group reviewed Superpave binder and mixture implementation region by region. While there is a wide variation in the number of Superpave projects being let in different states, most states are at least trying the system. Common issues raised by the different regions included training and certification, quality control/quality assurance issues and uniformity of implementation (or the lack thereof).

Most states are implementing or planning to implement the Superpave binder specifications. Adoption of these specifications region-wide was driven in the Northeast by the suppliers who said they were not going to implement piecemeal. A few states around the country were reported to be using "Superpave,+ , i.e., using the standard Superpave binder specifications then adding an elastic recovery or other tensile test. The release of revised binder specifications incorporating a new and improved direct tension test may make the added tensile tests obsolete.

On the mixture side, there is a wider variety in the level of implementation. The West Coast, for example, tends to be "testing the waters" with the exception of Arizona. Overall, nearly all of the states are trying at least one project this year, with even more planned for 1998.

Ramon Bonaquist (FHWA) reported on the Accelerated Testing Expert Task Group and its activities. Accelerated Testing includes full-scale test roads like MinnRoad and Westrack; full scale load tests like Purdue's Accelerated Pavement Testing Facility, the ALF, the Heavy Vehicle Simulator (HVS) and Texas's MIS; and laboratory tests like loaded wheel testers and the Superpave Shear Tester. The Accelerated Testing ETG has recommended that accelerated testing can play a role in Superpave validation using linked laboratory and full-scale testing. Lab tests give the flexibility to test many factors and perform replicate testing which can lead to stronger statistical relationships. Full-scale tests are more limited due to the time and resources needed. Many of the lab tests, however, exhibit a high level of variability in results which leads to poor discrimination between good and bad mixtures or changes in material properties. The FHWA has, in fact, cautioned against relying on wheel testers pending verification of their results.

The group participated in a long discussion of training and certification issues. The National Asphalt User-Producer Group suggested that the five Superpave Centers work together with the FHWA to develop minimum training and certification standards. (For related activities, see the article below.)

\section{States Move Toward Reciprocity}

$S^{2}$ tates from around the country took a major step toward reciprocity of technical certification at the Regional Training and Certification Conference in Kansas City in June. Teams of trainers were formed to develop the requirements for training and certification programs in four major areas including asphalt, concrete, aggregates and soil, and to reach consensus on core subjects and test methods that should be covered in each course.

The Asphait Development Team agreed to establish three levels of training and certification focusing on Superpave mix designs and procedures. They include the following:
Hot Mix Asphalt (HMA) Technician: required for per- sons developing, checking or approving mix designs. No prior work or education experience with bituminous materials is required prior to enrollment in the instruc- tional period and taking the written examination. Proficiency will be demonstrated by a satisfactory score over a specified group of tests.

\section{Hot Mix Asphalt (HMA) Laboratory Technician: required for persons performing laboratory testing of HMA materials and making decisions regarding the acceptability of HMA mixes. Upon completion of train- ing, the trainee should understand the theory of HMA design and should be capable of making adjustments to the plant for the purpose of meeting specifications crite- ria. No prior work or education experience with bitumi- nous materials is required prior to enrollment in the instructional period and proficiency testing. Proficiency will be demonstrated on a specified group of test proce- dures.}

\section{Asphalt Binder Technician: required for individuals working in a laboratory testing liquid asphaltic materials and making decirions with regard to the ability of the materials to meet the material specifications. This would include, but not be limited to Superpave binder specifica- tions.}

More work is needed to further define the course content assemble training materials, develop certification tests and establish certification policies (such as duration of certification period, decertification procedures, etc.). This topic was discussed further at the Superpave Center Coordination Meeting in June; the Centers agreed to work together on the issues of training and certification.

The ultimate goal is to have states agree, on a regional basis, to accept these core training courses and certifications. Courses will likely range from three to five days in length. If needed, a state could then require one-half to one day of additional training on tests and procedures specific to that state.

Other subject areas discussed by Development Teams included Aggregates (Aggregate Field Technician, Level I and Level II), Concrete (Field Strength Tester, Production Control Technician and Concrete Field Inspector) and Soils (Soils Field Inspector and Soils Lab Inspector).

This effort began with Regions 5 and 7 meeting four years ago and has expanded to include states from far beyond those regions. Over 15 states were represented at this year's meeting. With the establishment of the Training Development Teams and their work in reaching consensus, the group has moved beyond the talking phase and started to put together training and certification programs that can be used by all. 


\section{Superpave and Aggregate Properties: Where Did They Come From?}

$\int$ uperpave includes some old rules of thumb and some new and mechanistic based features. A key aspect to the performance of any asphalt mixture is the selection of the materials that will be used in the mixture.

Aggregate characteristics are a major factor in the performance of an asphalt mixture. In the Superpave mixture design system, many aggregate criteria were included to assure the performance of the asphalt mix. These criteria included coarse aggregate angularity, uncompacted voids in fine aggregate, flat and elongated particles, clay content and gradation parameters. The recommended limits set by SHRP on these aggregate criteria were established based on years of previous research.

Numerous studies have indicated that mixture stability increases with an increase in the amount of crushed particles to replace rounded gravels and sands. In 1992, Brown and Cross presented a paper at AAPT titled "A National Study of Rutting in Hot Mix Asphailt

Pavements." The paper reported on an extensive study of material properties and their relationship to pavement performance. The study included 42 pavements in 14 different states. Rut depth measurements, mix design information, construction records, traffic counts and pavement samples were collected for each of the pavements. The study included a detailed laboratory testing program on samples of the asphalt mixture obtained from rutted and good performing pavements. The data were analyzed to determine material and mixture properties and identify procedures that are necessary for the construction of rut resistant pavements. Of all the materials and mixture properties studied, coarse and fine aggregate angularity correlated best to pavement rutting.

The first indications from Westrack verify many of the Superpave aggregate recommendations. For the coarse graded mixes-those below the maximum density line-the coarse aggregate angularity was well below the recommended $100 \% / 100 \%$ ( 1 face/ 2 faces crushed).
The actual coarse aggregate angularity of the stone was $86 / 73$, well below the recommended values for a pavement carrying the equivalent of 50 to 75 millions ESAL's. These coarse mixes have not performed well and several sections have been removed. The sand in fine graded mixesthose above the maximum density linehad uncompacted void contents (FAA) of 45 percent. This is the value recommended by Superpave for a 50 to 75 million ESAL roadway. These mixes, though not expected to perform at such a high rate of loading, have performed better than expected. The fine mixes have out-performed the coarse mixes which did not meet the Superpave requirements.

The SHRP researchers did not do work on aggregates. However, they did build on the studies and recommendations of many researchers who came before them and the expertise of many practitioners. From this previous research, they developed rules and recommendations for the Superpave system. There will always be exceptions to any rule and the same is true of Superpave. However, before we change or completely throw out these rules to satisfy a few exceptions, we should take a close look at what we are doing and thoroughly evaluate the situation.

Excerpted from an article by John D'Angelo, FHWA

\section{NGaUPG Updates Future Plans}

$t$ its semi-annual meeting in Madison,
Wisconsin, in April, the North Central
Asphalt User-Producer Group -
(NCAUPG) Management Committee met to discuss the vision for the future of the organization and to revise the Action Plan. The group was realigned into two sub-groups instead of three. The North Sub-Group will consist of Iowa, Manitoba, Nebraska, North Dakota, Saskatchewan and South Dakota. The South Sub-Group will include Illinois, Indiana, Kansas, Missouri and Ohio.

In the full meeting of the organization, updates were provided on national implementation, AASHTO activities, the new low temperature algorithm and the Superpave Center. A panel of agency engineers and contractors discussed their experiences using Superpave in the field. John Hinrichsen (Iowa DOT), outlined their computer modeling program for designing Superpave mixnures. The minutes of the meeting will be available on our website or by calling us.

The second regional Technicians' Workshop immediately preceded the NCAUPG Meeting. Technicians and others in attendance shared their experiences and concerns with the binder testing equipment and procedures and the Superpave Gyratory Compactor. The main items identified as needing attention are: 1) timely communication of new information across the full spectrum of participants in Superpave implementation; 2) information on equipment calibration and preventative maintenance; 3) training and certification including refresher training; 4) training on construction use of modified binders; and 5) research on definition of modified binders and testing, a modifier separation test, variation in the $\mathrm{m}$ value at low temperatures, and the use of $\mathrm{N}_{\text {des }}$ and $\mathrm{N}_{\max }$ and field production verification.

The original goals of the NCAUPG are and continue to be:

1.Form local User-Producer Groups (UPG's)

2. Conduct executive level implementation seminars for local UPG's

3. Implement SHRP asphait binder and mixture specifications

4. Adopt and implement uniform volumetric mix design principles and verification of those designs, including field verification of mixes

The NCAUPG accomplished during its first five years:

1. Supplier Certification program developed

2. Non-Superpave test procedures standardized (Superpave uses many test methods that are currently used; the continued on page five 


\section{Westrack Analysis Continues}

II

estrack continues to attract the attention of everyone interested in Superpave. Initially designed as an experiment to study the effects of construction variability on pavement performance, the track is being interpreted by many as a test of Superpave. Numerous test sections were constructed at the facility with varying gradations, air void levels and asphalt contents. Some of the sections were designed according to Superpave specifications; most were not. Because some of these parameters were deliberately out of the range of typical specifications, failures were expected.

What has caught some people by surprise is the mode and timing of some of the failures. Many sections are showing both fatigue and rutting distresses. Typically, these two distress types do not occur together. According to Jon Epps (University of Nevada-Reno), early rutting at the site was predominantly related to the air void content at the time of construction, then the asphalt content became more critical. The severe rutting noted early on some sections was confined to the top 50 to $75 \mathrm{~mm}$. The first evidence of fatigue cracking was in the coarse mix with high air voids and low asphalt content. Some other mixes then began showing fatigue also. Air void content seems to be the critical factor.

Work continues at Westrack to verify the properties of the actual mixtures placed and analyze the distresses. Post-construction testing, for example, suggests that the crushed gravel coarse aggregate does not meet the Superpave coarse aggregate angularity requirements. The binder contents were also 0.3 to 1.7 percent higher than designed for all mixtures. The sections which reached failure conditions have been removed and replaced. The experiment will continue with accelerated loading and monitoring of these new sections, plus the remaining old sections. (For more insight on Westrack, see the article on page seven).

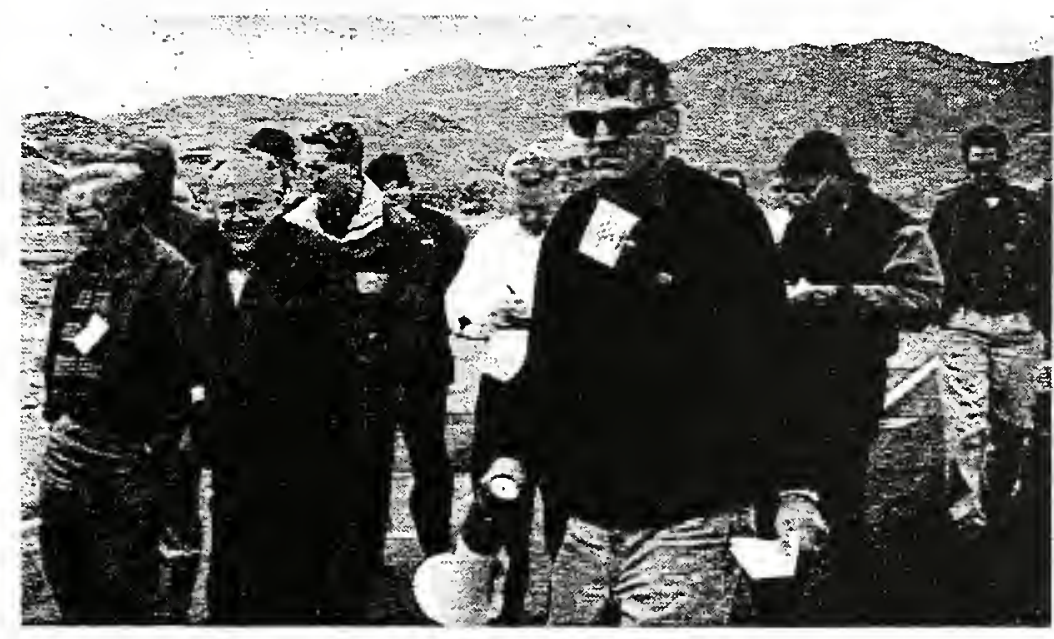

Jon Epps leads another tour of the Westrack facility. Members of the Transportation Research Board Committee on General Asphalt Problems walked the oval to see the results firsthand.

Some sections at Westrack are showing rutting, some fatigue cracking and some both distresses. Most sections were designed not to meet the Superpave specifications so that they would fail.

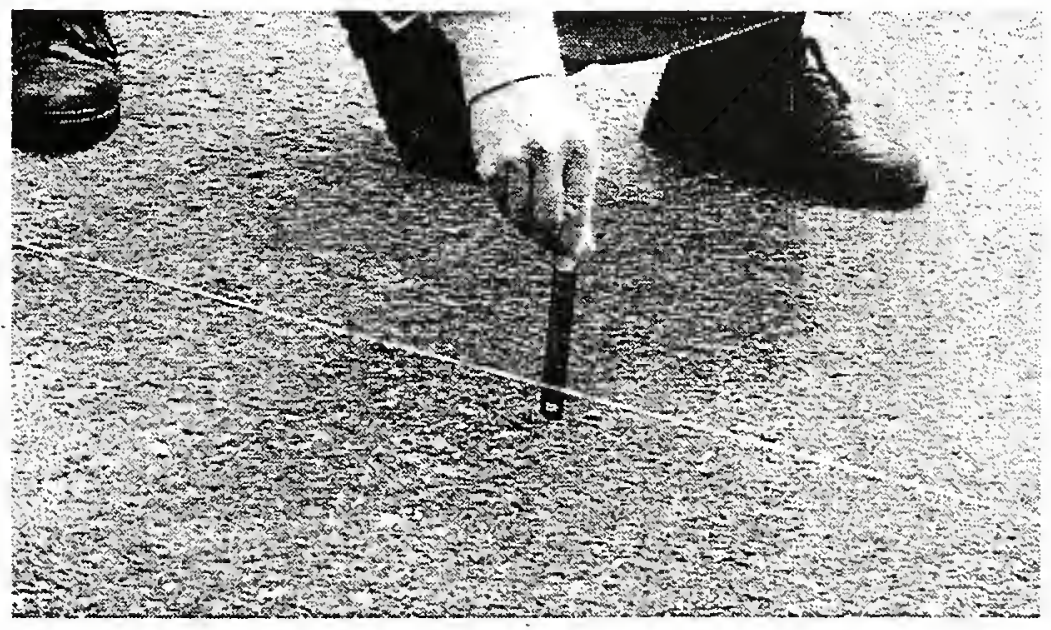

NCAUPG continued from page four need existed to improve methods or reduce test options to reduce test variability)

3. Asphalt binder specification adopted by most states

4. Networks have been set up to share experience

A revised set of activities to accomplish the goals developed at the Management Committee meeting in Madison on April 2, 1997, are as follows:

1. Assign tasks and timelines for completion

2. Monitor the performance of control versus Superpave pavements

- Define performance criteria

- Track performance; need to look at pavement performance over time

- Use PMS to help

- Synthesize information on how various pavement test sections perform

3. Uniform application of a mix design system

- Binder

- Mixture

- Project specific design data

- Feedback

4. Review, evaluate and refine a quality control/quality assurance procedure

- Identify QC/QA criteria

- Use and document standard test method, equipment and criteria

- Train and certify technicians

- Develop and implement a QC/QA specification

- Administrative procedures are specific to each agency

- Uniformity and consistency are paramount on technical aspects

5. Identify and collect problems encountered during the implementation of Superpave

- Problem hot-line for solutions

- SP center website $\star$ 


\section{Asphalt Technical Working Group Reviews Progress}

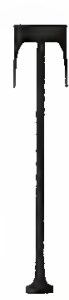
he Asphalt Technical Working Group (TWG) reviewed the status of Superpave implementation, research and other issues at a recent meeting in Woods Hole, Massachusetts. The Asphalt TWG serves as a forum to discuss and lend leadership in the implementation of Superpave technology. The TWG includes representatives of FHWA, state DOT's, industry, universities and Superpave Centers, the Federal Aviation Administration, U.S. Army Corps of Engineers and the Transportation Association of Canada.

Chairman Don Steinke (FHWA) asked the members and guests to consider and define the focus and future role of the TWG. By consensus, the group agreed that their future efforts should be directed toward developing a strategic plan for the group, encouraging technical training and certification, addressing and providing guidance on constructability issues, fostering needed research and development work, and facilitating improved communication.

Gary Henderson (Superpave Technology Delivery Team) reviewed the status of binder and mixture implementation, which he indicated are on track, and reviewed the progress on the Models Contract. Phase I findings from the Models Contract indicate that the existing models provide an excellent modular framework for the analysis of pavement performance, but.do have some significant shortcomings and theoretical inconsistencies, especially regarding load-related distresses. The Models Expert Task Group (ETG) decided the FHWA should pursue development of fundamental pavement performance models, but that the emphasis of the current contract should be shifted to accurately characterizing asphalt materials and developing a strength test. The materials characterization techniques developed under the existing contract will form the framework for the fundamental models to be developed under future contracts. The refined models, then, will not be available until after the year 2000 .

Wayne Brule (New York DOT) presented information from a Superpave Lead State Team survey on implementation.

Responses from 48 states indicate that 45 states have or will let a total of over 316 Superpave projects nationwide in 1997. The binder specifications will be implemented by at least 43 states by 1999 and the mix design procedures will be implemented by at least 41 states by 2000 . The complete summary of the survey results is available on our website or by calling the NCSC.

The TWG discussed the need for uniformity of implementation and approved the following recommendation:

The Approved Supplier Certification Plan as outlined in AASHTO PP26 is intended to promote uniformity and consistency in the certification and acceptance of asphalt binders. The Superpave Technical Working Group strongly encourages the DOT's and producers, through their regional User-Producer Groups, to develop a regional plan for certification and acceptance of asphalt binders. The use of regional plans will help reduce the costs, duplication of effort and confusion in the industry. The TWG strongly encourages the whole industry to work together on all issues related to the design and construction of asphalt pavements through their respective regional UserProducer Groups.

Other topics discussed by the group include Binder and Mixture ETG activities, the TRB SHRP Implementation committee, the Accelerated Pavement Testing ETG, Superpave training, the Superpave Centers, construction experiences and issues, follow-up research in the North Central region and through the National Cooperative Highway Research Program (NCHRP), Westrack (see article on page five) and the Asphalt Institute's planned 1998 Superpave Conference.

\section{NCSE Offers On-Site Training}

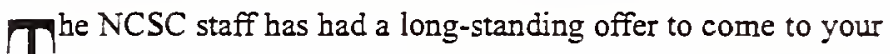
site to do training. Our most recent road trip for training was to Toledo, Ohio. Toltest, Inc., a private firm furnishing engi1 neering environmental geotechnical and testing services in Indiana, Michigan, Ohio and Pennsylvania, arranged for the NCSC to provide Superpave binder training to several of their lab technicians, engineering and management staff.

A brief lecture overview of Superpave and the binder specifications and tests, was followed by a lab session. Rhonda Richardson (NCSC Binder Branch Lab Manager) worked with Toltest Manager Curt Roupe and his staff through each of the binder test procedures using the firm's own equipment.

According to Roupe, the NCSC training "provided a very practical and technical approach for our staff...we have already seen positive results from the NCSC training."

If you would like to receive customized and/or on-site training, please contact the NCSC for more information. A schedule of regular three-day Binder and Mix Design courses to be offered at the NCSC over the winter will be available by the end of August 1997.

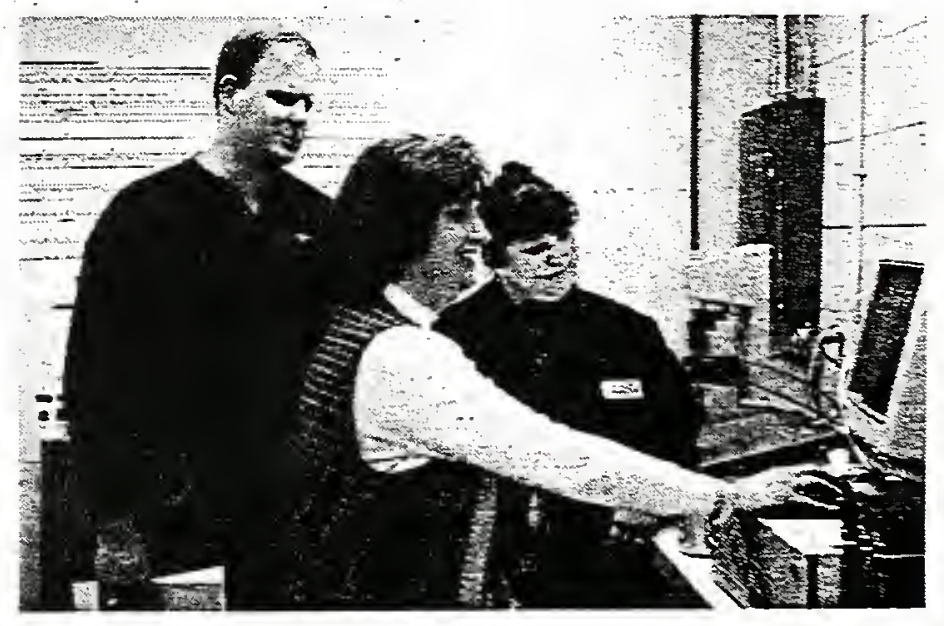

Rhonda Richardson, NCSC Binder Branch Lab Manager, provides on-site binder training to Evan Schumann and Lisa Kitchen in the Toltest Superpave binder testing lab. 


\section{Texas Hosts Superpave Symposium}

T. om Kennedy (University of TexasAustin) opened the symposium "Superpave-The Road to the Future," held in Austir, Texas, in May. Bobbie Templeton (Texas DOT) stressed that Superpave must be implemented as a system without adulteration and that AASHTO passed a resolution to this effect. Harold Mullen (Texas Hot Mix Asphalt Pavement Association) spoke favorably of the Superpave process but noted that much training is required. Byron Lord (FHWA) noted that there is a projected 20 percent growth in truck weight and miles driven, that the number of trucks increase at the rate of 500,000 per year, and that Superpave and partnership are keys to keeping the network intact.

William Tyler (Arkansas State Highway Department) related Arkansas's experience of a large project that was planned to be half Superpave and half the state's normal mix. As construction continued, the state decided to switch entirely. to Superpave. Dave Andrewski (Indiana DOT) and Ron Terrel (Milestone Contractors) then presented their experiences with Supeipave. Ervin Dukatz (Vulcan Materials) followed by relating the aggregate suppliers' experience. Dukatz stressed that the operator must know the deposit and treat it right, that the loader operator is very important, and that test results are only as good as the sample collected for the test. Dukatz closed with this advice: mine with a plan, match crushers to type of materials and desired shape, sample and test stockpiles correctly, and train your employees.

Don Siler (Marathon Oil Company) started the third session off by conveying the constraints of the suppliers. His talk included comments on how crude constraints affect the production and supply of binder and the differences between terminals and refineries and how to test at each. April Swanson (Amoco Oil) cautioned that sampling errors are a concern and that in this time of implementation, exchange samples should be run. Swanson also noted that the Asphalt Institute is preparing specific procedures for each manufacturer of each piece of liquid testing equipment. Gerry Huber (Heritage Research Group) discussed numerous supplier issues including the number of grades; the number of tanks; certification; testing variability; and costs of testing equipment, training and manufacturing equipment.

Harold Von Quintus (Brent Rauhut Engineering) reviewed the Superpave performance models work to date to kick off Session 4. His review included the models, and the problems and errors associated with models contract. He went on to describe Phase II that would accurately characterize and identify a strength test. The revised models will not be available until 2005. Brian Killingsworth (Brent Rauhut Engineering) then gave a presentation on NCHRP 9-7, Field QC/QA.

Recommendations include establishing QC limits based on production variance; using the Superpave Gyratory Compactor for $\mathrm{QC}$; basing plant QC on the estimated $\mathrm{G}_{\mathrm{mb}}$; and using a field shear device for validating mix and design adjustments.

John D'Angelo (FHWA) gave an update and the meaning of what is happening at Westrack. D'Angelo stated that the coarse mixes placed were higher on binder content than designed, leading to poorer performance than expected. The coarse mixes are being replaced with new coarse designs.

Hussain Bahia (University of Wisconsin-Madison) described the work going on in NCHRP 9-10, Characterization of Modified Binders. Bahia stated that work indicates that not all modified binders can be graded using SHRP tests. Some modified binders are rheologically complex and cannot be graded using the current specification.

In Session 5, Tom Kennedy presented guidelines for the design of Superpave mixes containing RAP. In summary, he stated that Superpave does not prohibit the use of RAP, but that the following guidelines should be respected when designing RAP mixes:
1) RAP particle size should be less than the maximum size of aggregate;

2) RAP stockpiles should be covered;

3) the specific gravity of virgin binder can be used for the RAP and virgin blend; and

4) the effective specific gravity of RAP can be used for VMA calculations.

D'Angelo gave an update on the Superpave binder test equipment. D'Angelo stated that a new temperature algorithm has been developed. Future plans call for a new low temperature specification combining the BBR and DTT. The BBR will be used to determine low temperature fatigue response and the DTT to measure low temperature cracking.

Huber gave a brief history and update of the Superpave Gyratory Compactor and $\mathrm{N}_{\text {design }}$ experiment. Huber mentioned that in addition to the two original Superpave gyratory compactors, seven new models are coming out and will be evaluated with a procedure developed by the Superpave Centers.

The symposium concluded with a tour of the South Central Superpave Center.

by David H. Andrewski, Indiana DOT

\section{NGSC Steering Committee Meets}

$A$ brief meeting of the North Central Superpave Center Steering Committee followed the NCAUPG meeting. The committee voted to add a representative of the Asphalt Institute to the Steering Committee. The Institute's President, $E d$ Miller, has since named Al Palmer, District Engineer, as their representative.

In other action, the Steering Committee gave approval to a plan to improve the communication function of the NCSC by adding a staff person to focus on communication through the newsletter, website and timely newsbriefs. The plan also includes computer and communications equipment upgrades. Industry support will be sought to fund these improvements. Updates on the Center's 


\section{Thinking of Buying a Compactor?}

f you are thinking about buying a new Superpave Gyratory Compactor, there are now many brands on the market. How do you choose which one to purchase? Will you get Ithe same results that the State or other lab gets? This dilemma is facing many contractors and others today.

The Superpave Centers and the Asphalt Mixture Expert Task Group have developed an evaluation procedure that should help to resolve these questions. Under the procedure, the new gyratory models are compared to one or both of the original workhorses (full sized Pine and Troxler models). Mixes with different properties are compacted in each gyratory and the properties of the resulting specimens are compared. Results of this testing, which is done by the Superpave Centers, are returned to the manufacturer. The Superpave Centers and the FHWA will not be developing "approved lists" of compactors.

If you are considering the purchase of a new gyratory compactor, ask the vendor if the equipment has been evaluated and ask to see the test results. Favorable results should let you buy with confidence.

\section{HESE Post-Doc Joh Opportunity}

The North Central Superpave Center is currently locking for a qualified post-doctoral candidate to work on research projects dealing with use of Reclaimed Asphalt 1 Pavement (RAP) in Superpave mixtures. Preferred candidates should have a background in asphalt materials and Superpave technology. The position will be available August 1, 1997, and will last between 12 and 18 months.

If you are interested in this position, please send your resume to Julie Smith at the NCSC.

\section{Calendar}

Jul 27-30 1997 Annual LTAP Conference

University of Minnesota

Duluth, Minnesota

Call Catherine Ploetz for details:

(612) 626-2259

Aug 10-14 8th International Conference on Asphalt Pavements: Design, Construction and Performance University of Washington Engineering Professional Programs Seattle, Washington

Call for details: (206) 543-5539

Sep 4-5 SHRP Lead State Conference St. Louis, Missouri

Sep 22-23 Mixture Expert Task Group Colorado Springs, Colorado

Oct 29-31 5th Annual U. S. Hot Mix Asphalt Conference and Superpave Workshop National Asphalt Pavement Association Phoenix, Arizona

Call for details: (800) HOT-MIXX

\section{8}

Apr 21-23 Superpave: Today and Tomorrow Asphalt Institute

St. Louis, Missouri

Call Mandee Hall for details:

(606) 288-4964
North Central 1205 Montgomery Street Supernave P. 0. Box 2382

West Lafayette, IN 47906 phone (765) 463-2317 fax (765) $497-2402$
Non-Profit Organization U. S. Postage

PAID

Purdue University 
Is Superpave Working in Indiana? 3

Binder ETG Meets

Aggregate Training Standards

NCSC 1997/8 Training Schedule

NCSC Lands NCHRP Contract
Lead State Teams Review Goals

5

NCSC Reviews $2^{\text {nd }}$ Year Operations 6

Superpave Experiences Recounted 7

AASHTO Issues New Standards 7

U. S. Hot Mix Conference

\section{What is Happening at WesTrack?}

II esTrack, FHWA's hot-mix asphalt performance
related specification test facility in Nevada, passed
another significant milestone in mid-April of
1997-the track has been trafficked for one full
year. The effects of accelerated loading are
already beginning to show on the pavement. The
application of more than 2.7 million ESAIs, from April 1996 to April 1997, has resulted in rutting in almost every test section and severe fatigue cracking has occurred in several other sections. This distress has required the removal of ten sections. A new mix design was developed for the replacement sections. The new mix designs were to fill-in the experimental cells not completed to date.

The new mixes have a coarse graded Superpave gradation made from quarried stone. The mix met all Superpave requirements for aggregate properties and volumetrics. Sections were placed as in the original sections with low, optimum and high asphait contents, and low, medium and high in-place air voids. Quality control testing was conducted behind the paver during construction; the data indicate the mixes had the required volumetric properties and reasonable gradation and asphalt content. The binder was checked and met Superpave requirements. Most of these new sections exhibited some deformation within two days of traflicking. There is something about these coarse graded mixes that needs to be more fully understood.

Coarse graded mixes, similar to the mix placed at WesTrack, have been placed on many pavements around the country. These mixes have performed well. From Baltimore to St. Louis to Phoenix, these mixes have been placed on pavements with high traffic and hot climates and have not had the failures we see at WesTrack. There are many questions about what has happened with the new sections placed at WesTrack

The FHWA understands the need to quickly address the questions that have emanated from the performance at WesTrack. To promptly address the questions, the FHWA is pulling together an independent team of experts to evaluate the new test sections. The team will look into each aspect of the design and construction of the new test sections to determine what might be the cause of the early distress. A report will be produced to put forward the findings of the team to the industry.

We will continue to work on answering the many questions on the performance of Superpave. There will be more refinements and corrections as we gain experience. Several sections at WesTrack have not performed as expected. Similar mixes are performing in the real world under real conditions. Only by continuing to build pavements and evaluate their performance will we improve our ability to design and build
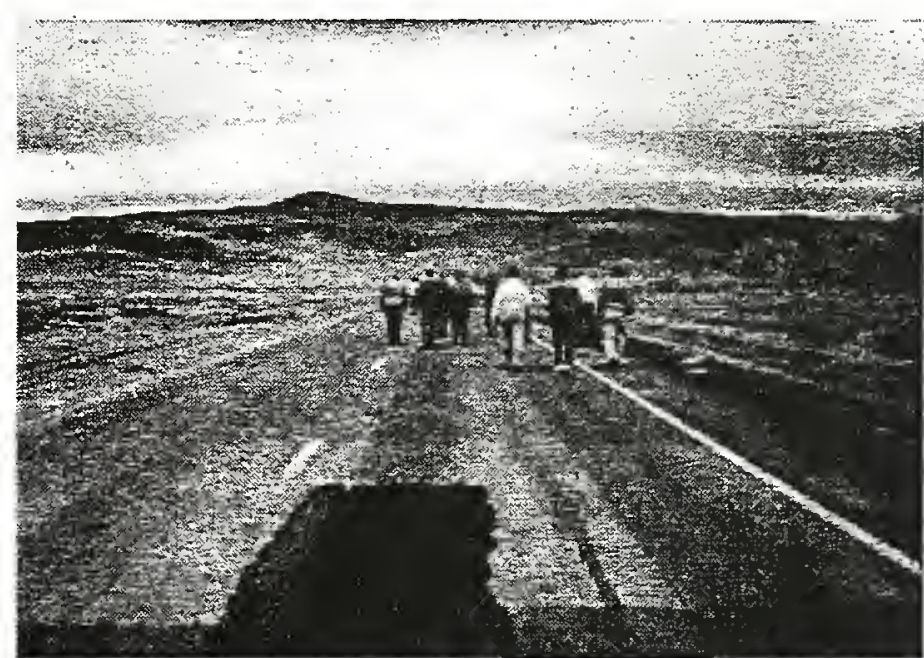

An independent review team walked the track at WesTrack, as did this earlier group, surveying the failed portions of the track. asphalt pavements for the $21^{\text {st }}$ century.

For more information, please contact Terry Mitchell at (703) 285-2434, e-mail [terry.mitchell@fhwa-dotgov]; or John D'Angelo at (202) 366-0121, e-mail [john.d'angelo@fhwa.dot.gov].

Note: The independent team evaluating the new sections at Wes Track just issued the preliminary report on their findings, identifying many factors that may have had a minor impact on construction. The team indicated that the major cause for the early rutting is "a combination of a course-graded mixture with high optimum asphalt content ( 5.7 percent) and a low binder stiffness (PG 64-22)." The final report, expected in December 1997, will include a summary of the data and recommendations to prevent similar problems. A preliminary report is available on our website or by calling the NCSC. 


\section{NGAUPG Fall Meeting Plans Announced}

he Fall meeting of the North Central Asphalt User-Producer Group will be held October 22-23, 1997, at the Hilton In near the Kansas City airport (formerly the DoubleTree and site of the Spring 1996 meeting). The meeting will begin at 1 p.m. on the $22^{\text {nd }}$ and end at 12 p.m. on the $23^{\text {rd }}$. The meeting of the full user-producer group will be preceded by a 1 meeting of the Management Committee at 10 a.m. on the $22^{\text {nd }}$. The North Central Superpave Center Steering Committee Meeting will follow from 12:30 to 4 p.m. on the $23^{\text {rd }}$.

A block of rooms at the Hilton will be held until October 7, so please call early to make your reservations, (800) 525-6322.

The hotel is located on 112th Street, along I-29 at Exit \#12.

The proposed agenda for the NCAUPG meeting is as follows:

DAY ONE: Wednesday, October 22, 1 to 5 p.m.

National Research Plan for Highways and Superpave Update Donald Steinke, FHWA

AASHTO Update

Haleem Tahir, AASHTO

Binder Update

Rick Smutzer, Indiana DOT

Mixture Update

Wayne Murphy, Minnesota DOT
DAY TWO: Thursday, October 23, 8 a.m. to 12 p.m.

Goal I: Local Agency/Industry Groups

Don Jordison, Iowa Asphalt Paving Association

Goal II: Benefits/Criteria For Pavement Performance Rick Smutzer, Indiana DOT

Goal III: Review, Evaluate and Re-Define Superpave Rebecca McDaniel, North Central Superpave Center

Goal IV: Review, Evaluate and Refine QC/QA

- Identify Criteria for QC/QA John Volker, Wisconsin DOT

- Use and Document Standard Test Methods and Equipment John Volker, Wisconsin DOT

- Training and Certification Laird Weishahn, Nebraska DOR

- Plan for Development and Implementation of Uniform Quality Specifications Gerry Huber, Heritage Research Group

Goal V: Monitor Constructability Issues

Lloyd Bandy, Indiana Asphalt Pavement Association

Future Plans

David Holt, Minnesota Asphalt Pavement Association Adjourn

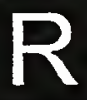

MAIl TO: Ken Archuleta

Federal Highway Administration

P. O. Box 419715

Kansas City, Missouri 64141

(816) 276-2732 phone • (816) 363-3347 fax

Please indicate which meeting(s) you will be attending. Make your check payable to NCAUPG.

NCAUPG Meeting

NCSC Steering Committee Meeting

Name

Companv

Address

City

Phone

$F a x$
$\$ 45$

$\$ 20$

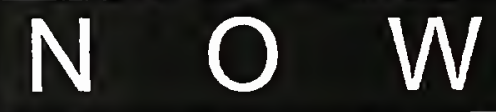

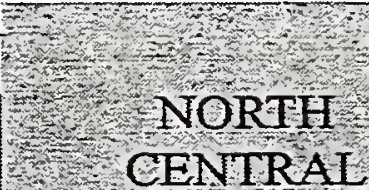

ASPHALT

USER

PRODUCER

GROUP

MEETING

October 22-23, 1997

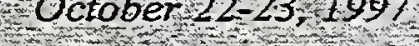

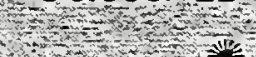

NCSC

STEERING

COMMIT TEE

MEETING

October 23, 7997

$7-1, y=$

Hiltón Inn

Kansas City, Missoin 


\section{Is Superpave Working in Indiana?}

Uperpave implementation is advancing in Indiana to the point where it will be utilized on all of the major projects on the State system. It will be required on all DOT and Local Public Assistance (LPA) QC/QA projects in 1998. PG Binders have been required on asphalt products and local public agency projects since January 1, 1997. Forty-five projects are in progress on the State system, including a few local agency projects. The Indiana projects contain 2,119,774 metric tons of hot mix asphalt.

There are two projects with designated traffic volumes of less than one million

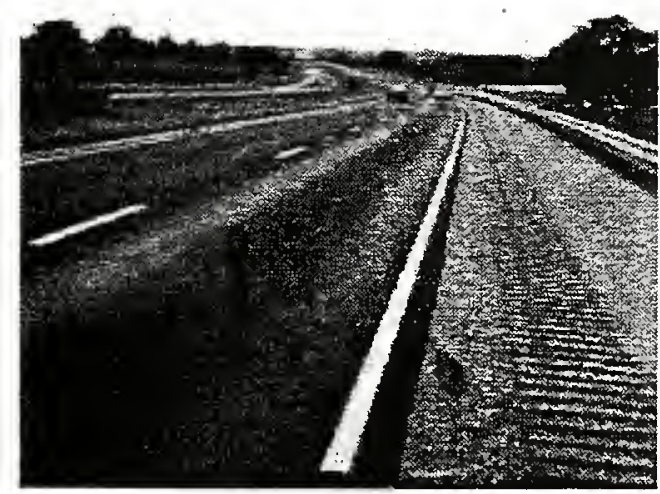

Flushing was observed on the driving lane throughout the mainline surface on one project in Indiana.

ESAIs, ten projects from one to three million ESALs, 16 projects from three to 10 million ESALs, eight projects from 10 to 30 million ESALs, seven projects from 30 to 100 million ESAIs, and one project over 100 million ESALs. PG Binder 64 22 is primarily used in mainline mixtures. Some mixtures use PG 58-28 and a few use PG 70-28. Shoulder mixes generally use $P G$ 58-28.

Construction of Superpave mixtures has been very satisfactory to date, although a few projects have experienced some tenderness and density problems. In addition, a few have experienced performance problems related to rutting and flushing.
Industry has met with the Department and identified the following common factors that may be contributing to the problems: high binder content in surface $9.5 \mathrm{~mm}$ mixtures; not using the actual specific gravity of the aggregates; moisture in the mixture; excessive 325 material; quality issues related to the fine aggregate (agg lime); use of an absorption test in conflict with curing period in PP 2; FAA requirements vs. low gyrations for three to 10 million ESAIs; design selection of the binder grade for mainline/shoulder, design and selection of ESALs for shoulder mixtures; and bag house fines.

Nine of the 45 projects were identified as experiencing rutting and flushing problems. Rutting is occurring on the shoulders on high volume interstates where traffic is maintained during re-construction operations. The existing design of the shoulders uses 500,000 ESAIs, but early distress is being attributed to the rate of application of the loadings during maintenance of traffic operations.

Shoulder design ESALs have been increased to $2,000,000$.

Flushing on eight projects has ranged from minor isolated "spots" in the mainline and/or shoulder mixtures to one catastrophic occurrence resulting in the removal and replacement of the driving lane surface course on I-74 west of Indianapolis.

The implementation of Superpave specifications has been very successful in Indiana. Field personnel and industry are pleased with the engineered mixture. The single I-74 project represented nearly 26,315 metric tons, or less than 1.5 percent of the total statewide mixture usage. The limited problems on the surface course appear to be related to the transition from Marshall to Superpave, likened to cook book mixtures compared to engineered mixtures. Superpave specifications have identified various shortcomings in the asphalt program that are not entirely related to Superpave. It is believed that the same problems in the mixtures (particularly flushing) were occurring under the Marshall design period, but the reasons were not fully apparent. Superpave has provided the mechanism to advance asphalt products in Indiana.

Superpave is working in Indiana. David H. Andrewski, Indiana DOT Victor (Lee) Gallivan, FHWA

\section{Binder ETG Meets, Focuses on Testing and Specification}

he Binder Expert Task Group discussed a number of testing and specification issues at their last meeting in June. A brief summary of those issues follows. Discussions continued on the comparison of Cannon and ATS Bending Beam Rheometers and other BBR testing issues. Several revisions to TP1, Standard Test Method for Determining the Flexural Creep Stiffness of Asphalt Binder Using the Bending Beam Rheometer (BBR), were proposed. These revisions would specify a 0.5 second loading time and require that the specific gravity of the bath fluid not exceed 1.10. Chuck Maggi, of Cannon Instruments, also discussed using a smaller radius for the support arms in the BBR to reduce testing variability. Four sets of new support arms were distributed for testing and comparison to the currently used, larger radius supports. Maggi also recommended use of a partial immersion type thermometer (ASTM 62C) calibrated to BBR test temperatures rather than a total immersion type thermometer, this will also reduce testing variability by placing tighter controls on the bath temperature. Dove Anderson, of Pennsylvania State University, presented a list of important factors relating to repeatability and reproducibility of BBR results. Gerry Reinke, of MTE Services, showed test results that indicate silicone BBR molds could be used if used properly. He also showed that variations in beam dimensions could also result when aluminum molds are used and, therefore, beam thickness should be measured and standardized regardless of mold type. Recommendations will be finalized at the next meeting of the group to be held in January 1998.

Vacuum degassing of PAV residue was also considered. A proposed degassing procedure was presented that would reduce the degassing time from three to four hours down to about 35 minutes for nonpolymer modified binders. Results of a study to optimize vacurum degassing conditions identified important factors to standardize for a vacuum degassing procedure.

Preliminary results of a study of factors affecting the horizontal direct tension continued on page seven 


\section{Aggregate Training Standards Developed}

Tn the last edition of this newsletter, we reported on the work to establish minimum training standards for asphalt binder and mixture technicians at the Region 5 and 7 Training and

Certification Workshop. This group has been working for four years to establish a basis for training uniformity and certification reciprocity among the states in this part of the country and possibly beyond. At the same conference, other training development teams worked on training requirements for aggregates, soils and concrete.

The requirements for aggregate training and qualification/certification are likely of interest to Superpave users, since aggregates constitute 95 percent or so of the mixture. In addition, qualification as an Aggregate Field Tester and Aggregate Laboratory Technician is proposed as a prerequisite for being certified as a Hot Mix Asphalt Technician.

Two categories of qualification/certification are proposed in the aggregates area. They are:

Aggregate Field Tester: required for persons at the construction site, at the aggregate quarry or pit, and at the asphaltic or portland cement concrete production facility and testing aggregate. The training will cover ten AASHTO or ASTM standard test methods.

Qualification at this level will require both a written and performance exam, which have yet to be developed. Aggregate Laboratory Technician: required for persons in the laboratory testing aggregates and making dectsions on quality or acceptability. Qualification as an Aggregate Field Inspector is required. This training will cover an additional 11 AASHTO and ASTM test methods. A written exam will be developed covering all 11 test methods. A performance exam will be developed covering eight of these tests.

Test methods specified for use under Superpave are included in both the aggregate and asphalt training programs.

Task groups from each of the four training development teams are meeting this Fall to continue the work that was initiated this Summer. The task groups viill begin the process of assembling and/or developing instructional materials for the proposed courses. The goal is to have training programs ready for use in the 1998/9 training season.

\section{HGSC Announces Winter 1997/8 Superpave Training Schedule}

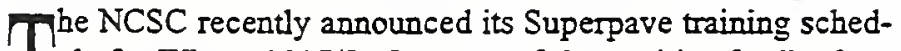
ule for Winter 1997/8. Because of the positive feedback we have received in response to last year's training efforts, the 1 Superpave Binder and Superpave Volumetric Mix Design courses will be offered again this year in the same format.

The Superpave Binder Course is designed to provide classroom overviews of the binder specification and test methods followed by hands-on laboratory work with all of the binder test procedures except direct tension. The course is based on materials developed by the National Asphalt Training Center. This three-
}

day course is primarily for binder lab technicians who will be performing these tests on a routine basis.

The Superpave Mix Design Course offers a thorough presentation of the Superpave mix design system and include brief overviews of the binder specification and mix analysis. The majority of this three-day course focuses on the Superpave Gyratory Compactor (including hands-on work), mixture volumetrics and the mix design procedure. The course concludes with a workshop session on the calculations used in the mix design process.

The Winter 1997/8 training course schedule is as follows (additional courses may be added depending on demand):

\begin{tabular}{c} 
Superpave Mix Design \\
\hline October 27-29, 1997 \\
November 5-7, 1997 \\
December 15-17, 1997 \\
January 26-28, 1998 \\
February 11-13, 1998 \\
March 24-26, 1998
\end{tabular}

Superpave Binder

October 14-16, 1997

December 3-5, 1997

April 1-3, 1998

All of the binder courses will take place at the NCSC Binder Branch in Indianapolis, Indiana. The mix design courses will take place alternately at the Binder Branch (November 5-7, January 26-28 and March 24-26) and the Mixture Branch in West Lafayette, Indiana (October 27-29, December 15-17 and February 11-13).

The NCSC staff is also available to travel to your facility to provide group training. We can customize the above courses to suit your needs, or develop courses from your concepts. If your organization needs customized training or envisions courses other than those outlined here, please contact the NCSC to discuss your ideas. We would be happy to work with you to meet your needs.

Our new training brochure, complete with registration information, was recently distributed. If you are interested in our courses and did not receive a brochure, please contact Julie Smith at the NCSC.

\section{NGSC Lands HGHRP Contract}

he North Central Superpave Center was selected by the
National Cooperative Highway Research Program to conduct
a two-year research effort on NCHRP 9-12, Incorporation of
Reclaimed Asphalt Pavement in the Superpave System. The project is focused on developing clear and detailed guidelines for incorporating RAP in the Superpave mix design and field control procedures, developing a manual of laboratory and field testing procedures for technicians, generating an implementation plan for moving the research results into practice and a final report summarizing the project. The effects of RAP on both binder and mixture properties will be considered.

The Asphalt Institute is partnering with the NCSC on the project as a subcontractor. Hamid Soleymani will be joining Purdue and the NCSC in October as a post-doctoral fellow to work on the project. Soleymani is currently completing a $\mathrm{PhD}$. at the University of Saskatchewan where he is working on a project entitled Implementation of the PG Binder System for Asphalt Pavement Recycling with Dr. A. T. Bergan, University of

continued on page seven 


\section{HCSC Helps Spread the Word to Local Agencies}

$A \begin{aligned} & \text { s states implement Superpave and make changes in their stan- } \\ & \text { dard specifications, many, if not most, cities and counties will } \\ & \text { also need to make the change-over, since they rely on their } \\ & \text { respective state's specification book. The local agencies buy }\end{aligned}$ binder and aggregate from the same suppliers, who are making the switch to Superpave in increasing numbers. The local agencies also hire the same hot-mix contractors; many of these contractors are investing in Superpave gyratory compactors and need to use that equipment on many projects to justify the expense. Factoring in the local agencies greatly increases the number of people needing Superpave training and understanding.

A network exists to contact, educate and advise the local agencies. Each state has a designated Technology Transfer $\left(\mathrm{T}^{2}\right)$ or Local Technical Assistance Program (LTAP) center. These centers provide training; publications, software and videos; newsletters; and technical assistance to thousands of people across the country.

Rebecca McDaniel, NCSC Technical Director, was invited to address the LTAP Centers at their annual meeting in Duluth, Minnesota, in July. Total attendance at the conference exceeded 230 people. More than 70 people attended the concurrent session on Applied Technologies, which included presentations on Superpave and Cost Effective Pavement Preservation. Other sessions at the conference were devoted to strategic planning, intergovernmental partnerships, needs assessment, best practices, using the internet, adult learning, and more.

McDaniel outlined the need for Superpave training and the resources that are available to help meet those training needs. The $T^{2}$ Centers can draw upon their regional Superpave Centers, Federal Highway Administration and Asphalt Institute to get training assistance. McDaniel also discussed the National Highway Institute (NHI) Courses that are in the works. One of the three Superpave courses will focus directly on Superpave for Local Governments. Other courses are available through NHI, the Superpave Centers, NCAT, the Asphalt Institute and some local universities.

McDaniel also provided some suggestions on assessing training needs in their state and what sorts of questions to ask their state DOT about Superpave implementation on a state level. Results from the Lead State Team survey on implementation showed the overall status of implementation nationwide.

The LTAP Centers can help to provide information on Superpave to a vast audience that needs to hear what Superpave is, how they can use it and what changes its implementation will require. By working with the FHWA and the regional Superpave Centers, the ITAP centers can ensure that they are providing accurate and up-to-date information to their clients, the local agencies.

\section{Lead State Teams Review Goals}

A fter one year of activity, the AASHTO Lead State Teams met in St. Louis, the site of their initiation, to re-examine and update their goals and action plans. The seven teams met individually to review their progress, confirm the status of implementation, and revise or renew their goals as needed.
PAST PROGRESS-The Superpave Lead State Team reported progress has been made in determining the status of implementation of the Superpave technology through a survey compiled by the New York DOT. This survey shows that 28 states used the binder and mix specifications in awarding 95 Superpave projects in 1996. In 1997, at least 44 states awarded a total of over 326 projects. Nationwide, 47 states have formal Superpave implementation plans; all states in the North Central Region bave plans. The survey also asked about barriers to implementation and the assistance states needed to overcome those barriers. These responses were reviewed in establishing new goals for the team.

The Lead State Team has also provided information about technical contacts who can help to answer questions and share experiences. This listing of experts includes people from the DOTs, industry and academia. The list was published in this newsletter and is available at our website. Other Lead State activities included completing a survey on training needs, which shows that thousands of people need Superpave training of various types. One of the team's earliest actions was to provide an example implementation plan to guide states that have not yet developed a plan.

A new pamphlet was unveiled at the meeting which will serve as a guide to Superpave resources. This pamphlet will provide information on the Superpave Centers, FHWA Superpave Technology Delivery Team, the Lead States, training resources, expert task groups and more. The pamphlet is being printed now and will be widely distributed soon. The NCSC will arrange to make copies available to the North Central Region.

NEW GOALS-The Superpave Lead State Team developed a new set of five goals, replacing earlier ones that were essentially complete and revising/updating some others. The five goals are:

1. Develop and execute strategies to remove or diminish the real and perceived risks associated with Superpave implementation to states and industry. Achieving this goal will require maintaining and sharing an upcated list of Lead State Team technical experts and key contact people in partner states. The team will also encourage rapid communication between and among the FHWA, Lead State Team, and industry and state partners.

2. To enable uniform national implementation, we shall identify and disseminate the unchangeable elements of the Superpave system. A recent AASHTO Subcommittee on Materials resolution recommends all AASHTO members implementing Superpave not "substantially modify" the specifications, test methods or requirements. This goal will identify the core elements of Superpave that cannot be changed without detriment to the system and which elements can be modified to some extent to meet local or regional conditions. This goal also includes identification of gaps in the research that should be assessed.

3. Summarize and advocate quality control/quality assurance $(Q C / Q A)$ guidelines stated in $A A S H T O P P-26$ and National Cooperative Highway Research Program (NCHRP) 9-7, Field Procedures and Equipment to Implement SHRP Asphalt Specifications. This goal involves reviewing continued on page six 


\section{HCSC Reviews Second Year Operations}

\begin{abstract}
t the end of its second year in operation, the North Central Superpave Center staff paused to review the progress made $A$ since the inception of the center and make plans for the 1 future. Activities in the areas of initiation of operations,
\end{abstract} communications, training, research, ruggedness testing, technology transier, funding and remodeling were reviewed. At the risk of blowing our own hom, we would like to share some of the highlights of our review with our readers to update you on what your Superpave Center is doing and planning.

ACCOMPLISHMENTS-The NCSC has established working relationships with the DOTs and industry in ten states and two Canadian provinces. This newsletter and the NCSC website [http://ce.ecn.purdue.edu/ spave/] are prime examples of the major emphasis the center has placed on communication of information to a wide audience. Communication and technology transfer also include face-to-face contact; the NCSC staff has made invited presentations to over 20 different organizations. Through representation on both the Binder and Mixture Expert Task Groups and cooperation with the other Superpave Centers, the NCSC has mechanisms to bring issues from the region into a national arena and vice versa.

Training is a second major emphasis area for the NCSC. Over 200 people have received formal training in Superpave binder testing, mix design or the Superpave gyratory compactor through NCSC training courses. Participants in these courses have included industry personnel from asphalt suppliers, hot mix paving contractors and aggregates suppliers; state and FHWA agency personnel; and university professors, students and staff. In addition to regularly scheduled courses at the Center, courses have been sponsored by industry and taught on location.

The third primary area of emphasis for the NCSC is research. Projects have been initiated on national, regional and state levels to address various Superpave issues including the use of reclaimed asphalt pavement, low temperature cracking, fine aggregate angularity, validation of Superpave and laboratory rut testers. The NCSC is working with the National Cooperative Highway Research Program, Asphalt Institute, various state DOTs and other universities on these research projects. (See "NCSC Lands NCHRP Contract" for more information on one of these research projects.)

The NCSC is also working with the other Superpave Centers on ruggedness testing of the indirect tensile tester and Superpave shear tester.

PROBLEMS-Any new venture involves some obstacles and problems. The initiation of the NCSC was no exception. Getting the program off the ground, establishing a funding mechanism and completing the necessary remodeling took longer than expected. Loss of a trained technician near the end of the first year was a setback that required hiring and training a new technician. These problems have now been overcome and the operation is in full swing.

Some problems have been experienced. with some of the specialized Superpave equipment that are continuing to delay the ruggedness testing somewhat. The NCSC is working with the vendors, FHWA and other Centers to work out the bugs. For the most part, vendor support has been very helpful.

PLANS-The NCSC plans to continue to stress communication through continued development of the newsletter and website. We will also be strengthening our efforts to amass and disseminate information on implementation issues and experiences. Twelve different courses have been scheduled for the 1997-98 training season continuing the emphasis on training. Our research efforts will also continue and we will work towards establishing more collaboration with other universities around the region. We will also be participating in an initiative to move Superpave into the undergraduate curricula of engineering universities and begin training the engineers of the future. This pilot effort is beginning in Indiana, but could be expanded to other states. The NCSC is also exploring ways to strengthen its ties to industry and the North Central Asphalt User-Producer Group.

Your suggestions, comments and questions are always welcorne. Please remember that we are a resource for you to use.

\section{LEAD STATE TEAMS continued from page five}

NCHRP 9-7 and developing a set of generic specifications in modular form that states can utilize to write their individual specifications.

4. Benchmark progress and assist implementation of Superpave by collecting, publishing and disseminating program and project level data. This goal will identify the information that needs to be collected on all or some Superpave projects and suggest a mechanism by which those data can be collected and disseminated. Key to this goal is determining what data will be useful and developing a format for collection of those data.

5. To increase AASHTO member implementation from 39 to 52, the Lead State Team will, based upon analysis and expert opinion, estimate, publish and disseminate the potential. financial benefits of Superpave. This goal will attempt to quantify the life cycle cost benefits of Superpave through the establishment of an expert panel to review and analyze data supplemented with their expert opinion. The ultimate goal is to encourage all 52 AASHTO members to use Superpave by demonstrating the benefits of implementation.

\section{YOUR INVOLVEMENT WTTH THE LEAD STATE}

TEAM-The Lead State Team is not an exclusive club. It is a group of committed states and industry partners that is working to "assist in the uniform implementation" of the Superpave system. You can participate with and use the resources of the Superpave Lead State Team in many ways. If you need technical or administrative advice about implementing Superpave on a state or project level, there are contacts who can help you. (Call the NCSC or check our website for information on the Lead State pool of expertise.) The sharing of information can go both ways, though The team will be asking for accounts of experiences with Superpave and data from Superpave projects through some mechanism that has yet to be determined. Please share your experiences-your gripes, problems and successes. This information is vital to getting a clear picture of how Superpave implementation is going and what areas need further attention. Using the Lead State Team (and the Superpave Center), you can share your experiences-good and bad-so that others can learn from them. 


\section{Interim Report on WesTrack \\ Performance of Coarse Graded Mixes at WesTrack-Premature Rutting \\ August 1997}

\section{INTRODUCTION}

Westrack, Federal Highway Administration's (FHWA's) hot-mix asphalt (HMA) performance-related specification test facility in Nevada, passed a significant milestone in mid-April of 1997; the track has been trafficked for one full year. During that time, over 2.7 million $80 \mathrm{kN}$ (18,000 lbs.) equivalent single axle loads (ESALs) were applied to the track. The loading was accomplished with triple tractor-trailer combinations and $89 \mathrm{kN}(20,000 \mathrm{lbs}$.) axle loads. The effects of accelerated loading are already beginning to show on the pavement. The application of more than 2.7 million ESALs resulted in rutting in almost every test section and fatigue cracking in many of the test sections. Several of the sections rutted over $25 \mathrm{~mm}$ and severe fatigue cracking occurred in several other sections. This distress required the removal of ten sections. A new mix design was developed for these replacement sections. The new mix design was to duplicate the coarse-graded mixes in the original construction with a better aggregate.

The original test sections included mixes with gradations above and below the Superpave restricted zone. All the mixes were $19 \mathrm{~mm}$ mixes produced with an unmodified PG 64-22 binder. The original mixes were placed with several variations. For each gradation, three different binder contents were used: optimum (medium), optimum plus 0.7 percent (high), and optimum minus 0.7 percent (low). In addition, for each gradation, the mixes were compacted on the track to three different air void contents: 12, 8 and 4 percent (high, medium and low density, respectively). The coarse graded mixes showed the most severe distress and hence made up most of the sections which were replaced.

The new mix had a coarse-graded Superpave gradation, below the restricted zone, made from quarried stone. The new mix was also produced with an unmodified PG 64-22 binder. The mix met all Superpave requirements for aggregate properties and volumetrics. Sections were placed as in the original construction with low, optimum and high asphalt contents and low, medium and high in-place air voids. Quality control testing was conducted behind the paver during construction and the data indicated the mixes had the required volumetric properties and the targeted gradations and asphalt contents. The binder was checked and met Superpave requirements. Most of the new sections exhibited some deformation in the first five days of trafficking. The mixes containing the higher binder contents and higher air void contents rutted to a greater degree, as expected. Rutting ranged from $12.5 \mathrm{~mm}$ to more than $37.5 \mathrm{~mm}$ in the various sections.

As a result of the early rutting, a team was selected to investigate the rutting at WesTrack, to reach conclusions about likely causes of the early rutting in the coarse-graded mixtures, and to recommend steps that could be taken to improve the performance of these coarse-graded mixtures at WesTrack and elsewhere around the United States.

The team members consisted of Ray Brown, Erv Dukatz, Gerry Huber, Larry Michael, Jim Scherocman and Ron Sines. Participants from the FHWA included John D'Angelo and Chris Williams.

\section{FINDINGS OF THE TEAM}

The team met in Reno, Nevada, on August 18-20, 1997, to talk with researchers (in particular Dr. Jon Epps and Mr. Adam Hand of the University of Nevada) and representatives of Granite Construction. The team inspected the plant, the quarry and the test track; and reviewed and discussed all available data. The team evaluated all factors that potentially could have resulted in the early rutting of the coarse-graded mixture. These factors included structural design, construction procedures, environment, traffic and mix properties.

The team evaluated each area and categorized the following as potential contributors to rutting:

\section{No Impact}

- Structural design

- Construction procedures 
Minor Impact

- Environment-Some rain during construction of test sections did not appear to be a problem. Moisture in the mixture may have contributed to asphalt softening. Air temperatures at the time of loading (July) were high.

- Traffic--The heavy trucks used at WesTrack had more channelized traffic than normal roads would experience.

- Aggregate-The aggregate had good qualities but the Plasticity Index was marginal.

- Fines to Asphalt Ratio-This ratio affects binder stiffness; although the mixtures met current criteria, this may have been a contributing factor.

- $\mathrm{N}_{\text {design }}$-Due to the accelerated loading applied to the test sections, the value selected for $\mathrm{N}_{\text {design }}$ may have been too low.

- Binder-Based on findings of states using coarse-graded mixes and SMA, a stiffer binder should have been selected for such a high traffic loading.

- VMA-Minimum VMA required was 13; design VMA was above 15. Higher VMA resulted in a higher asphalt content (5.7 percent) in order to meet a design air void content of 4 percent.

\section{Major Impact}

The consensus of the team is that the major cause of early rutting of the reconstructed test sections is a combination of a coarse-graded mixture with high optimum asphalt content (5.7 percent) and low binder stiffness (PG 64-22).

\section{RECOMMENDATIONS}

The team recommends that the designers and technicians, when specifying and designing coarse-graded mixes, be cautioned to take the following into consideration:

- Coarse-graded mixes are proving to be much more sensitive to binder content and binder stiffness. When they are used and the design ESAL is 3,000,000 or greater, increase binder stiffness one PG grade. Consider increasing the binder two grades for design ESALs greater than 10,000,000.

- If the design VMA content of the mix is more than two percent greater than the minimum required VMA, consideration should be given to reducing the VMA in the mix by changing the gradation of the aggregate and/or by increasing the amount of mineral filler incorporated into the mix.

- The potential performance of the mix should be checked by performing some type of strength or performance test: loaded wheel test, Marshall stability and flow, Hveem stability, Superpave Shear Tester (SST), or some other test with historical data availabie for comparison.

- If the binder content is reduced, care should be taken not to decrease the content to the point that early durability and fatigue problems occur.

\section{OTHER ACTIONS ITEMS/RECOMMENDATIONS}

- Develop HMA design and evaluation guidelines for designers and technicians by November 1, 1997

- Complete additional testing of WesTrack materials to validate team's findings. Complete and issue a report by December 1, 1997.

- Recommend to FHWA: Select a consultant to evaluate the early performance of Superpave mixes across the United States, especially coarse-graded mixes.

- Recommend to FHWA: Expedite work to provide a performance-related test for use with the volumetric mix design procedure. An interim test is needed.

- Recommend to FHWA: Consider placement of additional test sections at WesTrack to validate the recommendations in this report.

Any questions concerning this report should be addressed to any member of the investigating team, John D'Angelo or Chris Williams. 


\section{Superpave Experiences Recounted}

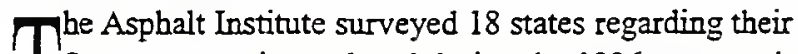
Superpave projects placed during the 1996 construction season. A report published in July 1997 summarizes the experi$I$ ences of these states on a total of 86 projects. Approximately

93 Superpave projects were constructed nationwide in 1996.

Experiences with Superpave were generally favorable. Difficulties were reported on 28 projects. The difficulties primarily related to achieving density or VMA, segregation, shoving under the roller, pick-up on pneumatic-tired rollers, and mix sticking to truckbeds. The report notes that "problems" are to be expected when implementing a new design system and learning to deal with different materials. The report adds that many of the "problems" were resolved during construction by implementing well-known corrective measures.

The report includes some comments on individual projects from ten states.

\section{AASHTO Issues New Provisional Standards}

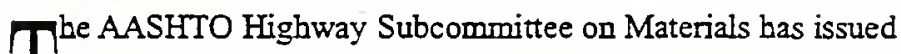
its 1997 Interim Edition of the AASHTO Provisional

Standards. This 202-page document includes the most up-to1 date versions of the test methods (TP), specifications (MP) and practices (PP) related to Superpave.

TP33, Standard Test Method for Uncompacted Void Content of Fine Aggregate (as Influenced by Particle Shape, Surface Texture and Grading), has been made a full standard and is no longer printed with the Provisional Standards.

Copies of the Interim Standards can be obtained from AASHTO, 444 North Capitol Street, N. W., Suite 249, Washington, DC 20001.

\section{U.S. Hot Mix Gonference Features Superpave Workshop}

T he Fifth Annual United States Hot Mix Asphalt Conference will include a full day of presentations on Superpave, in addition to other sessions on Construction Issues (segregation, 1 compaction and balancing production rates) and Controlling HMA Construction (training and certification, measuring density and smoothness). The Superpave Workshof will include the experiences of the Arizona, New York and Arkansas DOTs; Maricopa County, AZ; Glendale, AZ; and contractors from Utah and Florida. The afternoon session will consist of updates on WesTrack, Superpave specifications, ongoing research activities, aggregate issues, binder issues and a summary entitled "How Is Superpave Doing?"

The conference will be held October 29-31, 1997, in Phoenix, AZ. The Superpave Workshop is all day Thursday, October 30. Information is available from the National Asphalt Pavement Association (NAPA) at 1-888-468-6499.

\section{Thanks to Dick Ingherg}

ick Ingberg will be stepping down as the long term pavernent performance (LTPP) regional engineer when his contract ends September 22, 1997. LTPP support had enabled Mr. Ingberg to serve as NCAUPG secretary since the group's inception.

The region owes a debt of gratitude to Mr. Ingberg for his able assistance and dedication to the concept of a regional partnership between asphalt users and producers. Mr. Ingberg was instrumental in developing the NCAUPG into one of the most active and influential user-producer groups in the country.

Thanks, Dick, and best wishes for the future.

The NCAUPG Executive Committee is currently exploring options for fulfilling the secretary's duties.

\section{MCHRP Contract continued from page four}

Saskatchewan, and Dr. Hussain Bahia, University of Wisconsin.

This NCHRP research is on a national level. A regional pooled fund study on Use of Reclaimed Asphalt Pavement Under Superpave Specifications will compliment, but not duplicate, the national study. The regional study will focus specifically on regional materials, performance and issues.

The project was initiated in April 1997 and is scheduled for completion by March 31, 1999.

\section{Binder ETG continued from page three}

test were presented. Variables affecting the test results included such things as age and contamination of the molds used to form specimens, and contamination of the fluid bath. Alternative measures to control these factors were also considered. This study will continue and results will be discussed further at the next meeting.

Other studies are investigating the use of a microwave instrument to simulate long term aging behavior in lieu of the pressure aging vessel and a comparison of the Rolling Thin Film Oven to the modified German Rolling Thin Film Oven.

The contribution of the binder to fatigue behavior of the mixture continues to be a topic of concern to the ETG and a work plan to address this issue was discussed Part of this work plan will include an assessment of field projects exhibiting good and bad fatigue performance. Results of this study will also be discussed further at the next meeting.

Other on-going research projects discussed included NCHRP 9-10, Superpove Protocols for Modified Asphalt Binders; a comparison of mixtures incorporating PG 76-22 binders produced using different methods; and a validation experiment using the FHWA Accelerated Loading Facility (ALF). The Binder ETG will continue to follow these studies and consider their findings.

As this summary shows, there are a number of issues still under consideration and data are being collected to address those issues. The next meeting of the group in January 1998 should result in resolution of several of these issues. 


\section{Calendar of Events}

Oct 29-31 U. S. Hot Mix Asphalt Conference and Superpave Workshop

Phoenix, Arizona

For more information, call (301) 731-4748

Nov 6 41st Annual Kansas Asphalt Paving Conference

Lowrence, Kansas

For more information, call (913) 864-3969

Nov 16-19 The Canadian Technical Asphalt

Association Annual Meeting

Ottowa, Canada

Nov 18-19 Ohio Transportation Engineering

Conference

Columbus, Ohio

For more information, call (614) 292-4815

Nov 24-25 MAPA Workshop

Minneapolis, Minnesota

Dec 2-4 Southeastern Asphalt User-Producer

Group Meeting

Williamsburg, Vîrginia

For more information, call (334) 844-6240

1998

Jan 28-9 Binder ETG Meeting

Albuquerque, New Mexico

For more information, call (202) 366-0121

Feb 9-10 Nebraska Asphalt Paving Conference Keamey, Nebraska

Mar 16-18 AAPT Annual Meeting and Technical Session

April 21-23 Superpave: Today and Tomorrow St. Louis, Missouri

\section{Region Remains Intact}

\section{CORRECTION}

lert readers of the last issue of the Centerline ques-

tioned whether Michigan, Minnesota and Wisconsin 4 had seceded from the North Central region. These

1 states were inadvertently omitted from the article summarizing the reorganization of the North Central Asphalt User-Producer Group.

The article should have stated that the region is being realigned into two sub-groups, as follows:

North Sub-Group: Iowa, Manitoba, Michigan,

Minnesota, Nebraska, North Dakota, Saskatchewan, South Dakota and Wisconsin.

South Sub-Group: Illinois, Indiana, Kansas, Missouri and Ohio.

The Centerline is published quarterly by the North Central Superpave Center to provide up-to-date Superpave information to our subscribers in the North Central region and around the country. The Centerline is distributed free of charge. If you would like to receive this publication, please contact Julie Smith at the NCSC at (765) 463-2317 phone, (765) 497-2402 fax, or julie@ecn.purdue.edu $e$-mail.

Director
Jan Olek

Associate Director David A. Andrewski

Managing Editor/Writer

Rebecca S. McDaniel

Editor/Writer

Julie V. Smith

Designer

Julie V. Smith

Website Administrator

Julie V. Smith
North Central 1205 Montgomery Street Superivave P. O. Box 2382 Center

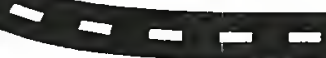

West Lafayette, IN 47906

phone (765) 463-2317

fax (765) 497-2402
Non-Profit Organization

U. S. Postage

PAID

Purdue University 
APPENDIX D 


\section{Course Descriptions and Outlines}

\section{Superpave Binder Course (3 days)}

This training course provides detailed instruction on the Superpave binder specifications and testing procedures. "A thorough introduction and overview is provided on the first day. The remainder of the course is mostly hands-on in the laboratory. Each participant will fabricate test specimens and perform tests on the bending beam rheometer, dynamic shear rheometer, and rotational viscometer. Calibration procedures will be demonstrated and conducted by participants where appropriate. An overview of the binder aging methods and direct tension tests also will be provided. The course concludes with a workshop session to grade an asphalt cement using the students' data, a summary of the binder specification, and a discussion of implementation issues.

The course is designed for laboratory technicians and managers who need to understand the binder specifications and test procedures. No prior knowledge of the Superpave specifications is required, but some experience with asphalt cement is helpful.

\section{SESSION I: BINDER OVERVIEW (4 howrs) \\ * Welcome and Announcements \\ * Background of Superpave Asphalt Performance-Tests \\ 米 Dynamic Shear Rheometer : \\ 光 Rotational Viscometer}

SESSION II: MORE BINDER OVERVIE

* Bending Beam Rheometer

米 Direct Tension Tester

* Binder Aging Methods

* Superpave Binder Specifications

* Instructions for Lab Sessions

SESSION III: CLASSROOM SESSIONS 4 hours ench)

The class will break up into groups and participate in threelaboratory sessions: Dynamic Shear Rheometer, Bending Beam Rheometer, and Rotational Viscometer and A gipg Procedures. Each session will last for four hours, constituting an entire mom ing or afternoon. The groups will rotate after each session until each group has completed all three laboratory sessions:

\section{SESSION IV: BINDER SPECIFICATIONS (4 hours)}

* Binder Specifications

* Grade Binder (using participant data)

* Implementation Issues

* Course Summary and Questions

* Course Evaluations and Conclusion

\section{Superpave Volumetric Mix Design (3 days)}

his training course provides detailed instruction on conducting a volumetric mix design. The course opens with an introduction of how asphalt mixtures behave, reviews mixture volumetrics in detail, works through an example mix design, and outlines the

Superpave aggregate requirements and design aggregate structures. An overview of the Superpave binder specification and construction issues also is provided. Hands-on training in the use of the Superpave gyratory compactor is provided to each participant. A workshop session gives each participant the chance to work through the calculations required to complete a mix design.

The course is designed for contractors and state personnel involved in mix design and testing. Some knowledge of basic principles of mix design and mixture volumetrics is helpful.

\section{SESSION I: INTRODUCTION (4 hours) \\ * Welcome and Announcements \\ \% Introduction to Superpave \\ * Materials Selection \\ * Superpave Gyratory Compactor}

\section{SESSION II: MIXTURE VOLUMETRICS (4 hours)}

* Mixture Volumetrics

* Instruction for Lab Sessions .

SESSION III: GYRATORY TESTING MACHINE (4 hours)

* Gyratory Testing Machine

SESSION IV: BINDER OVERVIEW (4 hours)

* Background of Superpave Asphalt Performance Tests

* Test Equipment and Methods

* Superpave Binder Specifications

* Implementation Issues

* Construction Issues

\section{SESSION V: VOLUMETRIC MIX DESIGN (4 hours)}

*Volumetric Mix Design

\% Performance Testing

\section{SESSION VI: CALCULATIONS WORKSHOP (4 hours) \\ * Calculations Workshop \\ * Software Demonstration \\ * Course Evaluations and Conclusion}

The class is split into two groups for the hands-on laboratory work. One group will use the gyratory compactor while the other group reviews the binder specification and discusses construction issues; the following afternoon, the groups will reverse. 


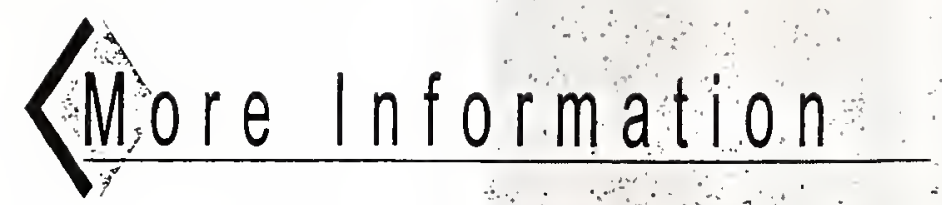

\section{Superpave On The Road}

We can customize the listed courses to suit your needs, or develop courses from your concepts. If you are interested in bringing our instructors to your facility for specialized Superpave training, call Julie Smith at (765) 463-2317.

\section{Course Times}

Courses run from 8 a.m. to 5 p.m. daily on the dates listed

\section{Location}

The binder courses will be held at the NCSC Binder Branch; the mix design courses will be be held alternately at the NCSC. Binder and Mixture branches. The Binder Branch is located at the Indiana DOT, Division of Materials and Tests, $120 \mathrm{~S}$. Shortridge Road, Indianapolis, IN 46219, (317) 232-5280. The Mixture Branch is: located at the Indiana DOT, Division of Research, 1205

Montgomery St., West Lafayette, IN $47906,(765) 463-2317$. Area maps, including hotel and restaurant locations, will be mailed. immediately upon receipt of your registration form.

\section{Accommodations}

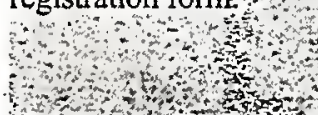

We recommend the Hampton Inn in Indianapolis (317) $359-9900$ and the University Inn in West Lafayette $(800) 7779808$ for your stay. Please make your reservations early

\section{What's Included}

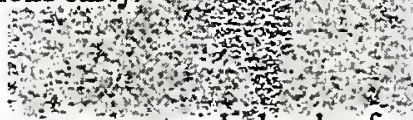

Text book(s), lecture notes, other program matenals, break refreshments, and a course certificate are covered by your regstivation fee Refund Policy

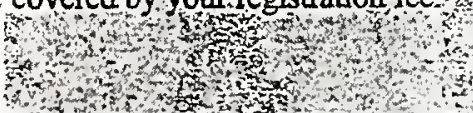

The registration fee is fully refundable until 14 days pror to the first day of the course. Cancellations after that time are subject to a \$50 late cancellation fee. Registants who do not attend and do not cancel are subject to the complete fee You may however, enroll a substitute at any time before the course begins,

\section{Continuing Education Units}

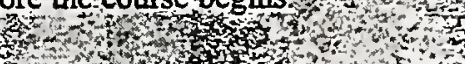

Continuing education units have been approved for these courses and will be issued upon completion of each course.s.

$$
\text { and }
$$

Purdue University is not responsible for costs incurred due to cancellation Purdue University is an equal accesslequal opportunity mstitution.
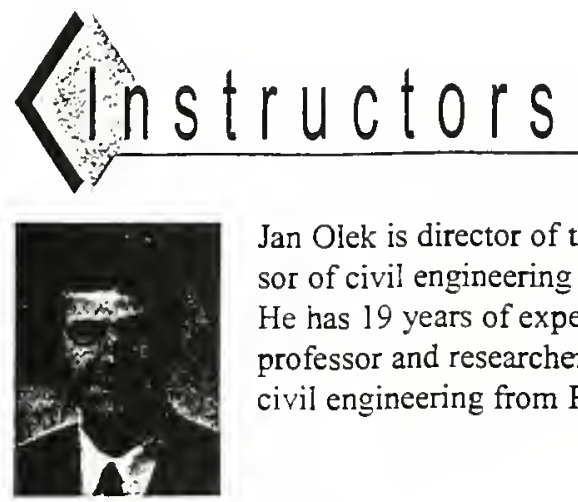

Jan Olek is director of the NCSC and a professor of civil engineering at Purdue University. He has 19 years of experience as a university professor and researcher. He holds a Ph.D. in civil engineering from Purdue University.

Jan Olek Ph.D., P.E.

Director

$\mathrm{NCSC}$

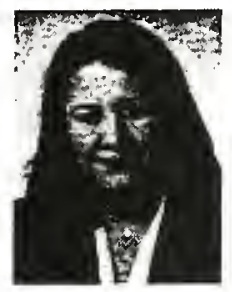

Rebecca McDaniel is technical director of the NCSC. She has over 10 years of experience in highway materials and pavement research with the Indiana DOT. She holds an M.S. in civil engineering from Purdue University.

Rebecca McDaniel m.S., P.E.

Technical Director

NCSC

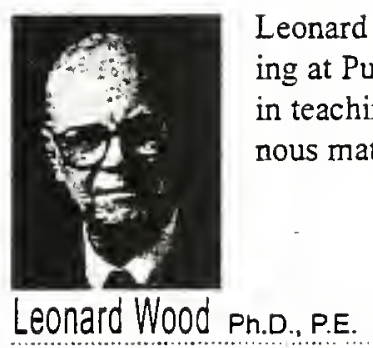

Professor

Purdue University

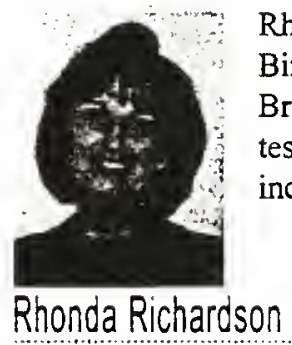

Rhonda Richardson manages the Superpave Binder Laboratory at the NCSC Binder Branch. She has 19 years of experience in testing materials and has run the lab since its inception four years ago.

Laboratory Manager Indiana DOT

Guest lecturers will assist with occasional course sessions. These will be announced on an individual basis. Guest lecturers may represent industry, the FHWA, the Asphalt Institute and other universities, bringing a broadened perspective to the course. The NCSC reserves the right to alter course schedules and substitute speakers when necessary. 
Name

Title

Company

Billing Address

City

State Zip

Physical Address

course confirmations ond certificates will be sent to this address

City

State Zip

Phone

Fax

)

I require auxiliary aids or services due to a disability. Please contact me at the physical address listed above.

I have enclosed a check for the full amount payable to Purdue University.

Please invoice my company using the following Purchase Order Number

$O$ Please charge my $O$ Visa $O$ MasterCard $O$ Discover Card Number

Expiration Date

Authorized Signature

Please photocopy this form as needed for additional registrants.
Be sure to register early. Class size is limited. Please indicate first and second choices to ensure you a place.

$$
1^{\text {st }} 2^{\text {nd }}
$$

O October 14-16, 1997 - Indianapolis

$\bigcirc \bigcirc$ December 3-5, 1997 - Indianapolis

$\bigcirc \bigcirc$ April 1-3, 1998 - Indianapolis

Superpave Volumetric Mix Design

Be sure to register early. Closs size is limited. Pleose indicate first and second choices to ensure you a place.

$\begin{array}{ll}1^{\text {st }} & 2^{\text {nd }} \\ 0 & 0 \\ 0 & 0 \\ 0 & 0 \\ 0 & 0 \\ 0 & 0 \\ 0 & 0\end{array}$

October $27-29,1997 \cdot$ W. Lafayette November 5-7, 1997 - Indianapolis December $15-17,1997 \cdot$ W. Lafayette January 26-28, 1998 - Indianapolis February 11-13, 1998 - W. Lafayette March 24-26, 1998 - Indianapolis

Call Nona Schaler at (765) 494-2756 for registration information, or Julie Smith at (765) 463-2317 for questions regarding course content 



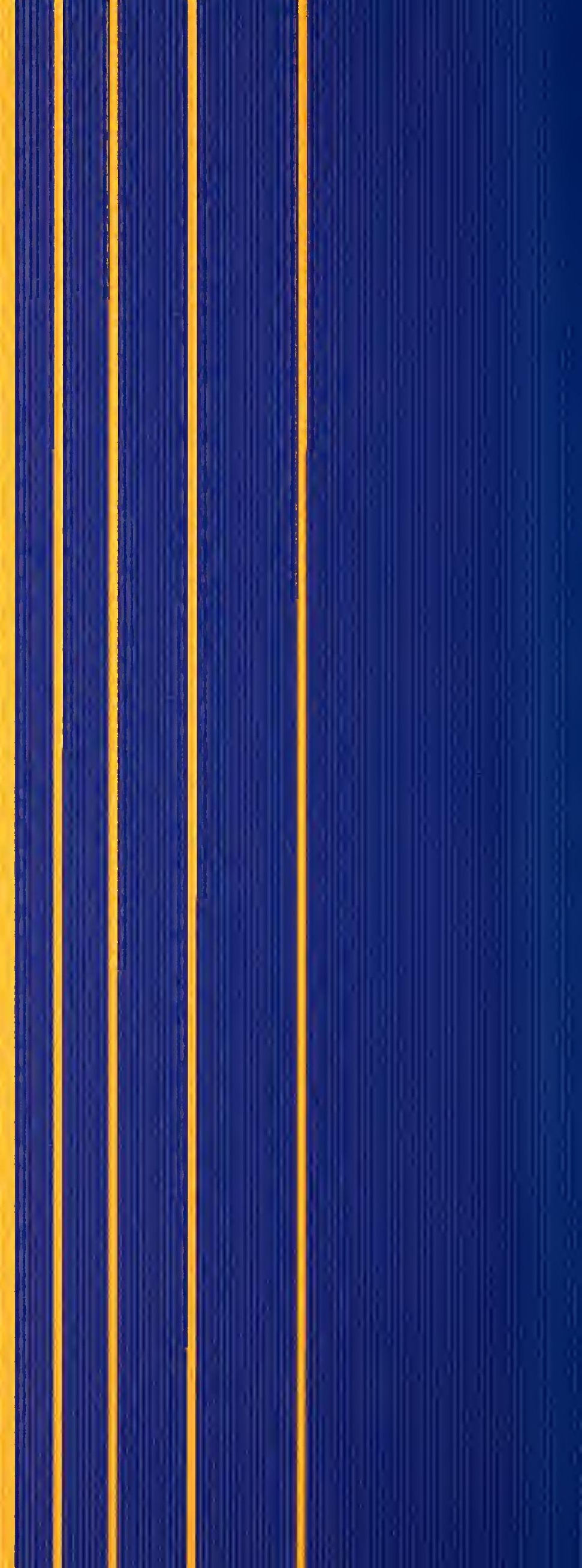

